\title{
Kinematic and Thermodynamical Structures of Longitudinal-Mode Snow Bands over the Sea of Japan during Cold-Air Outbreaks \\ Part I: Snow Bands in Large Vertical Shear Environment in the Band-Transverse Direction
}

\author{
Yoshinori YAMADA, Masataka MURAKAMI, Hakaru MIZUNO ${ }^{1}$ \\ Meteorological Research Institute
}

Masayuki MAKI, Sento NAKAI ${ }^{2}$, and Koyuru IWANAMI

National Institute for Earth Science and Disaster Prevention

(Manuscript received 17 December 2008, in final form 22 April 2010)

\begin{abstract}
The kinematic and thermodynamical structures of two longitudinal-mode (termed "L-mode") snow bands over the Sea of Japan occurring on February 8, 1991 and January 21, 1993 are analyzed mainly based on dualDoppler radar data. The L-mode snow bands with multicellular structure in 1991 and 1993 formed, respectively, at the early onset of and toward the end of cold-air outbreaks, where the magnitude of the band-transverse vertical shear was roughly $2 \times 10^{-3} \mathrm{~s}^{-1}$ approximately in the lower-half of the mixed layer. This magnitude was larger than that associated with L-mode snow bands characterized by axi-symmetric circulation, which will be described in Part II. Thermodynamical structures and the spatial distributions of water substances in the two snow bands were inferred from variational-based retrieval.

A pronounced feature of the airflow structures in both snow bands was upshear-tilting updrafts in the bandtransverse vertical cross-section. At least two factors could account for their formation: the existence of a certain depth of the vertical layer of the environmental band-transverse system-relative wind components directing to the upshear, and the lower terminal fall velocities of snow and graupels. The retrieval results showed that both snow bands had a subsaturated cold pool beneath the band around the surface, whose collision with the unstable ambient air could have been responsible for overall upward motion in the bands. With regard to the energetics of the band circulation, energy production by buoyancy and the band-transverse shear was dominant.

The repeated formation of new cells was observed in the two snow bands in the downshear side, which may have been triggered by the low-level collision of the outflow from active cells or a cold pool with the unstable ambient air. As the new cell developed enough, the older cell significantly decayed. Consequently, the successive formation of cells did not change the overall echo pattern of the L-mode snow bands without producing elongated echoes branching off into the downshear direction at large angles to the orientation of the L-mode snow bands.
\end{abstract}

Corresponding author: Yoshinori Yamada, Meteorological Research Institute, 1-1, Nagamine, Tsukuba, Ibaraki, 305-0052, Japan.

E-mail: yyamada@mri-jma.go.jp

1 Present affiliation: Japan Meteorological Agency.

2 Present affiliation: Snow and Ice Research Center, National Institute for Earth Science and Disaster Prevention.

(C) 2010, Meteorological Society of Japan 


\section{Introduction}

Various types of snow clouds develop over the Sea of Japan in winter. They are, for example, associated with cold-air outbreaks, cold fronts, a largescale convergence zone between two polar air masses (Okabayashi 1969), the Japan Sea Polar-air mass Convergent Zone (Asai 1988), shallow and deep convective snow bands behind synoptic lows (Murakami et al. 1996; Murakami et al. 2003), and wind-speed increase zones (Yamada et al. 1996). Among these, snow clouds forming during cold-air outbreaks are very common, and they organize into various forms at mesoscale. Indeed, Sakakibara et al. (1988a) on the basis of satellite and sounding data reported four types of snow clouds during a heavy snowfall event: isolated clouds, open cells, convective clouds in lines whose orientation was parallel to the low-level wind direction, and transverse rectilinear clouds.

Among these snow clouds, band-shaped snow clouds, or snow bands, which align roughly parallel to the prevailing northwesterly wind are very common types during cold-air outbreaks, and are easily identified in satellite images (e.g., Miura 1986). Such snow bands are referred to as longitudinal mode (hereafter termed "L-mode") snow bands, based on the morphological aspects as in the case of cloud streets, whose mode is longitudinal when they are aligned roughly along the mean horizontal direction (Atkinson and Zhang 1996). These snow bands are considered to be associated with roll circulations, whose theoretical analysis was made by Asai (1970). Comprehensive reviews of roll circulations have been written by Etling and Brown (1993) and Atkinson and Zhang (1996).

Band-shaped snow clouds occurring during coldair outbreaks over the Sea of Japan were often observed in PPI images at low elevation angles of Doppler radar during a field project from 1989 to 1993 in a coastal region of Tohoku District of Japan (e.g., Murakami et al. 1994b). These echoes were grouped into two types on the basis of the angle between the band alignment and the mean wind direction in the mixed layer. This angle was measured with respect to the mean wind direction looking downwind. One type had an angle $<40^{\circ}$, and the other corresponded to a large angle $>60^{\circ}$. The former was regarded as the L-mode snow band, and the latter the transverse mode. Among these L-mode snow bands, two bands occurring under the existence of large band-transverse vertical shear were observed by dual-Doppler radar. The kinematic and thermodynamic characteristics of such L-mode snow bands remain unclear because the observational studies on mesoscale structures of Lmode snow bands over the Sea of Japan are limited to the following two works over Ishikari Bay, Hokkaido, Japan. Fujiyoshi et al. (1998) studied meso- $\gamma$ scale structures of an L-mode snow band, and Yoshimoto et al. (2000) studied the interactions between two L-mode snow bands. Neither treated the L-mode snow bands in large band-transverse vertical shear conditions.

Although there is a large body of research on snow clouds over the Sea of Japan based on observations (Sakakibara et al. 1988b; Ishihara et al. 1989; Tsuboki et al. 1989; Satoh et al. 1992; Yamada et al. 1994; Yamada et al. 1996; Fujiyoshi et al. 1998; Yoshimoto et al. 2000; Yamada et al. 2004; Yoshihara et al. 2004; Kawashima and Fujiyoshi 2005), theories (Asai 1970), and numerical model simulations (Ikawa et al. 1991; Murakami et al. 1994a; Saito et al. 1996), most do not treat the kinematic structures of L-mode snow bands under large band-transverse vertical shear. Even for wind-parallel bands occurring during "lakeeffect snow storms" over Lake Michigan, numerous observational studies (e.g., Kelly 1982; Kristovich 1993; Kristovich et al. 2003) and model simulations (e.g., Hsu 1987; Hjelmfeld 1990; Ballentine et al. 1998) have not discussed band circulations in association with vertical shear. Recent numerical model studies (e.g., Cooper et al. 2000; Laird et al. 2003; Laird et al. 2004) and observations (Miles and Verlinde 2005) are relevant to the mode of organization regarding linear or cellular types and to cloud morphology. Thus, the kinematic and thermodynamical structures of L-mode snow bands in large band-transverse vertical shear conditions have not been elucidated as yet. These structures constitute basic information for an understanding of precipitation mechanisms.

Most Doppler radar studies of snow bands and snow clouds over the Sea of Japan made so far have concerned two- or three-dimensional kinematic structures, with less depiction of thermodynamical structures. This may hold true for the case of lake-effect snow storms over Lake Michigan. Thermodynamical structures can, however, be inferred from Doppler radar data by so-called retrieval, owing to the pioneering work of Gal-Chen (1978). Since then, various retrieval methods have been developed (e.g., Roux 1985; Ziegler 1985; 
Roux et al. 1993; Marécal et al. 1993; Liou et al. 2003). Among these, Hauser et al. (1988) retrieved pressure and potential temperature perturbations, and mixing ratios of water vapor and cloud by a variational method that combines the equations of motion, the thermodynamic equation, and the continuity equations of water substances by using a microphysical model. A retrieval method similar to that of Hauser et al. (1988) was employed in this study to deduce thermodynamical structures. Meso $\beta$-scale structures of L-mode snow bands will be better understood when kinematic and thermodynamical structures are considered as a whole.

The main objective of this study is to clarify the kinematic and thermodynamical structures of the two L-mode snow bands in an environment with large vertical shear in the band-transverse direction, based mainly on dual-Doppler radar observations with supplementary sounding data. They occurred toward the end of and in the beginning of coldair outbreaks, respectively. The data source of the present study will be introduced in Section 2. Section 3 presents the kinematic and thermodynamical structures of the L-mode snow band occurring on January 21, 1993, and those of another L-mode snow band on February 8, 1991 are explained in Section 4. Discussion takes place in Section 5, and Section 6 concludes. An outline of the retrieval method used for deducing thermodynamical structures and fields of water vapor and nonprecipitating water condensates (hereafter termed "cloud") is given in Appendix.

\section{Data}

The data used in this study were issued from a data set collected during the aforementioned field project from 1989 to 1993 . The description of the project and its facilities was provided by Murakami et al. (1994b), Murakami et al. (2003), Yamada et al. (1994), and Yamada et al. (1996). The objective of this project was to clarify precipitation mechanisms operating in snow clouds over the Sea of Japan and to examine the feasibility of cloud modification by seeding. The locations of some facilities important to the present study are shown concisely in Fig. 1 along with topography: locations of two X-band Doppler radars from the Meteorological Research Institute (MRI) and the National Institute for Earth Science and Disaster Prevention (NIED), and the observation site at Tobishima Island.
The primary data used in the analyses are from the two Doppler radars. These radars have a maximum detection range of $64 \mathrm{~km}$, and they were deployed about $37 \mathrm{~km}$ apart in a coastal region in order to collect dual-Doppler radar data. DualDoppler wind recovery was limited mostly to the area over the Sea of Japan. The location of MRI radar was at $\left(39^{\circ} 12.1^{\prime} \mathrm{N}, 139^{\circ} 53.8^{\prime} \mathrm{E}\right)$ in 1991 and $\left(39^{\circ} 12.4^{\prime} \mathrm{N}, 139^{\circ} 53.8^{\prime} \mathrm{E}\right)$ in 1993 . The NIED Doppler radar was at $\left(38^{\circ} 52.3^{\prime} \mathrm{N}, 139^{\circ}\right.$ $\left.51.9^{\prime} \mathrm{E}\right)$ in 1991 and $\left(38^{\circ} 52.4^{\prime} \mathrm{N}, 139^{\circ} 51.6^{\prime} \mathrm{E}\right)$ in 1993. The locations of the MRI and NIED radar sites in 1993 were slightly shifted to the north by $\sim 0.6 \mathrm{~km}$ and to the west-northwest by $\sim 0.5 \mathrm{~km}$ relative to those in 1991, respectively. DualDoppler wind synthesis was performed described by as Yamada et al. (1994) and Yamada et al. (1996), similar to that described by Ray et al. (1980), except for the use of a moving frame of reference, in which the position of the common grids was resolved in the ground-fixed Cartesian coordinates whose origin was placed at the MRI radar site. In this fixed frame, the $y$-axis coincided with the baseline, taking the northward direction as positive, while the $x$-axis was perpendicular to the $y$-axis, positive eastward. The $y$-axis was inclined five degrees clockwise from the north from 1991 to 1993. The $z$-axis went vertically upward, and the height was measured from the sea level. In the moving frame, the directions of horizontal and vertical axes were the same as those in the fixed frame, respectively. The horizontal and vertical grid resolutions of the common grids were $0.7 \mathrm{~km}$ and $0.3 \mathrm{~km}$, respectively, and the lowest level of CAPPI was set to a height of $0.3 \mathrm{~km}$.

Each volume scan consisting of PPIs at different elevation angles took several minutes, and dualDoppler radar observations were made at about seven- or eight-minute intervals. Vertical winds were calculated by integrating the anelastic mass continuity equation upward assuming that the vertical winds vanished at the surface. These vertical winds were subject to variational adjustment with the "Floating Boundary Condition" concept (Chong and Testud 1983). The parameters necessary for this adjustment technique for conical-scanbased dual-Doppler radar synthesis were given by Yamada (1997). Winds derived by means of the above method were considered accurate in regions of reflectivity $\geq \sim 15 \mathrm{dBZ}(\geq 10-15 \mathrm{dBZ})$ for 1991 (1993). In addition to these Doppler data, supplementary data were used from sound- 


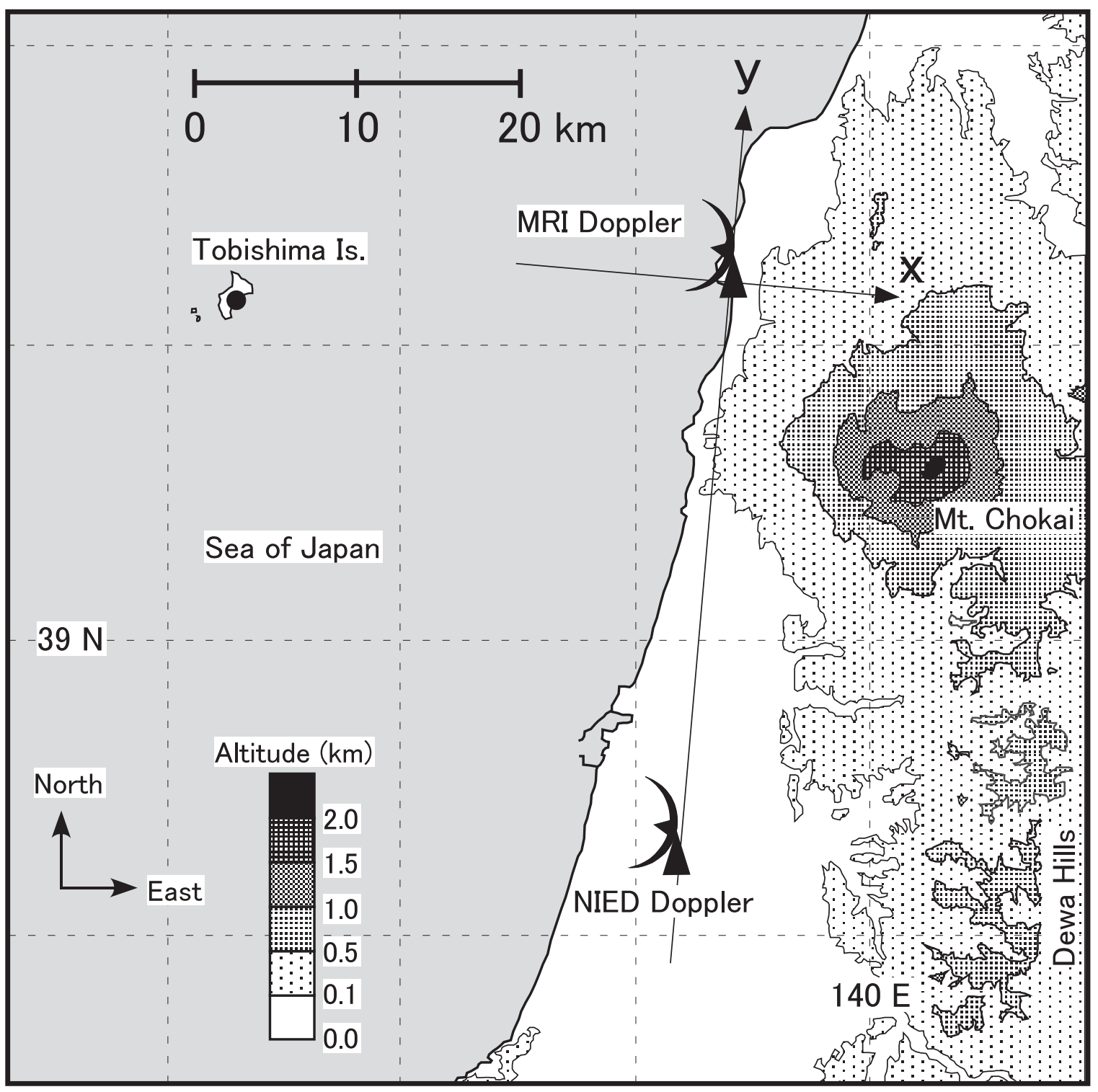

Fig. 1. Map showing the observation facilities important to the present study: MRI and NIED Doppler radar sites in 1993, and the observation site at Tobishima Island (solid circle), where sonde, microwave, and surface observations were made. The MRI and NIED Doppler sites in 1991 were close to those in 1993, respectively. The area of the Sea of Japan is darkened and topography is indicated by shading. The $x$ - and $y$-axes are the coordinates fixed to the ground by which the position of the common grid points for the wind recovery were resolved. Thin broken lines show longitudes and latitudes at 10-min intervals in both directions.

ings at Tobishima Island and routine soundings at the Akita Observatory $\left(39^{\circ} 43^{\prime} \mathrm{N}, 140^{\circ} 06^{\prime} \mathrm{E}\right)$ of the Japan Meteorological Agency (hereafter "JMA"). This observatory was situated near the coastal line at a distance of about $60 \mathrm{~km}$ approximately to the north-northeast of the MRI radar site.

\section{The January 21, 1993 snow band}

\subsection{Atmospheric conditions}

Figure 2 shows a surface weather map at 1500 JST $^{1}$ and 2100 JST, showing a typical pressure pat-

1 Japan Standard Time $=$ UTC +9 hours. 

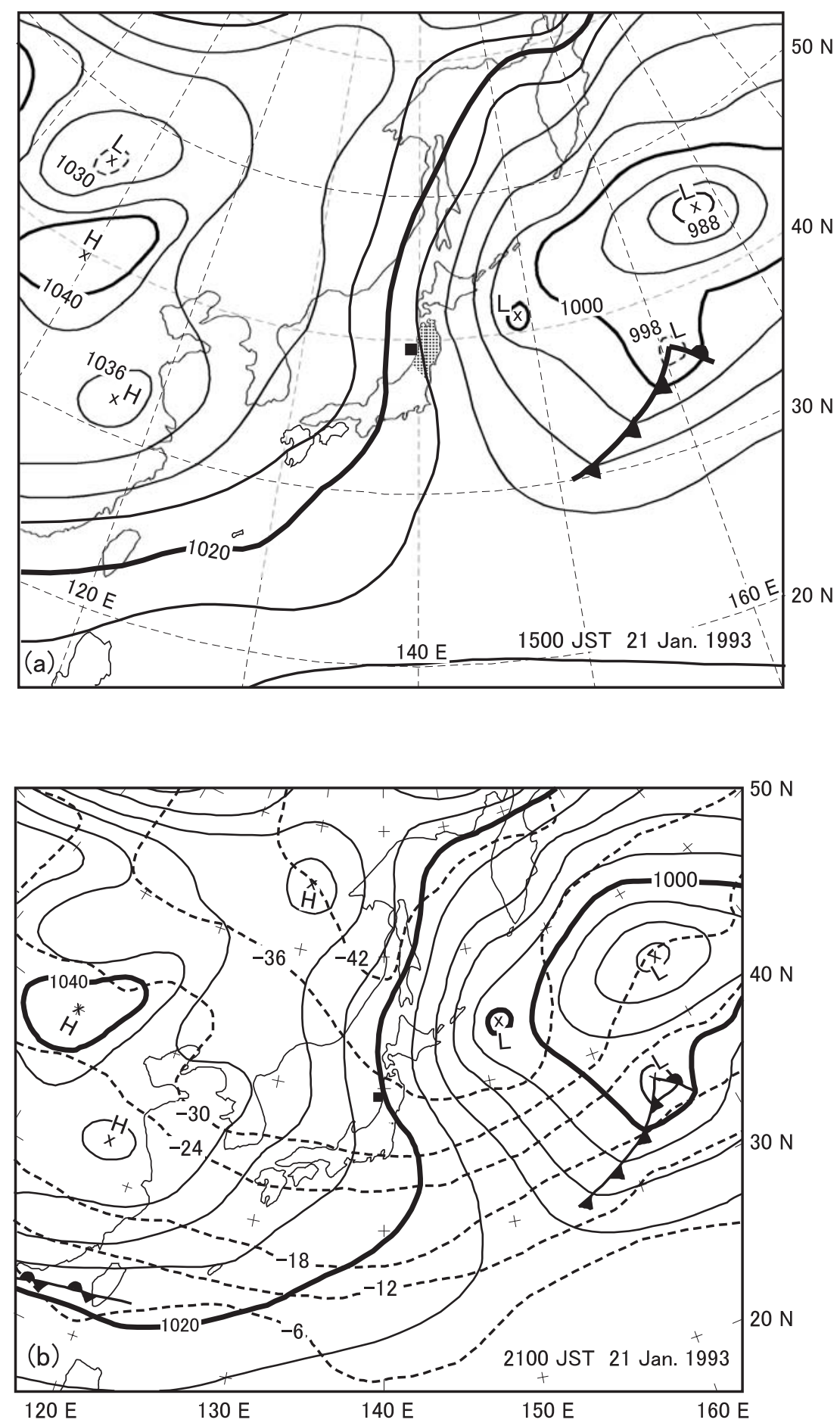

Fig. 2. (a) Surface weather map at 1500 JST. Solid lines are pressure contours at 4-hPa intervals. The location of the field experimental area is shown by a solid rectangle. Tohoku District is indicated by shading. (b) As in Fig. 2a, but for at 2100 JST with the superposition of the temperature field at the 500-hPa level. Dashed lines indicate temperatures at $6^{\circ} \mathrm{C}$-intervals. 


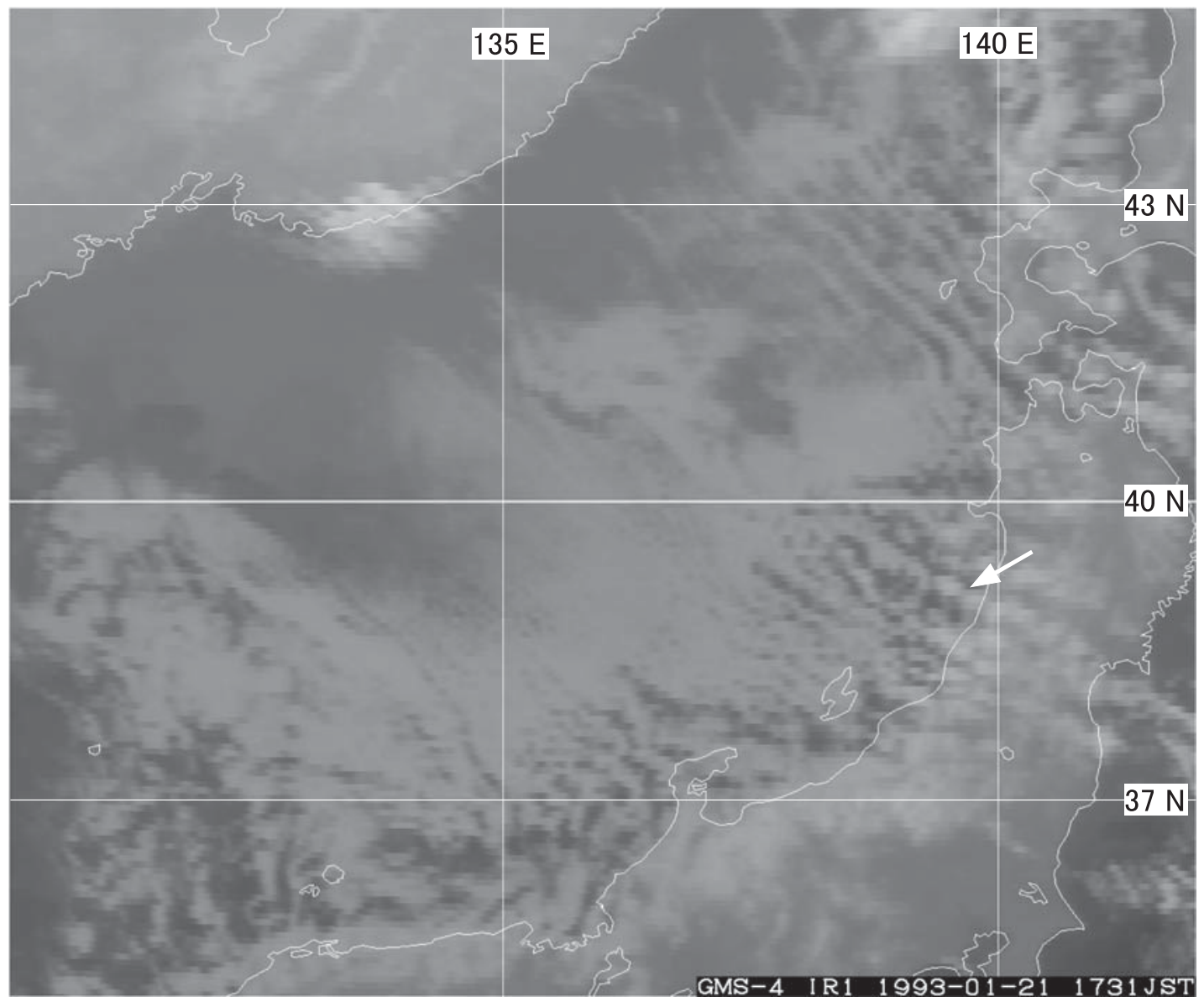

Fig. 3. Infrared satellite image at 1731 JST. The band analyzed in this study is pointed by an arrow.

tern of cold-air outbreak favorable for the development of snow clouds over the Sea of Japan because high pressure was located over the Siberian continent and low pressure over the Pacific Ocean. On this day, a very cold airmass covered the northern part of Japan as indicated by the $500-\mathrm{hPa}$ height temperature of $-40.2^{\circ} \mathrm{C}$ from the sounding at 0900 JST at the Akita Observatory. Under this cold airmass, L-mode snow bands formed, and one of them was probed using Doppler radars. In the 2100-JST map, however, the isopleths of temperature at the 500 -hPa height show that the cold airmass almost passed away over the experimental domain. In fact, the temperature at this height rose to $-35.1^{\circ} \mathrm{C}$ at 2100 JST at Akita. Since the dualDoppler radar observations of L-mode snow bands were made around 1700-1900 JST, the band analyzed appeared to occur under a very cold condition, but toward the end of an outbreak of winter monsoon. Figure 3 exhibits a satellite image at 1731 JST. Several L-mode snow bands are identified, oriented roughly in the northwest to southeast direction off-shore of Tohoku District. The arrowindicated L-mode snow band was analyzed in this study.

The thermodynamical structure observed by a sounding at 0900 JST at Akita is indicated in Fig. 4. It shows a convectively unstable stratification of low-level air below about 1-km height and a presence of deep mixed layer extending up to about $5.3-\mathrm{km}$ height. The 2100-JST sounding at Akita showed that the depth of mixed layer was about $5.1 \mathrm{~km}$. Thus, the atmospheric condition was favorable for the occurrence of deep snow clouds and snow bands. The 0900-JST sounding has shown that the lifting condensation level was about $0.44 \mathrm{~km}$, and that the Convective Available Potential Energy (CAPE) was small, about $10 \mathrm{~J} \mathrm{~kg}^{-1}$. 


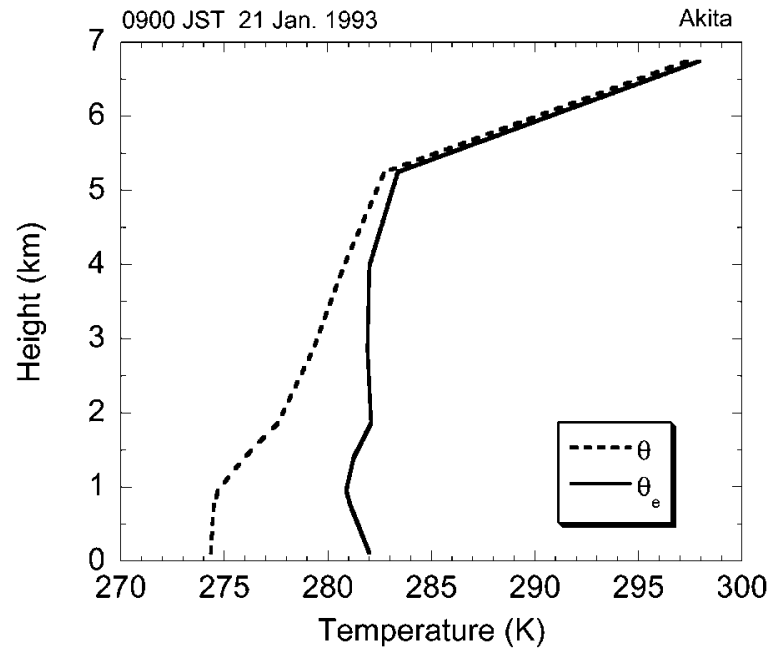

Fig. 4. Vertical profiles of potential (dashed line) and equivalent potential (solid line) temperatures from sounding at Akita at 0900 JST on January 21, 1993.

The observed L-mode snow band was formed under an environment with large vertical shear in the band-transverse direction. Figure 5 shows a hodograph from routine soundings at Akita at 0900 JST and 2100 JST. The 0900-JST profile indicated that northwesterly winds prevailed at almost all heights in the mixed layer, and that the change in wind direction with height was small. The 2100JST profile, in contrast, exhibited a large vertical shear below about $1.9-\mathrm{km}$ height in the bandtransverse direction. A large part of L-mode snow bands observed during the field experiment was, however, associated with weaker shear in this direction. The southern wind component at the $1.9-\mathrm{km}$ height may have been localized because the routine sounding data taken at Wajima Observatory $\left(37^{\circ}\right.$ $23^{\prime} \mathrm{N}, 136^{\circ} 54^{\prime} \mathrm{E}$ ) of JMA at $2100 \mathrm{JST}$ of the day, also facing the Sea of Japan, had shown that the prevailing wind was from the northwest and westnorthwest below the $500-\mathrm{hPa}$ height with no southerly wind components. Without the southerly wind component at the $1.9-\mathrm{km}$ height in Fig. 5, a large band-transverse vertical shear directing from southwest to northeast remained. Accordingly, it is safe to say that the band studied occurred under the existence of a large band-transverse vertical shear around the end of the cold-air outbreak.

The presence of this large vertical shear in the band-transverse direction was also identified in the vertical profiles of the averaged horizontal mean

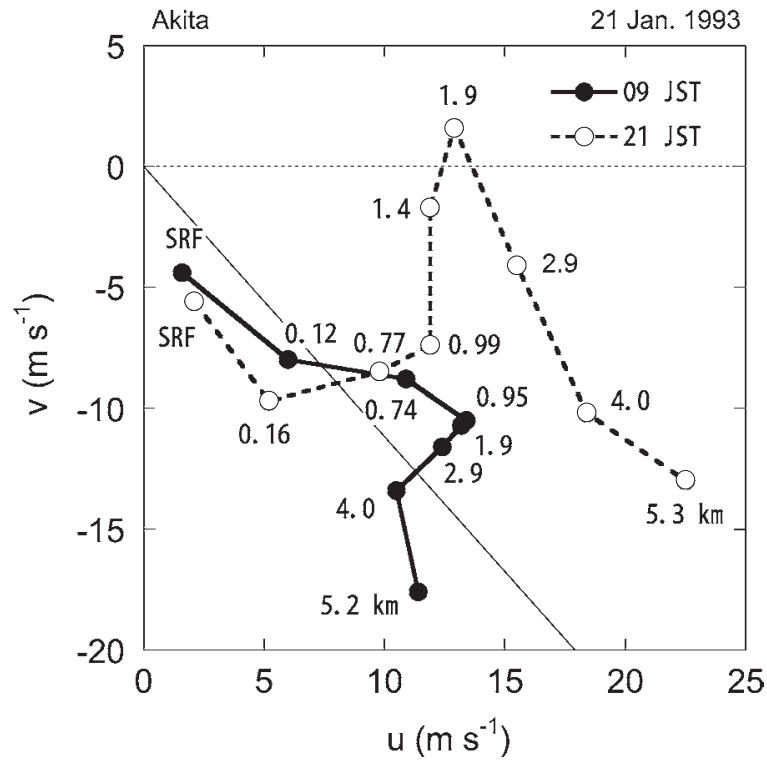

Fig. 5. Hodograph from routine soundings at Akita at 0900 JST (solid line with solid circles) and 2100 JST (dashed line with open circles). Numbers near the solid and open circles indicate the heights in kilometers, and "SRF" denotes the surface data. The band orientation is also shown by a thin solid line.

winds derived from dual-Doppler radar data shown in Fig. 6 for the band portion indicated in Fig. 7. When these profiles were derived, vertical profiles of horizontally averaged Doppler winds were calculated first for all dual-Doppler data. These vertical profiles at three observation times of 1749 JST, 1757 JST, and 1805 JST were subsequently used to obtain a temporally averaged profile. In this averaging process, Doppler winds at grid points with reflectivities $<20 \mathrm{dBZ}$ were used to extract a wind field that would not have been greatly affected by the band circulation. As in the previous hodograph, this figure shows a large vertical shear in the bandtransverse direction below the $2.7-\mathrm{km}$ height. This shear had a magnitude of $1.9 \times 10^{-3} \mathrm{~s}^{-1}$ between the heights of 0.6 and $2.7 \mathrm{~km}$ and was directed in the same direction, approximately from the southwest to the northeast, as the band-transverse propagation velocity. On the other hand, since the mean wind components in the band-parallel direction were mostly within $10-12 \mathrm{~m} \mathrm{~s}^{-1}$, the band-parallel vertical shear in this height interval was weak with a magnitude of $5.8 \times 10^{-4} \mathrm{~s}^{-1}$, directing northwest- 


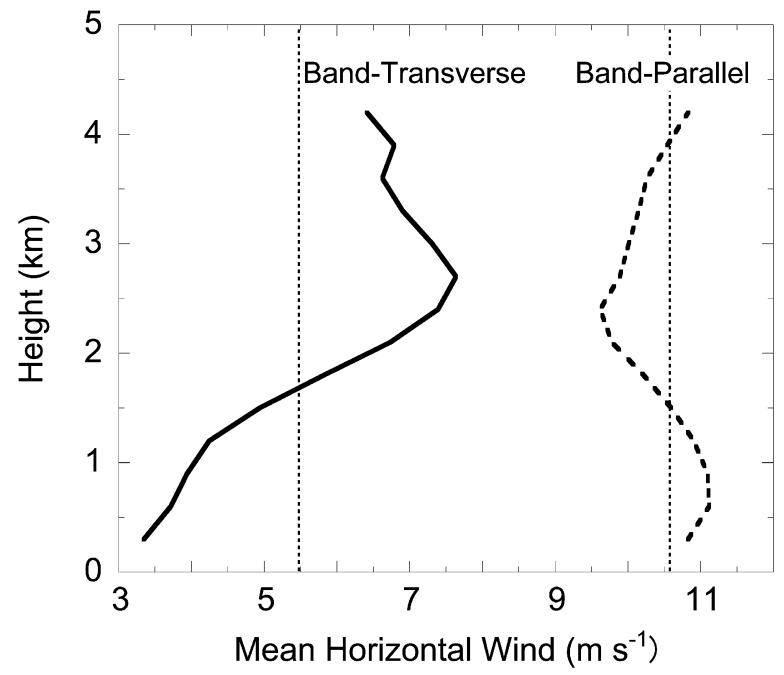

Fig. 6. Vertical profiles of mean horizontal wind components in the band-parallel (dashed line) and the band-transverse (solid line) directions. Positive values in the bandparallel and band-transverse components indicate the wind components toward the southeast and northeast, respectively. Thin dotted lines show the band motion in each direction.

ward. Thus, it was found from Figs. 5 and 6 that the band-transverse large vertical shear was confined roughly to the lower half of the mixed layer.

Figure 7 shows a time series of PPI images of the snow band observed by NIED Doppler radar from 1741 JST to 1821 JST. The band was more than $50 \mathrm{~km}$ long and about $10-15-\mathrm{km}$ wide. It contained high reflectivities $>34 \mathrm{dBZ}$. This figure shows that an overall echo pattern did not change greatly with time, but a multicellular structure was identified as shown later. The 15-dBZ echo top height of the snow band was about $4 \mathrm{~km}$ (see Fig. 14). The band orientation determined from PPI images at elevation angles $\leq 4^{\circ}$ was from $318^{\circ}$ to $138^{\circ}$. This orientation formed an angle of $23^{\circ}$ clockwise with respect to the mean wind in the mixed layer, looking downwind. The speed and direction of the mean horizontal wind in the mixed layer were, respectively, from $295^{\circ}$ to $115^{\circ}$, and $11.9 \mathrm{~m} \mathrm{~s}^{-1}$. This mean wind was computed by an averaging of the wind profiles in Fig. 6 in the height interval from 0.3 to $4.2 \mathrm{~km}$. During the dual-Doppler observations, this band traveled at a speed of $12 \mathrm{~m} \mathrm{~s}^{-1}$ from $297^{\circ}$. The mean vertical shear between the heights of 0.6 and $3.9 \mathrm{~km}$ formed an angle of $79^{\circ}$ with the direction of the band orientation looking upwind. This shear vector was also computed from the mean wind profile in Fig. 6 and was regarded as a mean shear vector in the cloud layer.

\subsection{Multicellular structure of the band}

The snow band eventually had a multicellular structure. Figure 8 shows time change in reflectivity fields at the height of $1.2 \mathrm{~km}$ in the band portion indicated in Fig. 7. At 1741 JST, an active cell of Cell 1 was located near $(x, y)=(-37.7,-9.6) \mathrm{km}$, where $x$ and $y$ stand for the horizontal coordinates of the common grids resolved in the fixed frame in Fig. 1, and relatively large reflectivities $>30 \mathrm{dBZ}$ were found in an elongated region near the trailing edge of the band. In other portions of the band, reflectivities were $<30 \mathrm{dBZ}$, and the cellular pattern was obscure. At 1749 JST, the development of a new cell (labeled Cell 2) was identified near the leading edge in the downshear of an active cell at around $(x, y)=(-27.5,-6.9) \mathrm{km}$, as indicated by an arrow. At this time, the older cell (Cell 1) at $(x, y)=(-32.4,-12.5) \mathrm{km}$ would have been in its maturity. By 1757 JST, Cell 2 had developed enough to have a maximum reflectivity exceeding $35 \mathrm{dBZ}$, whereas Cell 1 decayed significantly such that its region of reflectivities $\geq 30 \mathrm{dBZ}$ reduced considerably. Cell 2 seemed to move slightly toward the trailing edge and was gradually embedded within the band during its development. By 1805 JST, Cell 1 had disappeared, and Cell 2 retained its convective activity because the area of reflectivity $>30 \mathrm{dBZ}$ was similar to that at 1757 JST. At 1813 JST, Cell 2 seemed to be still developing on the basis of the enlargement of the region of reflectivity $>30 \mathrm{dBZ}$ compared with that at the previous observation time. It should be noted here that the formation of another new cell, labeled Cell 3 , occurred near the trailing edge in the downshear side of Cell 2. The relative position of this newly forming cell with respect to the moving frame of reference was close to that of Cell 2 at 1749 JST. As shown, new cells repeatedly developed near the leading edge, that is, in the downshear of the older cells, which decayed significantly by the time the new cells were sufficiently developed. It is interesting to note that the repeated generation of new cells did not form a downshear-directing narrow bandlike echo pattern, which branched off from the Lmode snow band at a large angle to the L-mode band orientation. 

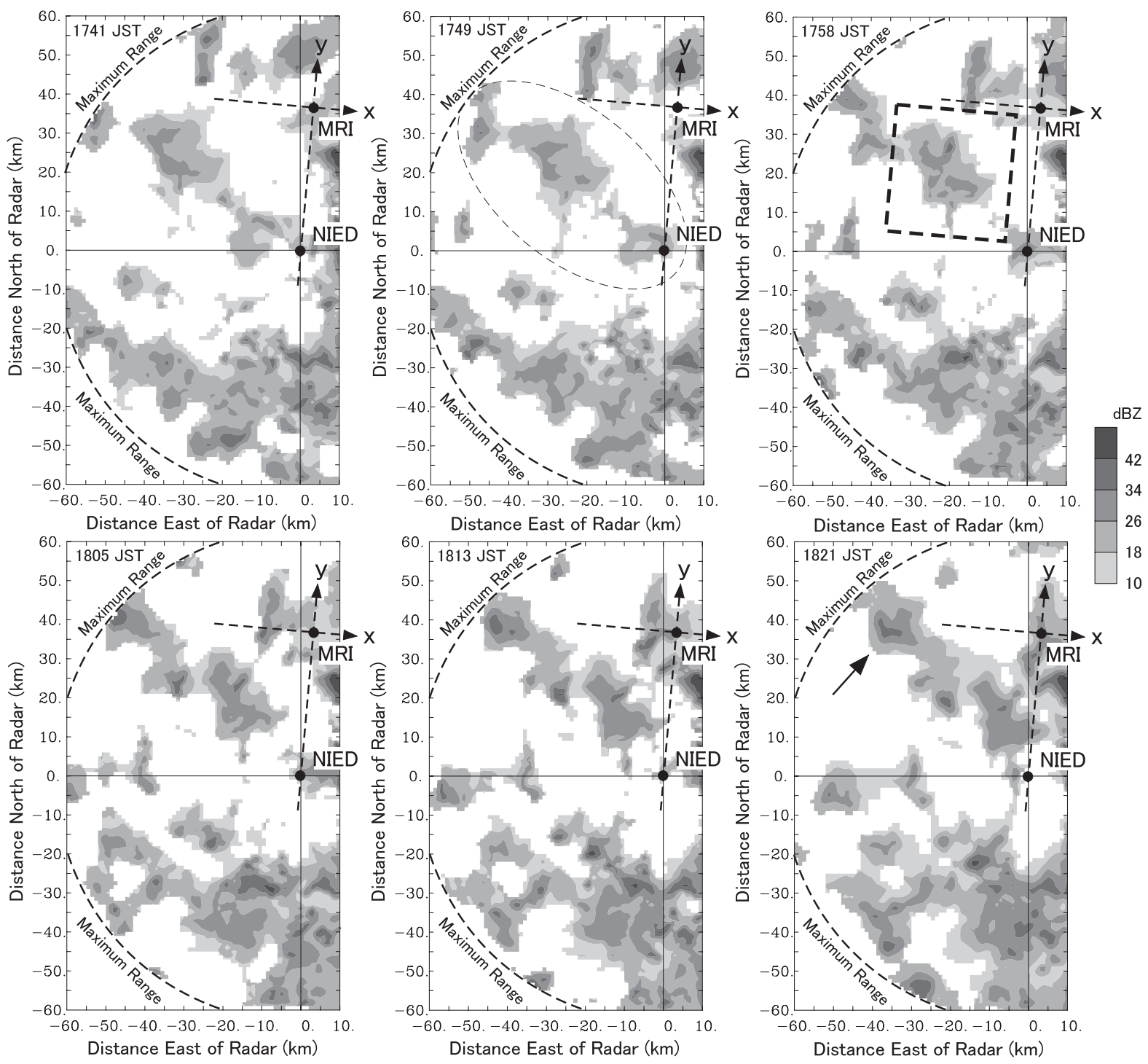

Fig. 7. PPI images of NIED Doppler radar at an elevation angle of $1.5^{\circ}$ from $1741 \mathrm{JST}$ to $1821 \mathrm{JST}$. Reflectivities are shaded at $8-\mathrm{dBZ}$ intervals, starting from $10 \mathrm{dBZ}$. The positions of MRI and NIED radars (solid circles), and the coordinates for the dual-Doppler synthesis are also shown. The respective $x$ - and $y$-axes are the same as in Fig. 1. The open rectangle of bold dashed line in the 1758-JST image indicates the domain for dual-Doppler wind retrieval in the moving frame at this time. The oval of thin dashed line in the 1749-JST image encloses the L-mode snow band analyzed in this study. The Sea of Japan extends approximately to the west of the base line for $x<0 \mathrm{~km}$. Reflectivities exceeding $42 \mathrm{dBZ}$ found around $25 \mathrm{~km}$ in the distance north of the NIED radar are probably contaminated by ground clutter. The arrow in the 1821-JST image indicates a band portion probed by dual-Doppler radar around 1845 JST.

\subsection{Check on the adequacy of retrieval}

The adequacy of the results of retrieval was considered in the light of the potential temperature perturbations because there were no other means or in situ data that enabled us to check the results directly for this case. Vertical profiles of potential temperature perturbations at 1749 JST and 1757 JST are shown in Fig. 9. The retrieval of temperature perturbations was considered to be successful because the presence of a cold pool beneath the 

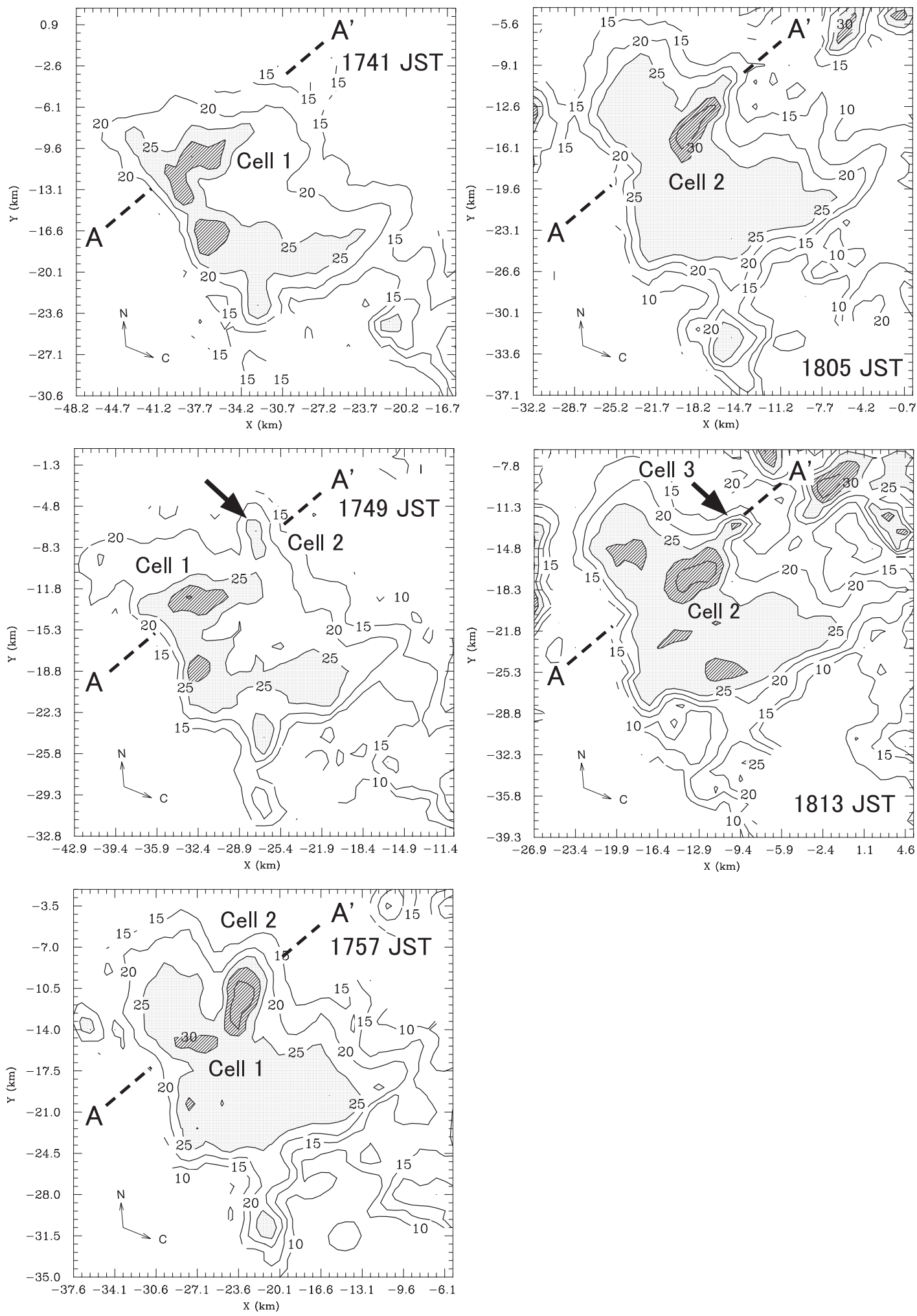


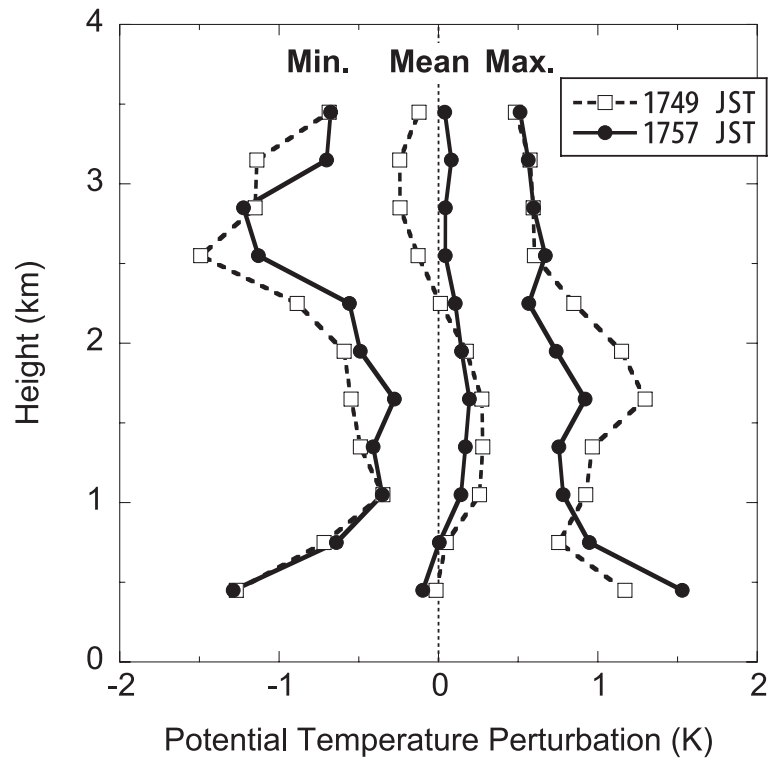

Fig. 9. Vertical profiles of maximum, mean, and minimum potential temperature perturbations at 1749 JST (dashed lines with open rectangles) and 1757 JST (solid lines with solid circles) from retrieval.

band around the surface and its strength were in good agreement with observational facts for other cases of isolated snow clouds (Yamada et al. 1994) and snow bands over the Sea of Japan (Yamada et al. 1996). These previous works have consistently reported the presence of a cold pool whose temperature deficit below about the $0.5-\mathrm{km}$ height was at most about $1 \mathrm{~K}$ with respect to the ambient air. For the present case, minimum temperature perturbations at the $0.45-\mathrm{km}$ height were about $-1.3 \mathrm{~K}$, and the predominance of negative temperature perturbations at this height, shown in Fig. 11 resulted in mean temperature perturbations between -0.1 and $0 \mathrm{~K}$. Thus, the retrieval rendered the thermodynamical character consistent with past observations. Accordingly, no bias correction was made for the potential temperature perturbations. The retrieved temperature perturbations in the band were mostly within about $\pm 1 \mathrm{~K}$, and the mean perturbation at each height was close to $0 \mathrm{~K}$. Most positive temperature perturbations above the lifting condensation level could be associated with diabatic heating resulting from condensation. The retrieved temperature and pressure perturbations at 1741 and 1805 JST showed characteristics similar to those at 1749 JST and 1757 JST (not shown).

The retrieved pressure perturbations were small, less than $1 \mathrm{hPa}$ in magnitude (not shown). Thus, no bias correction was made for pressure perturbations either. The increase in mean mass content of cloud with height was qualitatively consistent with observational results of the cloud water content in short-lived snow clouds (Murakami et al. 1994b), suggesting the appropriate inference of the mass content (not shown). The mean value at each height was derived from the non-zero cloud mixing ratios.

\subsection{Three-dimensional airflow and thermodynamical structures}

System-relative airflow structures in the band at 1757 JST in the horizontal cross-sections are shown in Fig. 10 up to the $3.3-\mathrm{km}$ height, above which the echo area largely reduced. The corresponding potential temperature perturbations and cloud and saturation deficit mixing ratios are shown in Figs. 11 and 12, respectively, but only at significant heights; the areal extent of these two fields became very small above $3.15-\mathrm{km}$ height due to the reduction in echo area. The system-relative and vertical wind fields exhibited a somewhat complex threedimensional character. The ascending inflow was located around the leading edge in a limited area, and the updrafts occupied the central portion of the band. The downdrafts, on the other hand, existed around the leading and trailing edges, and around the northern and southern portions of the band. Their areal extent around the leading edge was larger than that of the updrafts. The lifting of the inflow around the leading edge was probably induced by the low-level collision between the subsaturated cold pool beneath the band and the unstable ambient air. This cold pool was mostly subsaturated as depicted in the horizontal cross-

Fig. 8. Reflectivity fields at the 1.2-km height at five successive observation times taken at 8-minute intervals, from $1741 \mathrm{JST}$ to $1813 \mathrm{JST}$. Contours are drawn at 5-dBZ intervals, starting from $15 \mathrm{dBZ}$. Reflectivities between $25 \mathrm{dBZ}$ and $30 \mathrm{dBZ}$ are stippled, and those $>30 \mathrm{dBZ}$ are hatched. Dashed lines $\mathrm{AA}^{\prime}$ are the positions of the vertical cross-sections in Fig. 14. Bold arrows indicate the newly grown cells. The arrows labeled "N" and "C" denote the directions of the north and the band motion, respectively. The leading (trailing) edge of the band corresponds to the most northeast (southwest) side of this echo. 

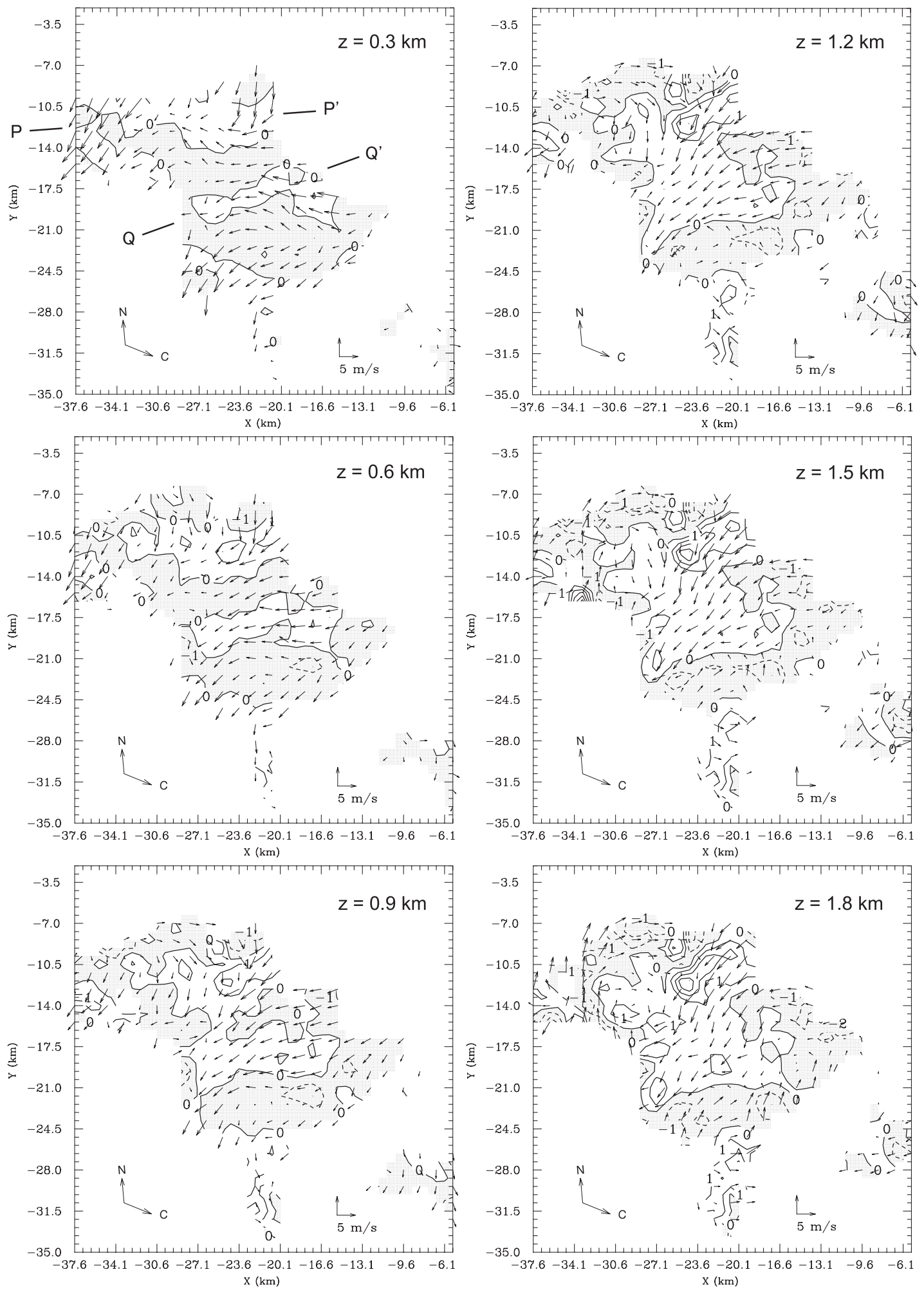

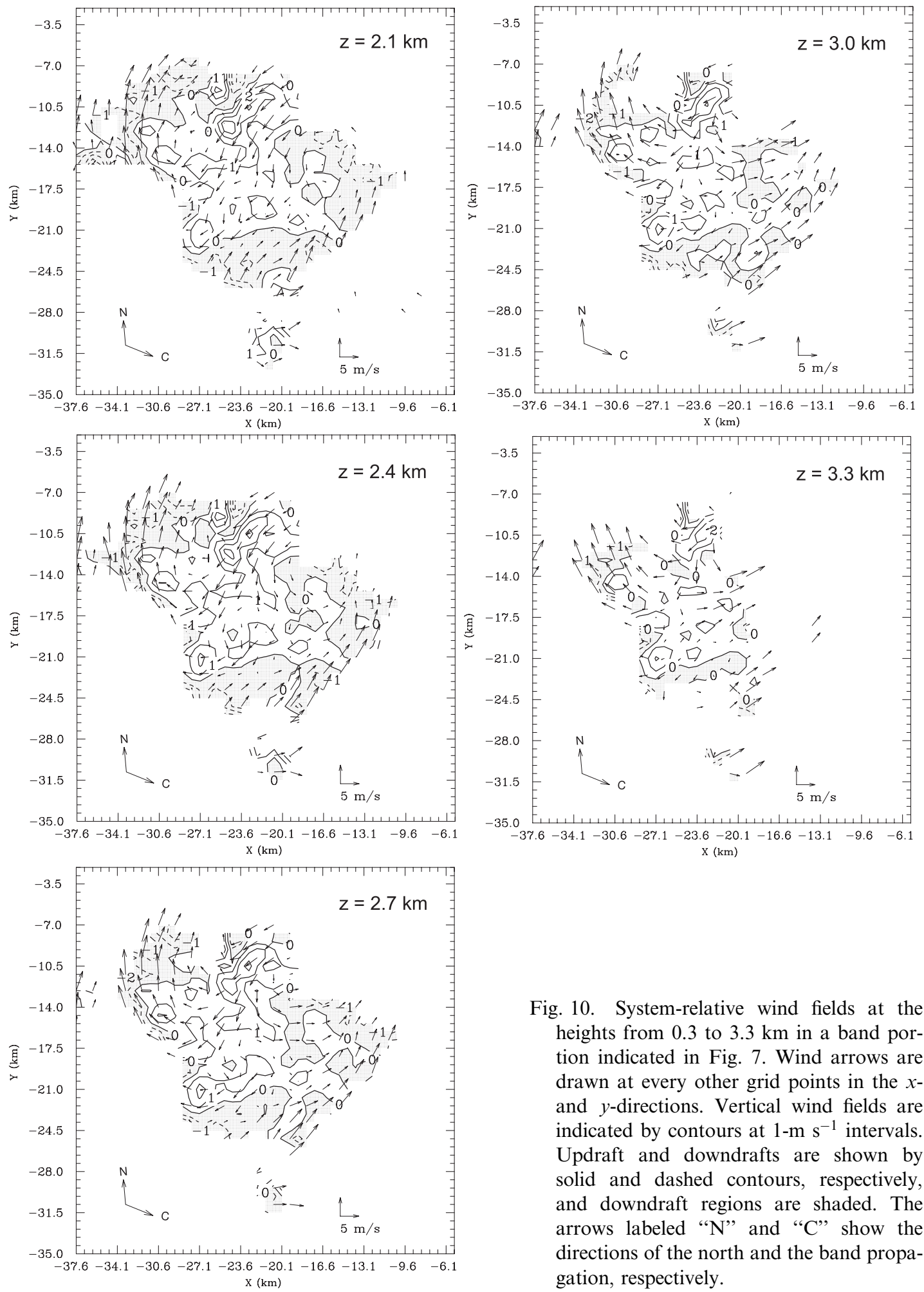

Fig. 10. System-relative wind fields at the heights from 0.3 to $3.3 \mathrm{~km}$ in a band portion indicated in Fig. 7. Wind arrows are drawn at every other grid points in the $x$ and $y$-directions. Vertical wind fields are indicated by contours at $1-\mathrm{m} \mathrm{s}^{-1}$ intervals. Updraft and downdrafts are shown by solid and dashed contours, respectively, and downdraft regions are shaded. The arrows labeled " $N$ " and " $\mathrm{C}$ " show the directions of the north and the band propagation, respectively. 

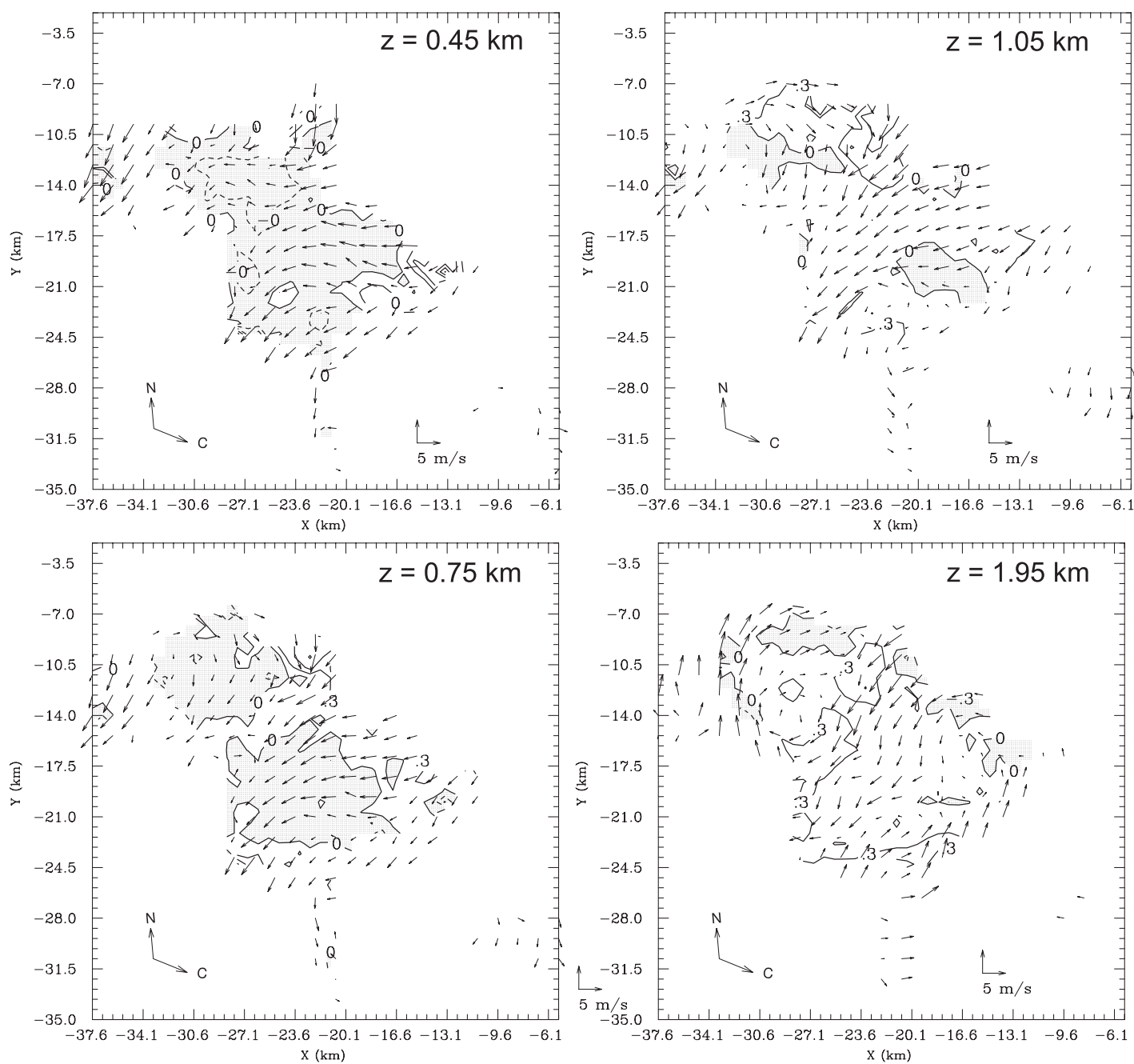

Fig. 11. Potential temperature perturbations at the 0.45-, 0.75-, 1.05-, and 1.95-km heights at 1757 JST. Contour interval is $0.3 \mathrm{~K}$. Positive (negative) perturbations are shown by solid (dashed) contours. Regions of negative perturbations are shaded. System-relative horizontal winds are also superposed and are drawn at every other grid points in both directions. These horizontal winds are mean winds at heights just above and below. The arrows labeled "N" and "C" are the same meaning as those in Fig. 10, respectively.

section at the $0.45-\mathrm{km}$ height in Fig. 12. The subsaturation favored the maintenance of the cold pool by the evaporative cooling of precipitation particles.

In the updraft region located in the center of the band, most of the ascending relative horizontal winds directed southwest, that is, in the upshear direction, and the maximum updrafts were at most $2 \mathrm{~m} \mathrm{~s}^{-1}$ there. These updraft regions were characterized by positive potential temperature perturbations of about $0.3-0.6 \mathrm{~K}$ as seen in the horizontal cross-section higher than $0.45-\mathrm{km}$ height in Fig.
11. Intense updrafts $>3 \mathrm{~m} \mathrm{~s}^{-1}$ were mostly associated with an active cell of Cell 2 in Fig. 8, where maximum updrafts reached $3.7 \mathrm{~m} \mathrm{~s}^{-1}$ at the 1.8 $\mathrm{km}$ height. Most updrafts in this cell also had relative horizontal wind components toward the upshear. Above the $1.8-\mathrm{km}$ height, the ascending horizontal winds exhibited, in turn, a divergent character such that the direction of the relative winds changed to the north and south around the trailing edge of the band. This divergent airflow was clearly identified at heights higher than $2.4 \mathrm{~km}$ and was an indication of the spreading of the up- 

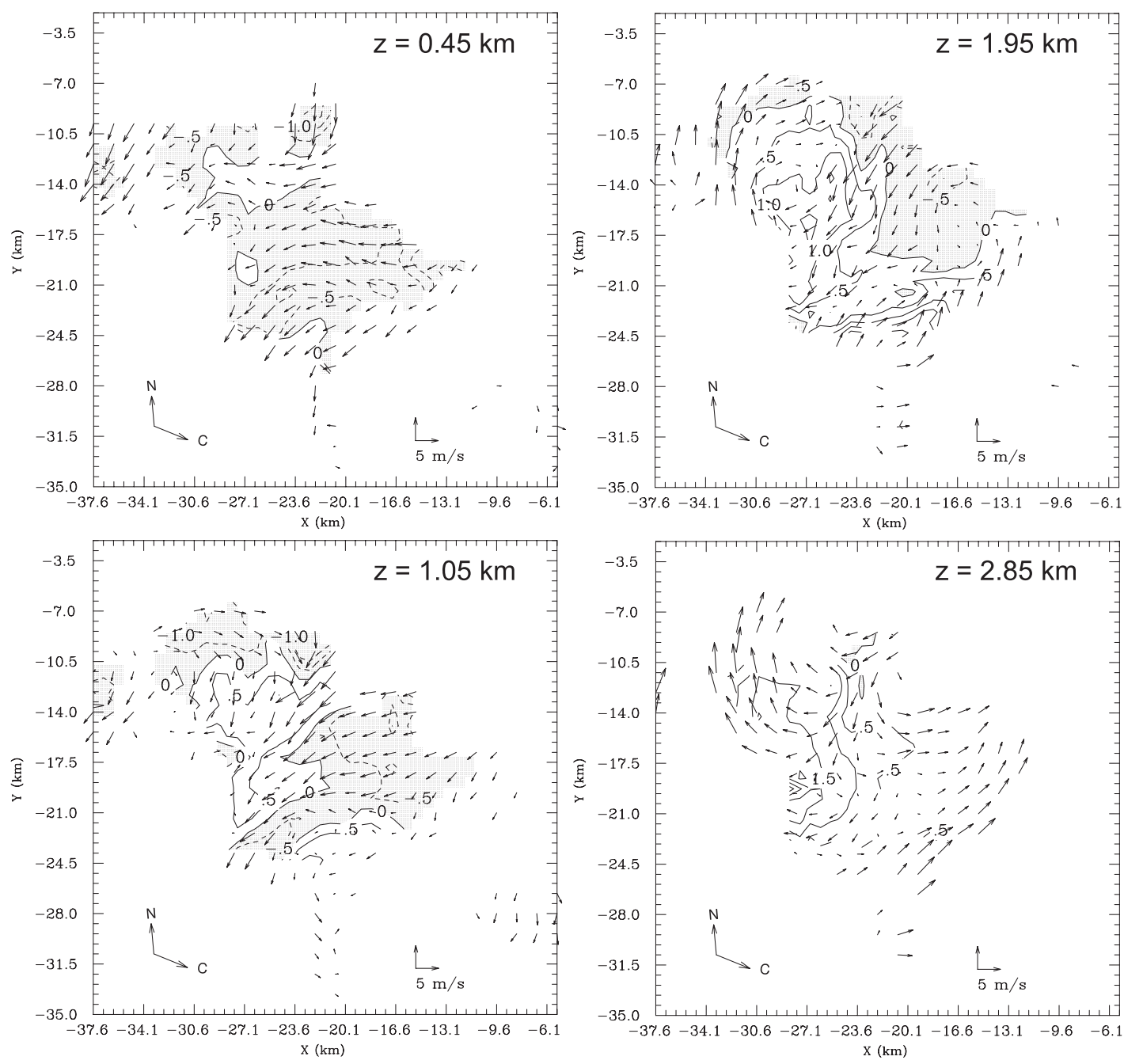

Fig. 12. As in Fig. 11, but for cloud and saturation deficit mixing ratios at the 0.45-, 1.05-, 1.95-, and $2.85-\mathrm{km}$ heights. The contour interval is $0.5 \mathrm{~g} \mathrm{~kg}^{-1}$, and subsaturated regions are shaded.

draft air near the upper portion of the mixed layer. This spreading probably contributed, in part, to the formation of weak echo regions around the active cell because the snow particles transported upward by the updrafts were subsequently carried away by the divergent airflow. The updraft regions were mostly saturated and contained large cloud mixing ratios as large as about $1.5 \mathrm{~g} \mathrm{~kg}^{-1}$ as in the horizontal cross-section at the $2.85-\mathrm{km}$ height in Fig. 12. In addition, band portions with high cloud mixing ratios were mostly located above the $1.05-\mathrm{km}$ height. The subsaturated regions in Cell 2 near $(x, y)=(-23.6,-10.5) \mathrm{km}$ at the level of $1.05 \mathrm{~km}$ in Fig. 12 appeared unnatural. This underestimation of the cloud mixing ratio may have arisen from the computation of the precipitation mixing ratio from reflectivity. Large reflectivities associated with the cell would have resulted in large precipitation mixing ratios relative to the collocated value of $q_{T}$. This is a limitation of the retrieval scheme employed in this study. There were two elongated updraft zones oriented at a large angle to the band orientation along lines $\mathrm{PP}^{\prime}$ and $\mathrm{QQ}^{\prime}$, respectively, at the height of $0.3 \mathrm{~km}$ in Fig. 10. Cell 2 was associated with the zone along $\mathrm{PP}^{\prime}$ whose magnitude of horizontal convergence was, on average, larger than that along $\mathrm{QQ}^{\prime}$. When viewed from the wind fields decomposed into the band-parallel and band-transverse directions (not shown), the bandparallel convergence would primarily have been im- 
portant in the formation of these zones. In each zone, convergence of the band-transverse airflow appeared to intensify the convergence around the leading edge.

Downdrafts were located near the northern and southern portions of the band as well as around the trailing edge. In addition, compensation and precipitation-associated downdrafts were observed; the presence of latter downdrafts will be shown in subsection 3.6. Downdrafts located in the northern portion originated at heights higher than $3 \mathrm{~km}$ because downdrafts with a relative wind component toward the northwest were found at heights of 3.0 and $3.3 \mathrm{~km}$. These downdrafts changed direction with the decrease of height in a clockwise sense. In fact, they were toward the northeast, that is, toward the downshear at the $1.8-$ to $2.7-\mathrm{km}$ heights and then to the southeast below the $0.9-\mathrm{km}$ height. Some of these downdrafts entered the band across the trailing edge around the northern end of the band in a height interval between 1.8 and $2.4 \mathrm{~km}$. They had negative potential temperature perturbations, and were at slight subsaturation, as suggested in the horizontal cross-sections at the 1.95$\mathrm{km}$ height in Figs. 11 and 12, respectively. At upper heights between 2.25 and $2.85 \mathrm{~km}$, it was deduced that most downdrafts had potential temperature perturbations of $\pm 0.3 \mathrm{~K}$, and that slightly saturated downdrafts were more numerous (not shown). Below the $1.5-\mathrm{km}$ heights, downdrafts were mostly subsaturated and had relative wind components to the southeast. The downdrafts located in the southern portion of the band also originated above the 3$\mathrm{km}$ height, as did the downdrafts in the northern portion, and had a horizontal wind component toward the northeast or the downshear. The greater part of them appeared to flow into the band across the trailing edge at around the southern end of the band. These downdrafts at a height of $2.55 \mathrm{~km}$ were mostly characterized by negative temperature perturbations about $-0.3-0 \mathrm{~K}$ around the trailing edge (not shown). At the heights of 1.5 and $1.2 \mathrm{~km}$, downdrafts near the leading edge in the southern portion were directed toward the upshear, whereas those near the trailing edge were toward the downshear. Below the $1.2-\mathrm{km}$ height, most downdrafts in the southern portion of the band had a component toward the southwest or the upshear. Accordingly, these downdrafts rotated clockwise, when looked upwind. Subsaturation of these downdrafts was notable at the $0.45-\mathrm{km}$ height as in Fig. 12.
Other than the two downdrafts mentioned above, there were subsaturated downdrafts around the trailing edge, originating at upper heights. Some of these entering the band across the trailing edge were identified at around $(x, y)=(-27.1,-19.6) \mathrm{km}$ in a small area in a height interval between 0.9 and $1.8 \mathrm{~km}$. They were slightly cooler than the environment; this is depicted in the horizontal crosssections at the height of $1.05 \mathrm{~km}$ in Fig. 11. These downdrafts seemed to intensify the horizontal convergence between the ascending air from the leading edge; thus, acting to maintain or intensify the updrafts in the region near the trailing edge. The existence of this middle-level convergence will be shown in the mass transport analysis.

The downdrafts around $(x, y)=(-23.6,-9.1)$ and $(-19.4,-14.0) \mathrm{km}$ were considered to be compensation downdrafts because they were nearly adjacent to the active cell in the upwind and downwind directions. These downdrafts originated at least at heights $\geq 2.1-2.7 \mathrm{~km}$ and flowed into the band across the leading edge at heights $\leq \sim 2.4 \mathrm{~km}$. They seemed to be mostly subsaturated as seen at the 1.95-km height in Fig. 12. Airflow structures in the band-parallel vertical cross-sections passing the position of the active cell showed that these downdrafts seemed to enhance the low-level horizontal convergence beneath the active cell (not shown).

Eventually, the airflow structures in the band were characterized by upshear-tilting updrafts. The kinematic and thermodynamical structures observed at 1741,1749 , and 1805 JST were similar to those at 1757 JST.

\subsection{Mass transport analysis}

In order to examine further the airflow structure, we made mass transport analysis. This analysis revealed both the horizontal mass convergence/ divergence in relation to vertical mass transport and the relative importance of band-parallel and band-transverse airflow as well. A new approach was developed in this study, unlike that employed in Chong et al. (1987), Lin et al. (1990), and Yamada et al. (1996).

To perform the mass transport analysis, we prepared for each analysis time a Cartesian coordinate system in which the horizontal axes were directed in the band-parallel and band-transverse directions, denoted as $x^{\prime}$ and $y^{\prime}$ axes, respectively. In this system, the vertical axis was common to that of the original, and the respective grid resolutions in the horizontal and vertical directions were the same as 
those for the common grids. The wind components resolved in the original coordinates were then redefined by interpolation at the grid points in this new system where the horizontal wind components were further resolved in the $x^{\prime}$ and $y^{\prime}$ directions. Subsequently, the new approach estimated a mean net mass transport per elementary grid box, defined by the grid resolutions $\left(\Delta x^{\prime}, \Delta y^{\prime}\right.$, and $\left.\Delta z\right)$ of the newly defined coordinates, between two heights of $z$ and $z+\Delta z$. Here, $\Delta x^{\prime}, \Delta y^{\prime}$, and $\Delta z$ were the grid resolutions in the $x^{\prime}, y^{\prime}$, and vertical directions, respectively.

The mean net mass transport in the vertical direction $F_{z}(z+\Delta z / 2)$ at a height $z+\Delta z / 2$ may be written as:

$$
F_{z}\left(z+\frac{\Delta z}{2}\right)=\frac{1}{N} \sum\left[m_{z}(z+\Delta z)-m_{z}(z)\right],
$$

where $m_{z}(z)$ defined at a height of $z$ and $m_{z}(z+\Delta z)$ defined at a height of $z+\Delta z$ are the vertical mass transport across the lower and upper planes of elementary grid box, respectively, and $N$ is the total number of the elementary grid boxes involved in the summation. The summation is performed over all elementary grid boxes lying between $z$ and $z+\Delta z$. Division by $N$ provides a mean net mass transport in the vertical per elementary grid box, permitting a comparison of the magnitudes of $F_{z}$ at different heights. The term $m_{z}(z)$ is defined as:

$$
m_{z}(z)=\rho w A \text {. }
$$

Here, $\rho$ is the air density, $w$ the vertical wind component, $A$ the area of the upper or lower plane equal to $\Delta x^{\prime} \cdot \Delta y^{\prime}$. Likewise, the net mean net mass transport in the $x^{\prime}$ and $y^{\prime}$ directions may be written, respectively, as:

$$
F_{x^{\prime}}\left(z+\frac{\Delta z}{2}\right)=\frac{1}{N} \sum\left[m_{x^{\prime}}\left(x^{\prime}+\Delta x^{\prime}\right)-m_{x^{\prime}}\left(x^{\prime}\right)\right]
$$

and

$$
F_{y^{\prime}}\left(z+\frac{\Delta z}{2}\right)=\frac{1}{N} \sum\left[m_{y^{\prime}}\left(y^{\prime}+\Delta y^{\prime}\right)-m_{y^{\prime}}\left(y^{\prime}\right)\right] .
$$

Here, $m_{x^{\prime}}\left(x^{\prime}\right)$ and $m_{x^{\prime}}\left(x^{\prime}+\Delta x^{\prime}\right)$ are the mass transport in the $x^{\prime}$-direction across the lateral plane of elementary grid box located at $x^{\prime}$ and $x^{\prime}+\Delta x^{\prime}$, respectively. $m_{y^{\prime}}\left(y^{\prime}\right)$ and $m_{y^{\prime}}\left(y^{\prime}+\Delta y^{\prime}\right)$ indicate the mass transport in the $y^{\prime}$-direction across the lateral plane of elementary grid box located at $y^{\prime}$ and $y^{\prime}+\Delta y^{\prime}$, respectively. $m_{x^{\prime}}(x)$ and $m_{y^{\prime}}(y)$ may be respectively written as:

$$
m_{x^{\prime}}(x)=\rho u^{\prime} \Delta y^{\prime} \Delta z
$$

and

$$
m_{y^{\prime}}(y)=\rho v^{\prime} \Delta x^{\prime} \Delta z
$$

where $u^{\prime}$ and $v^{\prime}$ stand for the horizontal wind component in the $x^{\prime}$ - and $y^{\prime}$-directions, respectively. The above processing for the horizontal directions eventually estimates the band-parallel and bandtransverse mean net mass transport of the snow bands per lateral plane of an elementary grid box across the lateral boundaries of echo because the mass transport across a common plane of adjacent elementary grid boxes in respective directions is canceled out in the summation. A great advantage of this new approach is its applicability to dispersed and irregular-shaped echoes such as snow clouds and snow bands over the Sea of Japan, because it does not require in echo regions under investigation the specification of a parallelepiped whose size is usually much larger than the elementary grid box.

The results at two selected times of 1749 JST and 1757 JST are displayed in Fig. 13. The results at 1741 JST and 1805 JST were similar to those in this figure, despite slight time-by-time changes in each profile. The analysis volume was the whole band portion in Fig. 10. In order to increase the accuracy, elementary grid boxes located at the most outer peripheries of the echoes were excluded from the calculation because recovered Doppler winds at and near echo boundaries seemed sometimes to be contaminated by relatively large errors. The accuracy of these analyses was considered good because the magnitudes of the residual term were very small; this term is defined as the sum of the three terms of $F_{x^{\prime}}, F_{y^{\prime}}$, and $F_{z}$. These results depicted that mass convergence in the band-parallel and band-transverse directions accounted for the vertical mass divergence below a non-divergent level located at about $2.5-\mathrm{km}$ height, above which mass divergence in the band-parallel and bandtransverse directions resulted in mass convergence in the vertical direction. The term $F_{y^{\prime}}$ was, however, a small positive value below the $0.75-\mathrm{km}$ height at the 1757-JST analysis. These positive values indicated the outflow overwhelmed the inflow. The band-transverse mass convergence $\left(F_{y^{\prime}}\right)$ was found to be relatively important below the non-divergent level. Large magnitudes of this term between the heights of 1.35 and $1.95 \mathrm{~km}$ could have come from the convergence between downdrafts flowing into the band across the trailing 

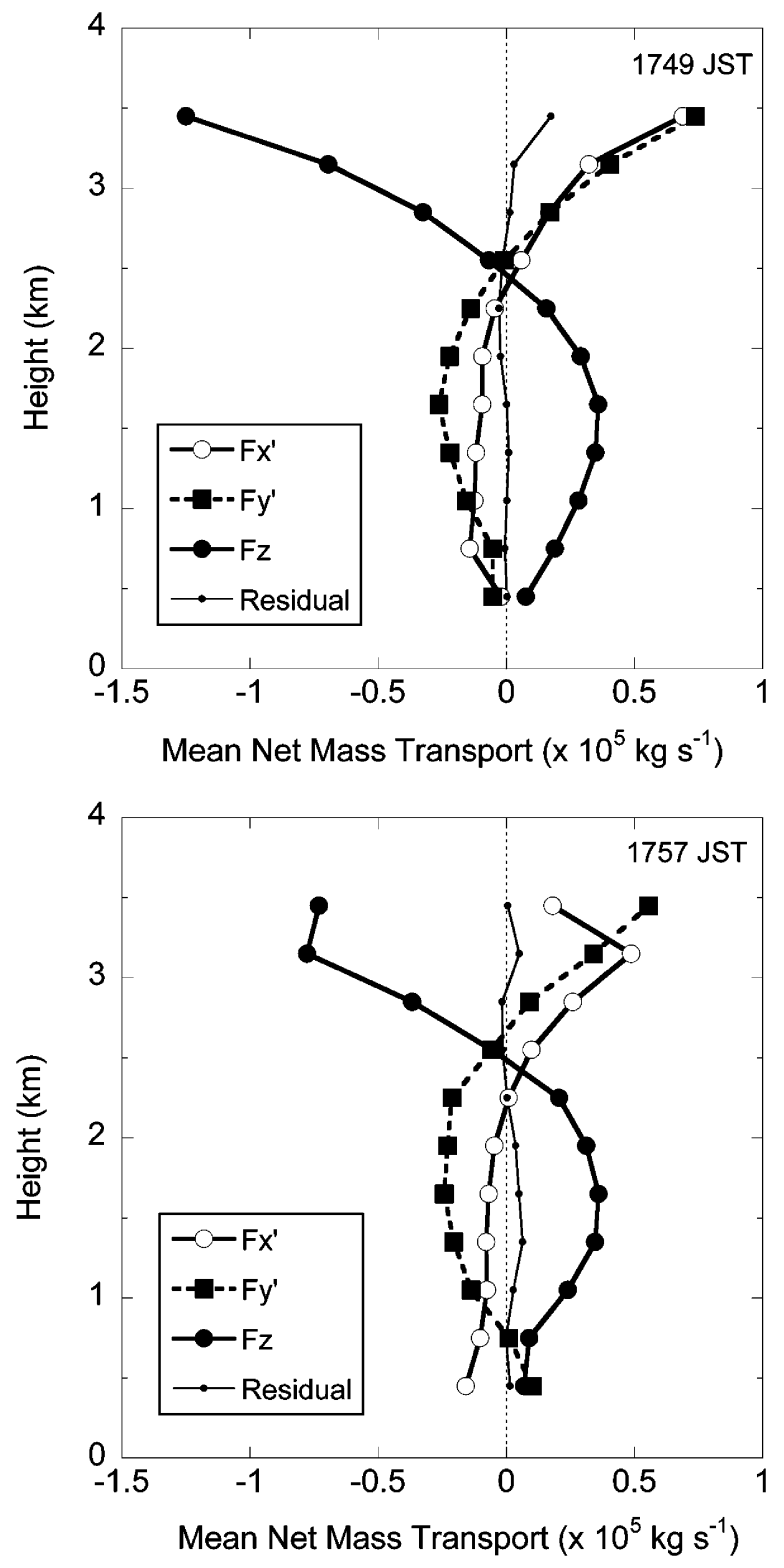

Fig. 13. Vertical profiles of the mean net mass transport for an elementary grid box in the band-parallel (bold solid lines with open circles), band-transverse (bold dashed lines with solid squares), and vertical (bold solid lines with solid circles) directions at two analysis times of 1749 JST and 1757 JST. Residual terms are shown by thin solid lines with small solid circles.

edge and the main updrafts. With regard to the term $F_{x^{\prime}}$, its non-negligible magnitudes would reflect a three-dimensional feature of the airflow structures and tended to decrease gradually with height up to about the non-divergent level. Above this level, the mass divergence in the band-parallel and band-transverse directions was comparable.

\subsection{Airflow structures in vertical cross-sections}

Structures of airflow and reflectivity were examined in band-transverse vertical cross-sections along lines $\mathrm{AA}^{\prime}$ in Fig. 8 from 1741 JST to 1813 JST (Fig. 14). A characteristic airflow structure of the band was depicted well in these cross-sections passing the updraft core of Cell 1 at 1741 JST and 1749 JST and of Cell 2 at other times. The positions of these cross-sections were almost the same in the moving frame of reference. Cells 1, 2, and 3 in Fig. 14 represent the same cells labeled Cell 1, 2, and 3 in Fig. 8, respectively. A pronounced feature of the airflow structures common to most figures in Fig. 14 was the upshear-tilting updrafts, and the updraft and downdraft regions were separated as in a longlasting circulation in a squall line (e.g., Rotunno et al. 1988). The low-level inflow across the leading edge became the major updrafts in the band, while downdrafts were located around the trailing edge. Most of these downdrafts originated at upper heights of 3-3.5 km, and they fell down almost vertically. There were some downdrafts penetrating the band between 1- and 2-km heights across the trailing edge. These middle-level downdrafts could have contributed to the maintenance of cells near the trailing edge because of the convergence with the updrafts flowing toward the trailing edge. Lowlevel outflow was also found across the trailing edge.

At 1741 JST, the presence of an active cell (labeled Cell 1) was identified at around $7<$ $X<10 \mathrm{~km}$, where $X$ stands for the horizontal distance. An overhanging echo region depicted by a $20-\mathrm{dBZ}$ contour was perceived at around the $2-\mathrm{km}$ height ahead of the leading edge, where a new cell (labeled Cell 2) had developed in the downshear side by 1749 JST. This development could have been triggered by a low-level interaction between the outflow from Cell 1 and the ambient air even though it was not clearly indicated in this figure. Such interaction was, however, suggested in airflow structures shown in the band-transverse verticalcross sections from dual-Doppler winds at around 1845 JST for other band portion of the same Lmode snow band indicated in Fig. 7 (not shown). In any case, the detection of such interaction is very difficult by radars for cells in the early stage 

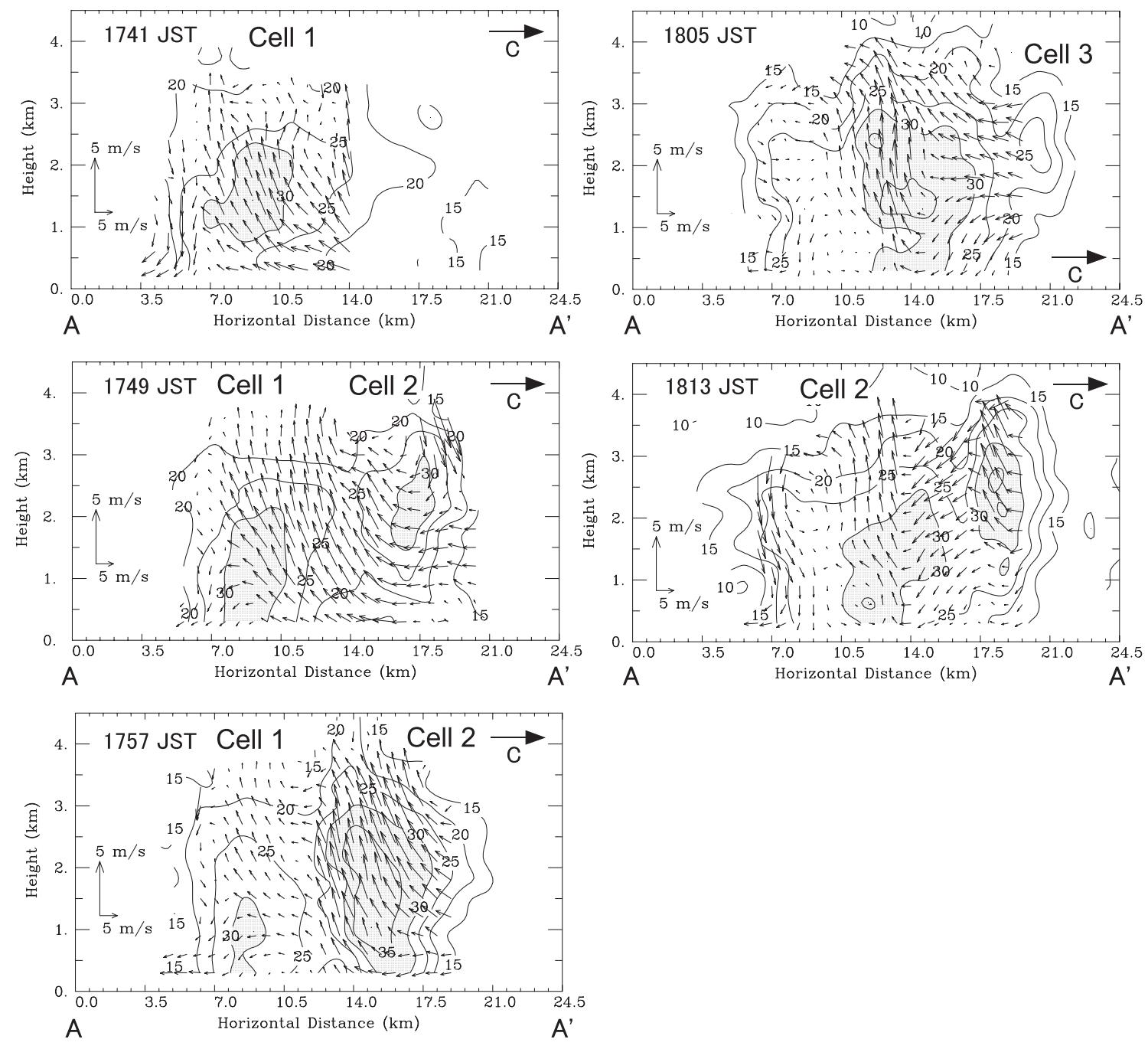

Fig. 14. Time series of reflectivity and airflow structures in the vertical cross-section along lines $\mathrm{AA}^{\prime}$ in Fig. 8 from 1741 JST to 1813 JST. Arrows are vector representation of the system-relative horizontal wind components and vertical air velocities projected onto the plane. They are drawn parallel to the stream line at each grid point because the ratio between the lengths of the reference arrows of $5 \mathrm{~m} \mathrm{~s}^{-1}$ in the horizontal and vertical directions are exactly the same as that between the lengths corresponding to the unit length of $1 \mathrm{~km}$ in the horizontal and vertical directions, respectively. This representation is employed throughout the paper. Reflectivity contours are indicated by solid lines at 5-dBZ intervals. Regions with reflectivities $>30 \mathrm{dBZ}$ are shaded. The direction of the band motion is also shown in each panel by an arrow labeled "C".

of development because they scarcely contain precipitation particles. This newly grown cell appeared to be in the developing stage at 1749 JST because its high reflectivity core characterized by a $30-\mathrm{dBZ}$ contour remained aloft, and the reflectivities at the lowest height below this core were weak at between 15 and $20 \mathrm{dBZ}$, which implied weak precipitation rate at the surface. In this stage of development,
Cell 2 did not suppress inflow toward Cell 1 located at $X=7-10.5 \mathrm{~km}$, in which downdrafts associated with precipitation were found at about $X=7 \mathrm{~km}$ below the 1-km height. By 1757 JST, Cell 2 developed enough for its updrafts to reach about $4 \mathrm{~m} \mathrm{~s}^{-1}$. High reflectivities exceeding $30 \mathrm{dBZ}$ now touched the lowest height of $0.3 \mathrm{~km}$, suggesting the intense precipitation rate at the surface. At this 
time, Cell 2 was considered to be in a mature stage. Most low-level inflow across the leading edge appeared to enter this cell because a precipitation core reaching the surface prevented this inflow from going to Cell 1. The cutoff of this inflow at 1757 JST could have brought about a significant decay of Cell 1. Indeed, the vertical extent of the high reflectivities $(\geq 30 \mathrm{dBZ})$ had reduced, and the magnitudes of updrafts became weak at less than $1 \mathrm{~m} \mathrm{~s}^{-1}$. Cell 1 could still remain owing to slight low-level inflow toward this cell. In Cell 1, downdrafts associated with precipitation were also identified at 1749 JST. At 1805 JST, Cell 1 was scarcely identifiable, and Cell 2 seemed to have begun decaying because the extent of the reflectivity region with values of $\geq 35 \mathrm{dBZ}$ was reduced, and the magnitudes of updrafts weakened. Downdrafts around the trailing edge spread around the surface to induce a low-level convergence with the low-level inflow in the band at around $X=13.3 \mathrm{~km}$. This collision could have helped induce or maintain intense updrafts in Cell 2. In this cell, downdrafts at around $X=14-16 \mathrm{~km}$ were associated with precipitation because they were located in regions with high reflectivities. The formation of another new cell (labeled Cell 3) was observed as an elevated echo at about $X=21 \mathrm{~km}$ in the downshear side. At 1813 JST, Cell 3 was still in the developing stage because the high reflectivity core with values exceeding $30 \mathrm{dBZ}$ was limited to above $\sim 1.5-\mathrm{km}$ height, and reflectivities at the lowest height beneath this core were small at around 15-20 dBZ. In contrast, Cell 2 had decayed as seen in the reduction of vertical extent of high reflectivity region with values greater than $30 \mathrm{dBZ}$. Cell 2 might have been sustained by a low-level convergence at around $X=13 \mathrm{~km}$ between the inflow from the leading edge and the spreading downdrafts, as at 1805 JST.

The upshear-tilting updrafts, similarly to those in the vertical cross-sections from 1741 JST to 1757 JST were also observed both in other bandtransverse vertical-cross sections passing the updraft region located in the central portion of the band and in other band portion (designated by an arrow in PPI image at 1821 JST in Fig. 7) of the same L-mode snow band observed at around 1845 JST (not shown). Accordingly, they could be a common kinematic feature for the L-mode snow band treated in this study. These airflow structures differed significantly from axi-symmetric roll-like circulations reported thus far over Lake Michigan for wind parallel bands (Kelly 1982; Kristovich 1993). The airflow structures in vertical crosssections parallel to the band orientation have, on the other hand, shown that the updrafts went almost vertically upward because of weak vertical shear in this direction (not shown).

\subsection{Vertical transport of the horizontal momentum and heat flux}

The vertical transport of horizontal momentum was investigated next because it is affected by the structure of the band circulation. The vertical fluxes of horizontal momentum in the band-parallel $\left(\overline{u^{\prime} w^{\prime}}\right)$ and in the band-transverse $\left(\overline{v^{\prime} w^{\prime}}\right)$ directions were computed, where $u^{\prime}, v^{\prime}$, and $w^{\prime}$ stand for the deviations at each height with respect to the horizontally-averaged mean winds in the bandparallel, band-transverse, and vertical directions, respectively. These mean winds were computed by averaging the dual-Doppler winds in the analyzed domain, using all available wind data irrespective of reflectivity.

Figure 15a shows vertical profiles of the momentum flux at 1749 JST and 1757 JST. Similar profiles were obtained at 1741 JST and 1805 JST as in these figures. Changes in the vertical flux at these two times in both directions were small. The magnitude of vertical flux of horizontal momentum in the band-transverse direction was predominant over that in the band-parallel direction at heights between 1 and $3 \mathrm{~km}$. The band-transverse profiles had minima reaching $-1 \mathrm{~m}^{2} \mathrm{~s}^{-2}$ at the heights of 2.1 and $2.4 \mathrm{~km}$ at $1757 \mathrm{JST}$ and $1749 \mathrm{JST}$, respectively. The magnitudes in the parallel direction were, on the other hand, small at almost all heights, without large variation with height. This large difference in the profiles could have been accounted for the upshear tilt of updrafts in the bandtransverse direction as depicted in Fig. 14.

The vertical heat flux was also computed at each height as:

$$
\overline{\theta_{v}^{\prime} w^{\prime}}
$$

where $\theta_{v}^{\prime}$ is the virtual potential temperature perturbation with respect to the averaged value in a horizontal domain considered, and $w^{\prime}$ is the perturbation in the vertical wind with respect to the horizontally averaged value. In the calculation of $\theta_{v}^{\prime}$, retrieved potential temperature perturbations and water vapor mixing ratios were used. The results at two observation times of 1749 JST and 1757 JST are shown in Fig. 15b. Time-by-time 


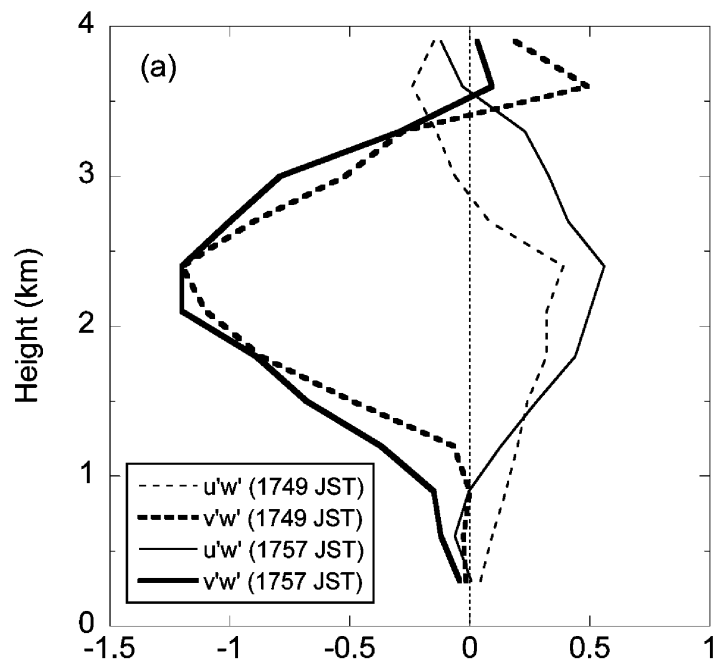

Vertical Flux of Horizontal Momentum $\left(\mathrm{m}^{2} \mathrm{~s}^{-2}\right)$

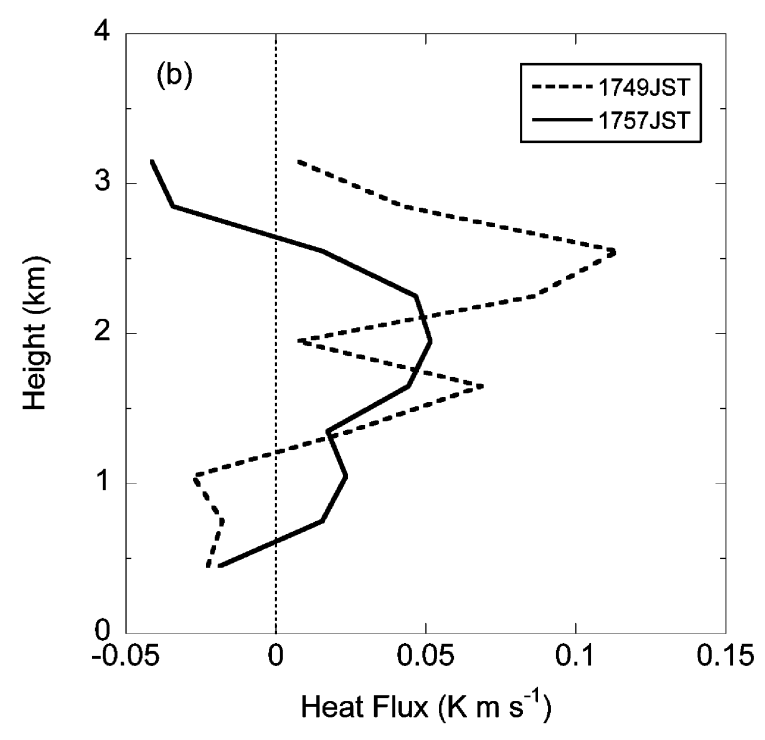

Fig. 15. (a) Profiles of vertical flux of horizontal momentum at 1749 JST (dashed lines) and 1757 JST (solid lines). The flux of the band-parallel and the bandtransverse directions (denoted as $\overline{u^{\prime} w^{\prime}}$ and $\overline{v^{\prime} w^{\prime}}$, respectively) are indicated by thin and bold lines, respectively. Positive values represent upward transport for both directions. (b) Profiles of vertical heat flux at 1749 JST and 1757 JST. Positive values are for upward transport.

change in these vertical profiles was not large. The heat flux was mostly positive (upward) between the heights of 1 and $2.5 \mathrm{~km}$ with maximum values reaching about $0.1 \mathrm{~K} \mathrm{~m} \mathrm{~s}^{-1}$, but negative (downward) at other heights. The downward transport below the $1-\mathrm{km}$ heights was probably caused by mass loading. Similar features were found in the 1741-JST and 1805-JST analyses as those in this figure.

\subsection{Energy conversion rates}

In order to investigate the band maintenance mechanisms, energy conversion rates involved in the energetics of band circulation due to the vertical shear and buoyancy were computed from the retrieved winds, temperature perturbations, water vapor, and cloud and precipitation mixing ratios. The conversion rates from vertical shear in the band-parallel and band-transverse directions (denoted as $P_{P}$ and $P_{T}$, respectively) were computed as:

$$
P_{P}=-\overline{u^{\prime} w^{\prime}} \frac{\partial \bar{u}}{\partial z}
$$

and

$$
P_{T}=-\overline{v^{\prime} w^{\prime}} \frac{\partial \bar{v}}{\partial z},
$$

where $\bar{u}$ and $\bar{v}$ are, respectively, the band-parallel and band-transverse mean horizontal winds at each height, both of which were horizontally-averaged values using all available dual-Doppler wind data. $u^{\prime}, v^{\prime}$, and $w^{\prime}$ denote the same meaning as those in the evaluation of the vertical flux of horizontal momentum, respectively. The conversion rate due to buoyancy $P_{B}$ was estimated in terms of the virtual potential temperature perturbation as:

$$
P_{B}=\frac{g}{\theta_{0}} \overline{\theta_{v}^{\prime} w^{\prime}},
$$

where $g$ is the gravitational acceleration, $\theta_{0}$ the undisturbed potential temperature, and $\theta_{v}^{\prime}$ the virtual potential temperature perturbation with respect to the horizontal average at each height. When $P_{B}$ is expressed in terms of the "apparent potential temperature perturbation" $\theta_{a}$, this term (denoted as $\left.P_{B A}\right)$ may be evaluated as:

$$
P_{B A}=\frac{g}{\theta_{0}} \overline{\theta_{a} w^{\prime}},
$$

where $\theta_{a}$ is defined as in Hauser et al. (1988):

$$
\theta_{a}=\left(\theta-\theta_{0}\right)+\theta_{0}\left[0.61\left(q_{v}-q_{v 0}\right)-q_{c}-q_{p}\right] .
$$

In this equation, the subscript " 0 " represents the undisturbed values, and $\theta$ the potential tempera- 
ture. This temperature accounts for the loading effect of water condensates. In evaluating $P_{B A}$, we also used $\theta_{a}$ with respect to the horizontallyaveraged value.

Vertical profiles of each conversion rate at 1749 JST and 1757 JST are shown in Fig. 16. The buoyancy conversion $\left(P_{B}\right)$ and the band-transverse shear conversion $\left(P_{T}\right)$ had large positive values at middle heights, and were comparable in magnitude at most heights. $P_{B}$ were negative at low heights and at upper heights, whereas $P_{T}$ was positive at most heights. The large positive values of $P_{T}$ resulted from the upshear-tilting updrafts, indicating the energy conversion from the band-transverse mean flow to the band circulation. Compared with these two terms, the magnitude of $P_{P}$ was very small although this term had slightly positive values at most heights. These results suggested that the conversion by buoyancy and the band-transverse shear were the major source of the band circulation. In terms of the "apparent potential temperature perturbation", the buoyancy production term $P_{B A}$ was, however, greatly reduced. It has negative values at high and low heights, retaining small positive values only at the middle heights. Thus, water loading had a significant effect in reducing the buoyancy conversion. When loading effects were considered, the relative importance of $P_{T}$ increased. Analyses at 1741 and 1805 JST showed characteristics similar to these profiles.

\subsection{Conceptual model of kinematic and thermodynamical structures}

Figure 17 schematically illustrates the kinematic and thermodynamical structures of a deep L-mode snow band of about 4-km depth on January 21, 1993. It occurred toward the end of an outbreak of very cold air, where band-transverse vertical shear was large. This large shear was confined approximately to the lower half of the mixed layer. Multicellular structure was observed in this band. The typical kinematic structure in the band-transverse vertical cross-section passing the updraft core of an active cell is also illustrated to highlight the upshear-tilting updrafts.

A significant feature of the airflow structure was the upshear-tilting updrafts, which were consistently observed in most updraft regions. These updrafts seemed to be created by a low-level collision between the subsaturated cold pool and the ambient unstable air flowing into the band across the leading edge. The presence of such a subsaturated
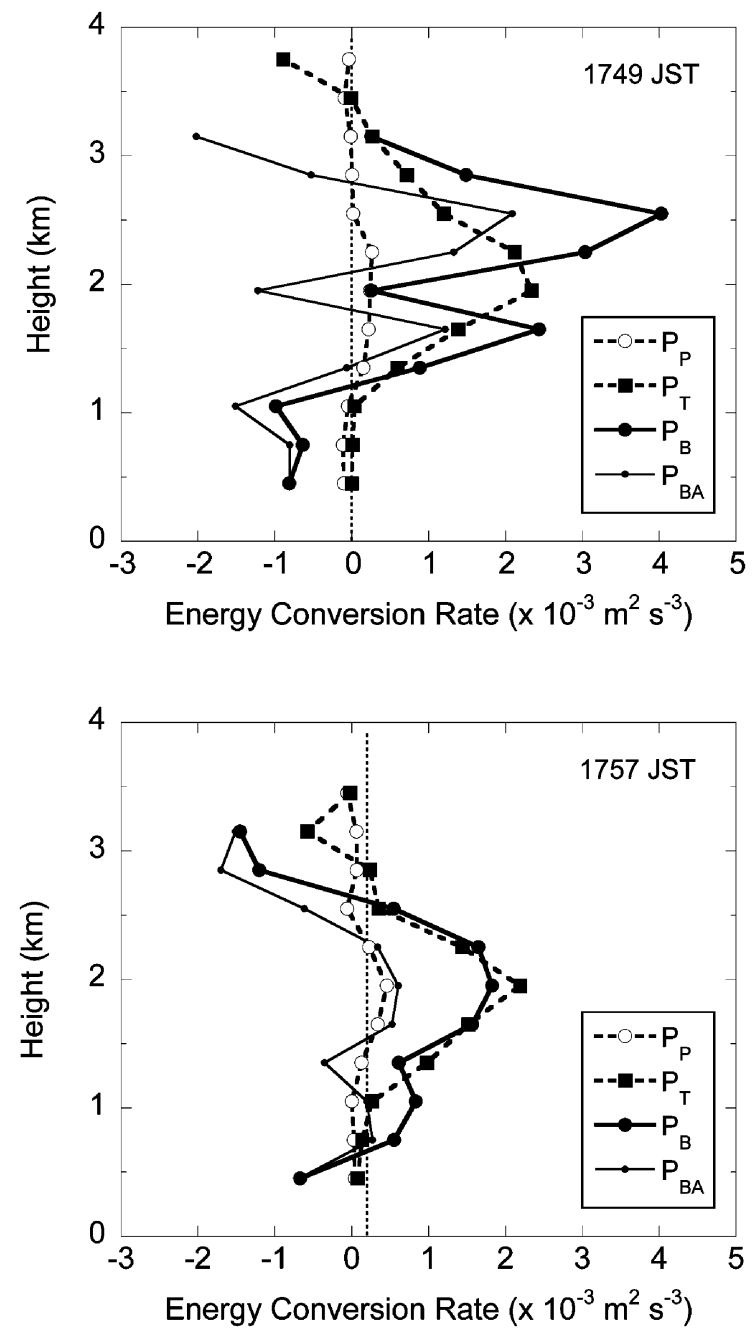

Fig. 16. Profiles of energy conversion rates by the vertical shear and buoyancy at 1749 JST and 1757 JST. The conversion rates by the band-parallel and band-transverse shear are indicated as $P_{P}$ (dashed lines with open circles) and $P_{T}$ (dashed lines with solid rectangles), respectively, whereas conversion rates by buoyancy based on virtual potential temperature perturbations and apparent potential temperature perturbations are shown by $P_{B}$ (bold solid lines with solid circles) and $P_{B A}$ (thin solid lines with small solid circles), respectively. Positive values indicate the energy flow toward the increase of the band circulation energy.

cold pool was deduced from the retrieval, consistently with past observations of snow clouds and snow bands over the Sea of Japan. These updrafts 


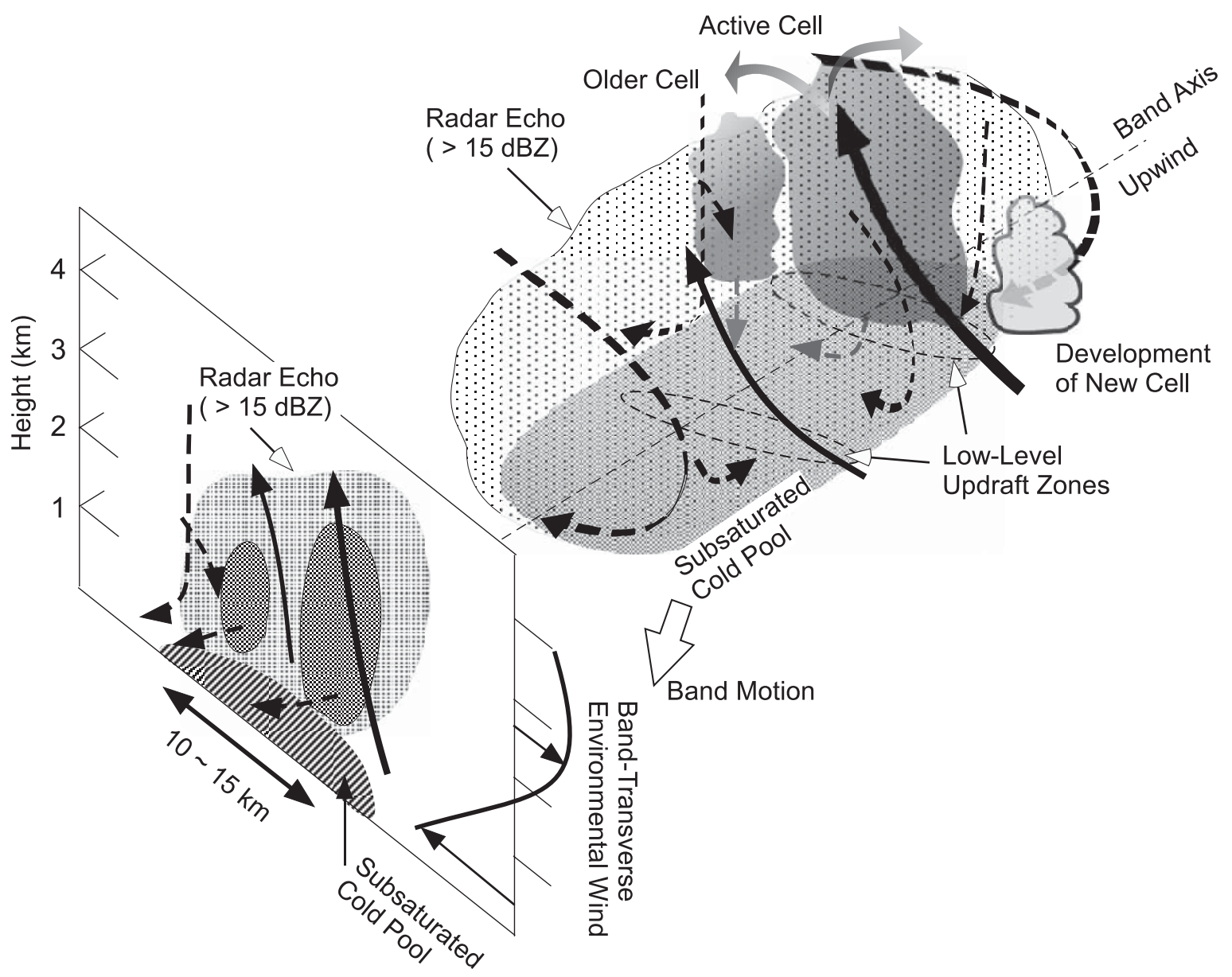

Fig. 17. Schematic illustration of the L-mode snow band on January 21, 1993. The arrows indicate systemrelative airflow, and updrafts (downdrafts) were shown by bold solid (dashed) arrows. Ovals marked by dashed lines represent the low-level updraft zones along lines $P P^{\prime}$ and $Q Q^{\prime}$ in Fig. 10. The upshear-tilting updrafts are also highlighted in the band-transverse vertical cross-section passing the updraft core of the active cell with the profile of the band-transverse environmental relative horizontal wind at right.

were mostly characterized by positive temperature perturbations. They spread toward the upwind and downwind in the upper portion of the mixed layer.

Downdrafts were situated around the northern and southern portions, and around the trailing edge. Most of them originated at upper heights, and some downdrafts around the trailing edge penetrated into the band across the trailing edge between 1- and 2-km height. Other downdrafts associated with precipitation were also found at low heights as depicted in vertical cross-sections in Fig. 14. In addition, compensation downdrafts were found in the upwind and downwind locations close to the active cell. The downdrafts, regardless of their location and origin, would be further chilled by evaporation of precipitation particles during their fall, creating or maintaining a cold pool beneath the band around the surface, resulting in a low-level temperature contrast. These downdrafts transported horizontal momentum from upper to lower heights. This vertical transport of horizontal momentum might have induced the low-level collision, which could have been responsible for the formation of updraft region around the leading edge, between the cold pool and the ambient air. The mid-level downdraft entering the band across the trailing edge appeared to contribute convergence to sustain the updrafts of the older cell at that height.

Repeated generation of active cells was observed 
around the leading edge, that is, in the downshear side. There was a possibility that these cells could be triggered by low-level collision between the outflow of the pre-existing active cell and the unstable ambient air. Large updrafts reaching roughly $4 \mathrm{~m} \mathrm{~s}^{-1}$ were associated with these active cells. Each newly grown cell seemed to be gradually embedded in the band as it developed, and another new cell was induced in the downshear side of the band near the leading edge. The position of the new cell generation in the band portion appeared to remain approximately the same in the moving frame of reference. The older cell decayed significantly as the new cell developed. One cause of the decay of the former active cell was the interception of the low-level moist air by the well-developed new cell. Despite the successive generation of new cells, the overall echo pattern of the snow band did not change greatly with time.

\section{The February 8, 1991 snow band}

A second example of an L-mode snow band under large vertical shear environment in the bandtransverse direction occurred on February 8, 1991 in the early onset of a cold-air outbreak. As in the first case, this snow band was also characterized by upshear-tilting updrafts.

\subsection{Atmospheric conditions}

Figure 18 shows a surface weather map at 1500 JST about one hour prior to dual-Doppler observations of the snow band studied in this paper. This map represents a pressure pattern similar to that typical of the cold-air outbreaks; high and low pressure were over the continent and over the $\mathrm{Pa}$ cific Ocean, respectively. Pressure contours aligned roughly in a north-south direction over the Sea of Japan. The cold-air outbreak in the field experimental region was considered to start at around 1500 JST based on data on this day collected at Tobishima Island by sounding and the JMA's operational surface mesonet of 10-min sampling intervals. Figure 19 shows a hodograph from the 0851- and 1456-JST soundings, suggesting that the cold-air outbreak could have occurred between these observation times. The horizontal wind directions at 1456 JST were mostly from northwest or west-northwest below the $4.8-\mathrm{km}$ height, which was sufficiently higher than the top of the mixed layer of about 3-km depth (see Fig. 20). The existence of a large vertical shear in the north-south direction was identified below the $2.1-\mathrm{km}$ height. The
0851-JST wind profile, in contrast, had southerly wind components from the $2.9-\mathrm{km}$ height up to the temperature inversion level of the $7.9-\mathrm{km}$ height. The northwesterly or west-northwesterly strong surface winds started to blow at around 1500 JST. These strong winds with a mean speed of $\sim 14 \mathrm{~m} \mathrm{~s}^{-1}$ continued until the end of the day. Moreover, the surface air temperatures began to drop sharply after 1420 JST. These sounding and surface data were synthetically indicative of the onset of cold-air outbreak at around 1500 JST.

The thermodynamical structure from the 1456JST sounding is shown in Fig. 20. It shows that the low-level air from the surface up to about the $0.8-\mathrm{km}$ height was stratified convectively unstable. The lifting condensation level was determined to be $0.33 \mathrm{~km}$, and the CAPE was small at about $4 \mathrm{~J} \mathrm{~kg}^{-1}$. In addition, this sounding showed the temperature at the $500-\mathrm{hPa}$ height of $-38.5^{\circ} \mathrm{C}$, which was warmer than that for the previous deep case by about $3^{\circ} \mathrm{C}$.

Figure 21 displays an infrared satellite image at 1631 JST. Several band-like clouds were seen offshore of the Tohoku District. These clouds could be regarded as L-mode snow bands because their alignment from west-northwest to east-southeast was roughly parallel to the mean horizontal wind in Fig. 23. Among these, the arrow-indicated one was probed by dual-Doppler radars. The band portion around the arrowhead was oriented approximately in the east-west direction, as it was in the PPI images in Fig. 22.

The snow band that appeared on this day is shown in PPI images in Fig. 22. The band was oriented approximately west to east as in the satellite image and had an elongated shape, whose length and width of the band were several tens of kilometers and about ten kilometers, respectively. The band consisted of several cells although a cellular pattern was not clearly discernible in these images. The band traveled at a speed of $14 \mathrm{~m} \mathrm{~s}^{-1}$ from $304^{\circ}$ to $124^{\circ}$ during dual-Doppler observations from 1615 JST to 1659 JST. The reflectivity and the shape of the band did not change very much with time. The band orientation, determined from PPI images at elevation angles $\leq 4^{\circ}$, was from $271^{\circ}$ to $91^{\circ}$, whereas the mean wind direction in the mixed layer was from $306^{\circ}$ to $126^{\circ}$. This mean wind was computed by using the wind profiles shown in Fig. 23 in a height interval between 0.3 and $2.7 \mathrm{~km}$. With these mean wind profiles, a representative vertical shear vector in the cloud layer between the 


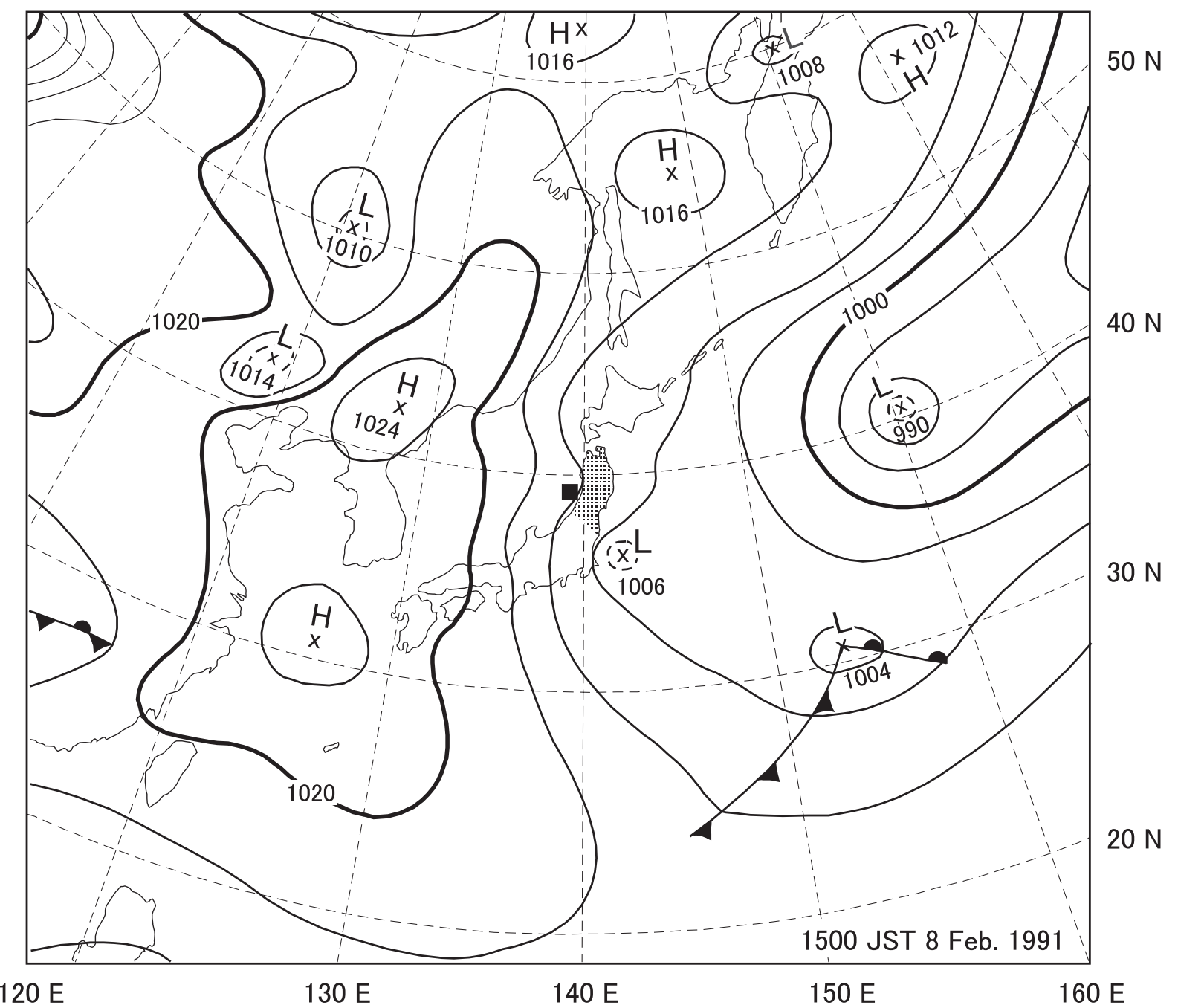

Fig. 18. As in Fig. 2a, except for 1500 JST on February 8, 1991.

heights of 0.6 and $2.4 \mathrm{~km}$ was also computed. It was directed northward and formed an angle of $85^{\circ}$ with respect to the band orientation looking upwind. The collection of data from sounding, surface mesonet, satellite, and PPI suggested that the snow band analyzed in this study was grouped into the L-mode snow band occurring at the beginning of a cold-air outbreak.

The existence of large vertical shear in the bandtransverse direction was shown by the vertical profiles of Doppler-derived horizontal mean winds (Fig. 23). These profiles were derived from five Doppler wind recoveries from 1615 JST to 1645 JST for the band portion indicated in Fig. 26, through the method has already been described for the deep case in 1993. This figure illustrates that the vertical shear in the band-transverse direction was larger than that in the band-parallel direction. A significant band-transverse vertical shear whose magnitude reached $2.1 \times 10^{-3} \mathrm{~s}^{-1}$ was confined between the $0.6-$ and $1.8-\mathrm{km}$ heights so that it was present roughly in the lower half of the mixed layer. The direction of this shear was northward, opposite to that of the band-transverse propagation velocity. In contrast, the magnitude of the band-parallel vertical shear in this height interval was weak at $5.8 \times 10^{-4} \mathrm{~s}^{-1}$, which was about one order of magnitude smaller than that in the band-transverse direction. This shear was directed westward. Accordingly, the snow band under investigation appeared 


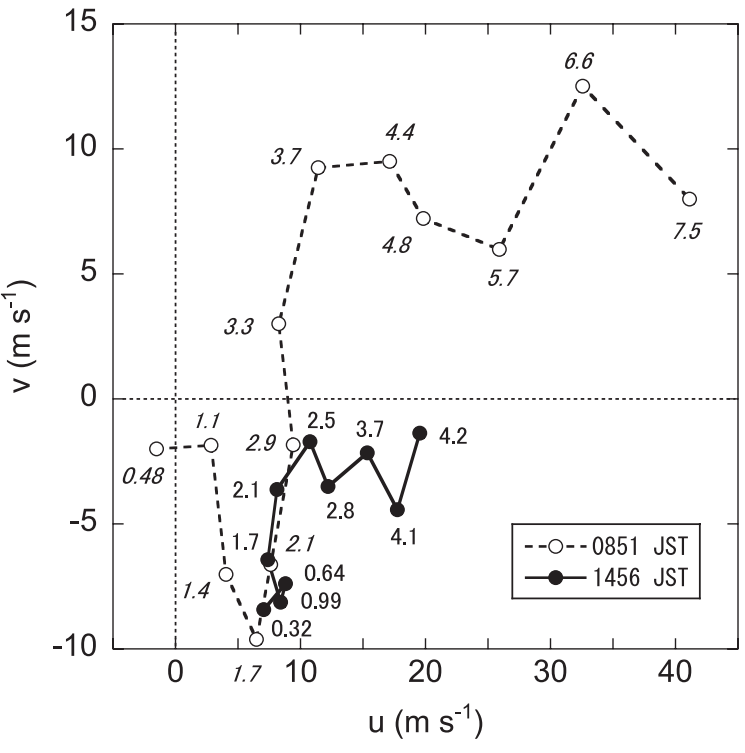

Fig. 19. Hodograph at 0851 JST and 1456 JST observed at Tobishima Island indicated by dashed line with open circles and solid line with solid circles, respectively. Data at selected heights are plotted to avoid complexity. Numbers near the open and solid circles indicate heights in kilometers, and the heights referred to the 0851-JST sounding are in italic type. Note that the range span of $u$ and $v$ is different.

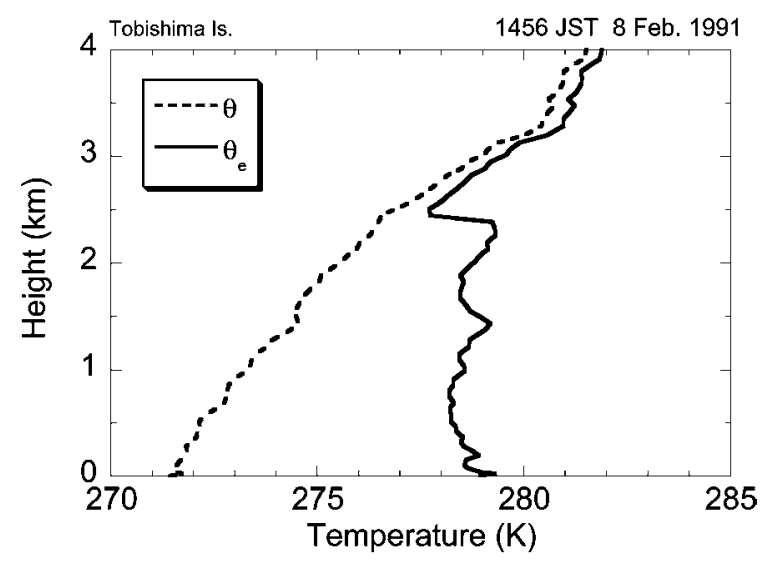

Fig. 20. As in Fig. 4, except for the sounding taken at Tobishima Island at 1456 JST on February 8, 1991.

to form in an environment where the vertical shear in the band-transverse direction was much stronger than that in the band-parallel direction, as in the previous deep case.

\subsection{Multicellular structure of the band}

A multicellular structure was observed as in Fig. 24, which shows time change in reflectivities at the height of $2.1 \mathrm{~km}$ from 1615 JST to 1659 JST for the same band portion in Fig. 26. A systematic generation of cells as in the former deep case was, however, not observed. The three arrow-indicated cells, labeled "A", "B", and "C", were newly grown cells, and each of them formed close to and in the downshear side of the corresponding older cells. Cell B did not develop enough, and it decayed soon. A sign of its development was also inferred from a $20-\mathrm{dBZ}$ contour rounding out toward the downshear at around $(x, y)=(-22.6,-26.4$ $-22.9) \mathrm{km}$ at $1652 \mathrm{JST}$, where $x$ and $y$ are the horizontal position. Since the growth of these cells seemed to follow the significant decay of the corresponding pre-existing active cells in the upshear side, their triggering could have resulted from the low-level convergence between the outflow from these active cells or a cold pool and the ambient unstable air. Such interaction was suggested from airflow structures in snap-shot images in bandtransverse vertical cross-sections (not shown). In addition, the presence of a cold pool was inferred from retrieval as explained in the next subsection.

\subsection{Check on the adequacy of retrieval}

The retrieval of the potential temperature and pressure perturbations, water vapor, and cloud mixing ratios in a three-dimensional volume was done for this snow band with the same methodology as in the deep band in 1993. The results of retrieval were considered adequate from the retrieved potential temperature perturbations at the lowest analysis height of $0.45 \mathrm{~km}$ because the presence and strength of a cold pool implied from Figs. 25 and 27 were consistent with those observed for other cases (Yamada et al. 1994; Yamada et al. 1996), as in subsection 3.3. Indeed, the temperature deficit of the cold pool relative to the environment was about $1.3-1.7 \mathrm{~K}$ as indicated by the minimum perturbations (Fig. 25), and the predominance of negative perturbations (Fig. 27) yielded mean temperature perturbations falling within -0.1 to $-0.3 \mathrm{~K}$ (Fig. 25). Accordingly, no bias corrections were made for the potential temperature perturbations. The vertical profiles show that the potential temperature perturbations mostly lay within $\pm 2 \mathrm{~K}$. Above approximately $1.65-\mathrm{km}$ height, positive perturbations became dominant corresponding to diabatic heating associated with condensation. As for 


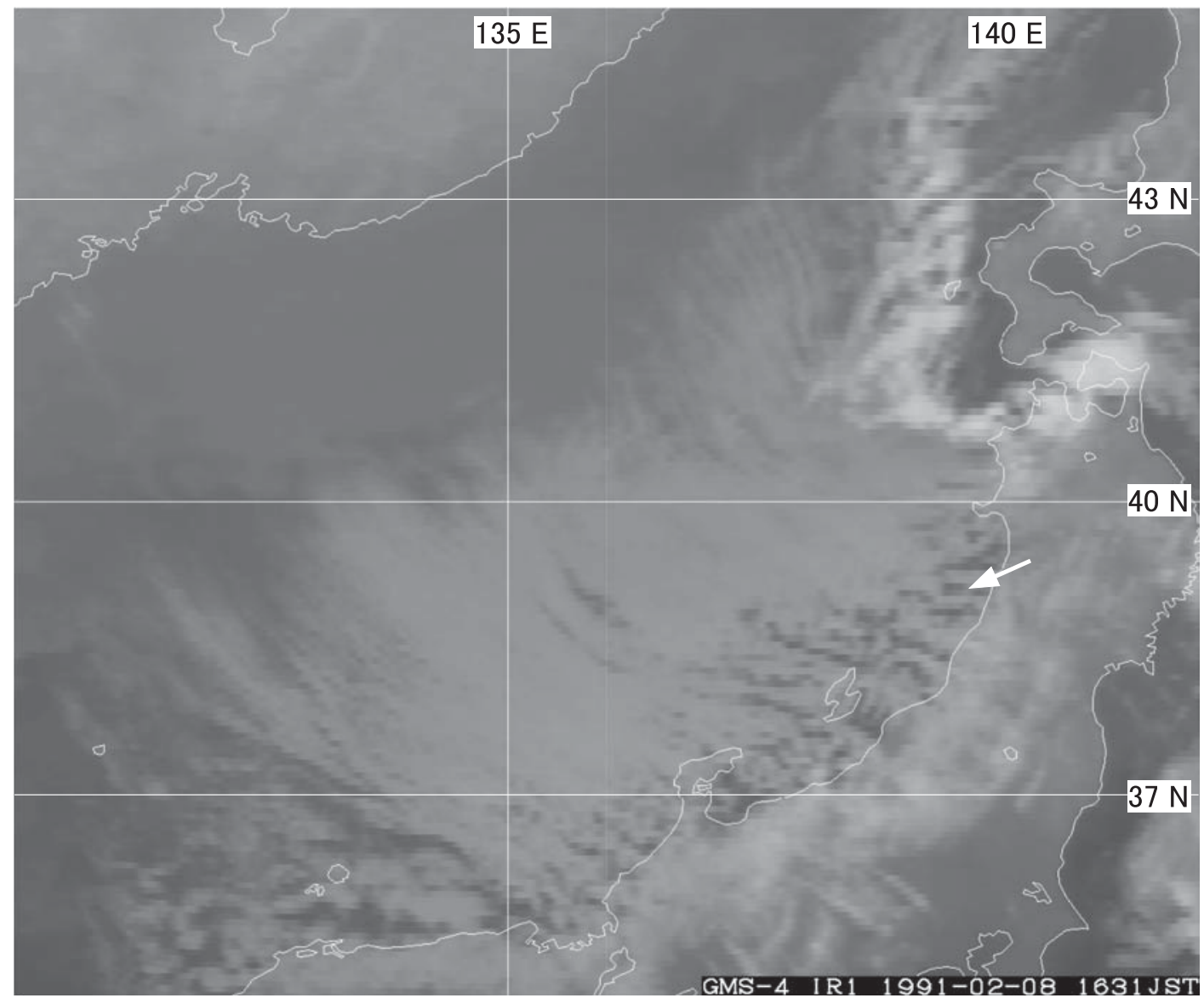

Fig. 21. As in Fig. 3, except for at 1631 JST on February 8, 1991.

the negative values in the mean perturbations between heights of about 1.0 and $1.6 \mathrm{~km}$, they might have resulted from, in part, the fact that the dualDoppler wind data were not well obtained at grid points with relatively weak reflectivities $\leq$ about $10-15 \mathrm{dBZ}$ for this snow band because of the condition of the hardware. The absence of such wind data would have underestimated the upward transport of low-level unstable air containing relatively large amounts of water vapor. The analyses at 1622 JST and 1645 JST showed similar features to those in this figure.

The pressure perturbations were very small, being within $\pm 1 \mathrm{hPa}$ (not shown), and no bias corrections were made to them either. The retrieved mean mass content of cloud at each height tended to increase with height, and its maximum values were about $0.5 \mathrm{~g} \mathrm{~kg}^{-1}$ at $1630 \mathrm{JST}$ and $1637 \mathrm{JST}$, and about $1 \mathrm{~g} \mathrm{~kg}^{-1}$ at 1622 JST and 1645 JST (not shown).

\subsection{Three-dimensional wind fields derived from dual-Doppler radar data}

Three-dimensional wind fields derived from dualDoppler observations at 1630 JST are shown in Fig. 26 up to the $2.7-\mathrm{km}$ height, above which the echo area greatly reduced. The corresponding fields of potential temperature perturbations, and cloud and saturation deficit mixing ratios are shown in Figs. 27 and 28, respectively, but only at some important heights; these two fields were in very small area of upper portions of the band at heights $\geq 2.55 \mathrm{~km}$ because of the reduction in the echo area. At other observation times from 1615 JST to 1659 JST, the overall airflow structures did not differ significantly from those described here. In addition, the thermodynamical and water substance fields at 1622, 1637, and 1645 JST resembled, on the whole, to those at 1630 JST, respectively.

A general view of the airflow structure was char- 

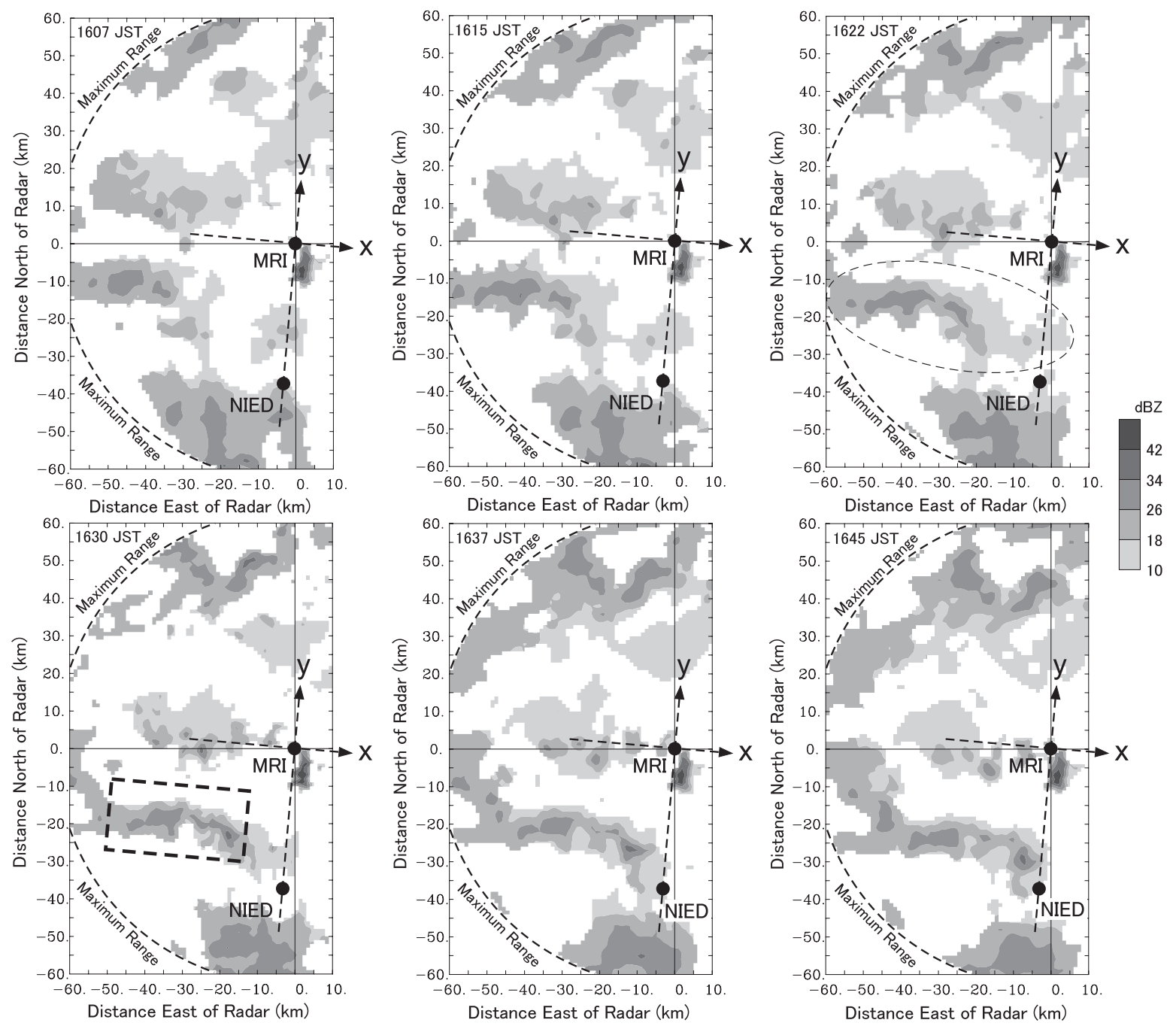

Fig. 22. As in Fig. 7, except for PPI images of the MRI radar from 1607 JST to 1645 JST. The 1630-JST image shows the band portion for the wind retrieval at this time by a rectangle of bold dashed line. Reflectivities $>42 \mathrm{dBZ}$ near the MRI radar are likely contaminated by ground clutter. The oval of thin dashed line in the 1622-JST image encloses the L-mode snow band studied.

acterized by updrafts around the trailing edge and downdrafts around the leading edge even though the updraft and downdraft regions took on a patched pattern. The system-relative horizontal wind components in the band-transverse direction were dominant in the whole volume; this will be clearly shown later in mass transport analysis. Most updrafts had relative wind components toward the leading edge, that is, toward the upshear direction. The ascending relative inflow across the trailing edge was identified up to the $1.8-\mathrm{km}$ height. The low-level convergence between the cold pool and the unstable ambient air flowing into the band could have accounted for the formation of these updrafts. The presence of such a cold pool was deduced as already stated, and this cold pool was considered mostly subsaturated as in the corresponding horizontal cross-section at the $0.45-\mathrm{km}$ height in Fig. 28. The updraft region appeared as a narrow zone around the trailing edge at the heights $\leq 0.9 \mathrm{~km}$, where the downdraft area dominated. The updraft area increased with height between the 1.2- to $1.8-\mathrm{km}$ heights, above which the updraft region became dominant. Magnitudes of updrafts in the band were mostly less than $2 \mathrm{~m} \mathrm{~s}^{-1}$. A divergent airflow feature was observed at around 

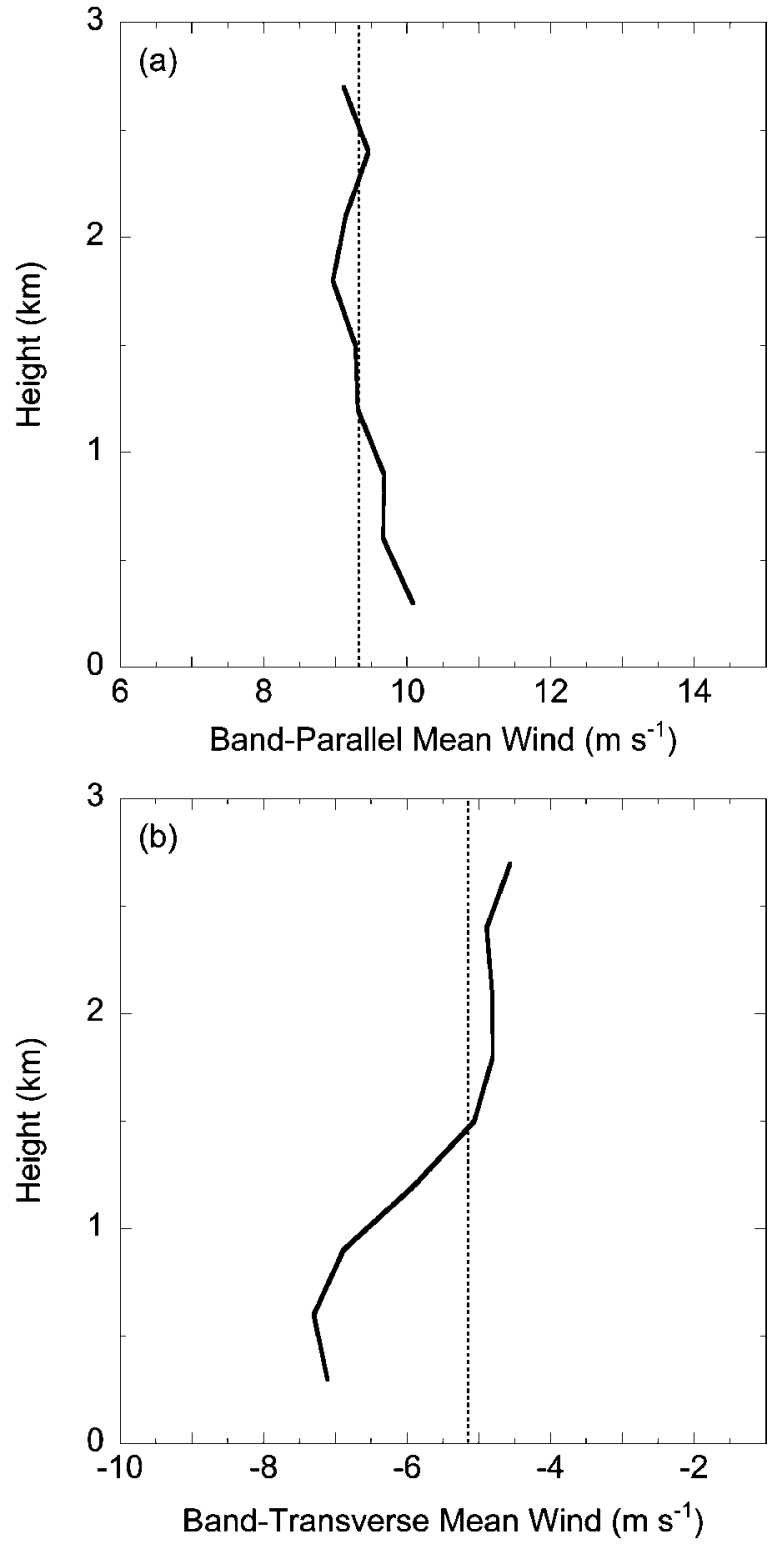

Fig. 23. Profiles of the band-parallel and band-transverse mean wind derived from dual-Doppler winds for the band portion indicated in Fig. 22. These profiles are shown separately so that the abscissa in (a) and (b) has the same range span of $9 \mathrm{~m} \mathrm{~s}^{-1}$ as in Fig. 6. The dotted lines show the band propagating velocity in the respective directions. (a) The band-parallel mean wind. Positive values indicate the wind components toward the east. (b) The bandtransverse mean wind. Negative values correspond to the southward wind components. $(x, y)=(-31.5,-19.6) \mathrm{km}$ at the $2.1-\mathrm{km}$ height. Most of the updrafts were associated with positive temperature perturbations whose typical magnitudes were about $0.3-0.6 \mathrm{~K}$ as seen from Fig. 27, and were considered saturated as in Fig. 28. Large cloud mixing ratios of about $0.5 \mathrm{~g} \mathrm{~kg}^{-1}$ were found at upper heights $\geq \sim 2 \mathrm{~km}$ as at the $1.95-\mathrm{km}$ height in Fig. 28. Other than the updrafts mentioned above, minor updrafts were found around the leading edge for about $x=-42--35 \mathrm{~km}$ and $x=-28--14 \mathrm{~km}$ at $\leq \sim 0.6-\mathrm{km}$ height; these seemed to result from the low-level convergence between the downdraft-originated outflow and the low-level air ahead of the band.

Downdrafts were found around the leading and trailing edges and at low-levels associated precipitation. Most of the downdrafts located around the leading edge had a relative wind component toward the forward with respect to the band motion, as did the updrafts. In particular, there were large outflows across the leading edge below the heights $\leq 0.6 \mathrm{~km}$. This outflow probably resulted from the spreading of downdrafts, and its magnitude tended to decrease with height. Between the heights of 1.8 and $2.4 \mathrm{~km}$, some of the downdrafts near the leading edge between about $x=-28.0$ and $-17.5 \mathrm{~km}$ had relative components directing northward, whereas others located at about $x=-38.5$ $-31.5 \mathrm{~km}$ had southward relative components. The existence of subsaturated downdrafts entering the band across the leading edge were also identified at heights between 0.9 and $1.5 \mathrm{~km}$ for roughly $x=-33.6--28.0 \mathrm{~km}$. Their subsaturation was inferred from the cloud and saturation deficit mixing ratios at the height of $1.05 \mathrm{~km}$ in Fig. 28 (see at around $x=-31.5 \mathrm{~km}$ ). Other than the downdrafts around the leading edge, downdrafts flowing into the band across the trailing edge were discernible at the 1.2-km height, for example at about $x=-37.8 \mathrm{~km}$ and $x=-29.4 \mathrm{~km}$. They were probably compensation downdrafts and were located in inter-cell space, as seen from the reflectivity field in Fig. 24. These downdrafts appeared to be subsaturated as can be inferred from the horizontal cross-section at the $1.05-\mathrm{km}$ height in Fig. 28, and were identified up to the $2.1-\mathrm{km}$ height; see for example at about $x=-35 \mathrm{~km}$ and $-30 \mathrm{~km}$ at the heights of 1.8 and $2.1 \mathrm{~km}$. Downdrafts with speed exceeding $1 \mathrm{~m} \mathrm{~s}^{-1}$ located at about $(x, y)=$ $(-30.1,-21.0) \mathrm{km}$ at the $0.9-\mathrm{km}$ height seemed to be associated with precipitation because they occurred in a high reflectivity region. 

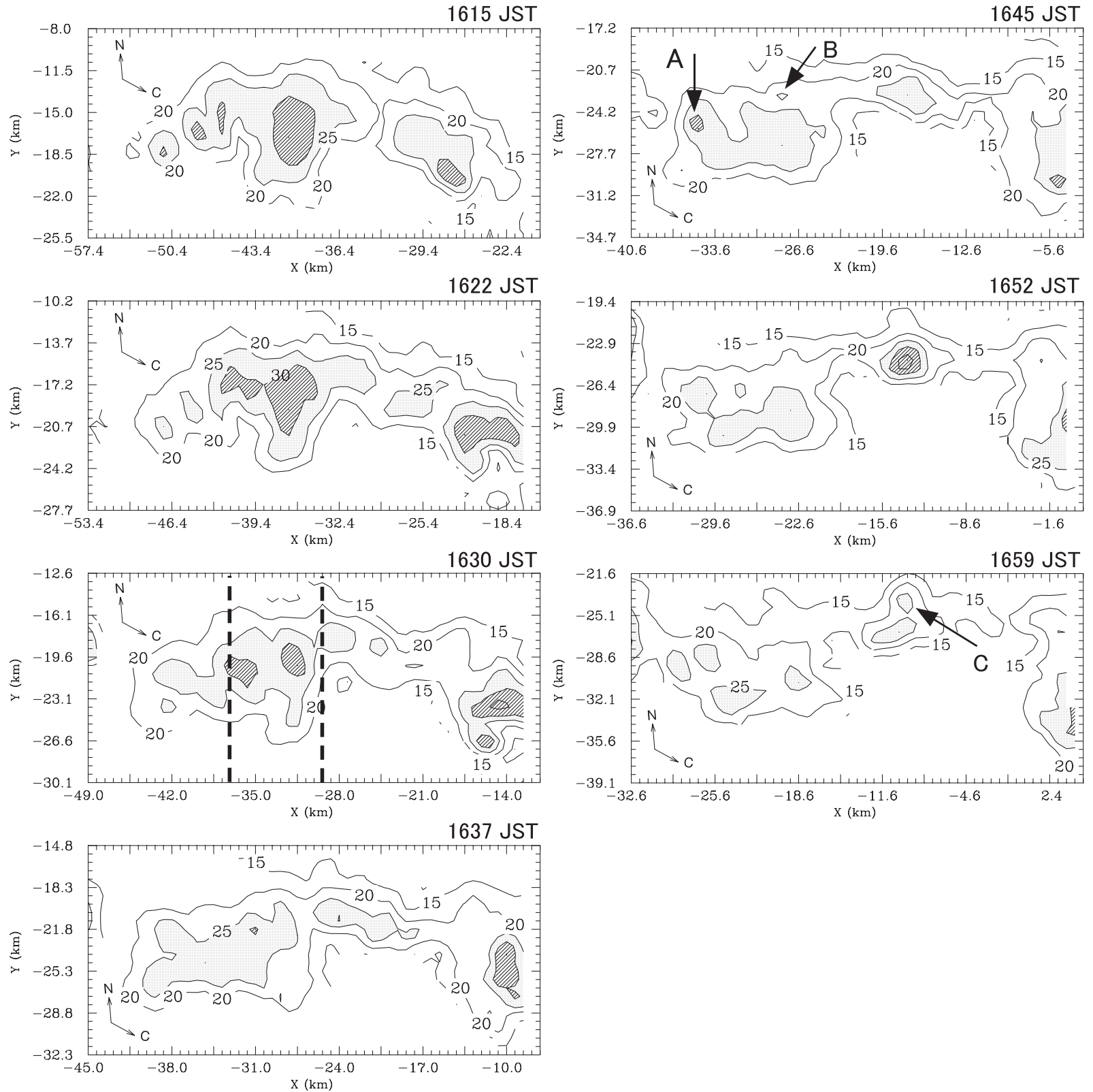

Fig. 24. As in Fig. 8, except for the L-mode snow band on February 8, 1991 at the 2.1-km height at successive seven observation times taken at 8-min intervals, from 1615 JST to 1659 JST. The mean structures in the band-transverse vertical cross-section in Fig. 30 was made for the band portion between the bold dashed lines in the 1630-JST field.

\subsection{Mass transport analysis}

Characteristics of airflow structures were further investigated by mass transport analysis with the same method applied to the snow band on January 21, 1993. The analysis was made for the whole band portion in Fig. 26. Figure 29 shows two repre- sentative results at 1630 JST and 1637 JST. The very small magnitudes of the residual terms at both observation times ensured that the analyses were sufficiently accurate. The results show that the mean net mass transport in the band transverse and vertical directions (denoted as $F_{y^{\prime}}$ and $F_{z}$, re- 


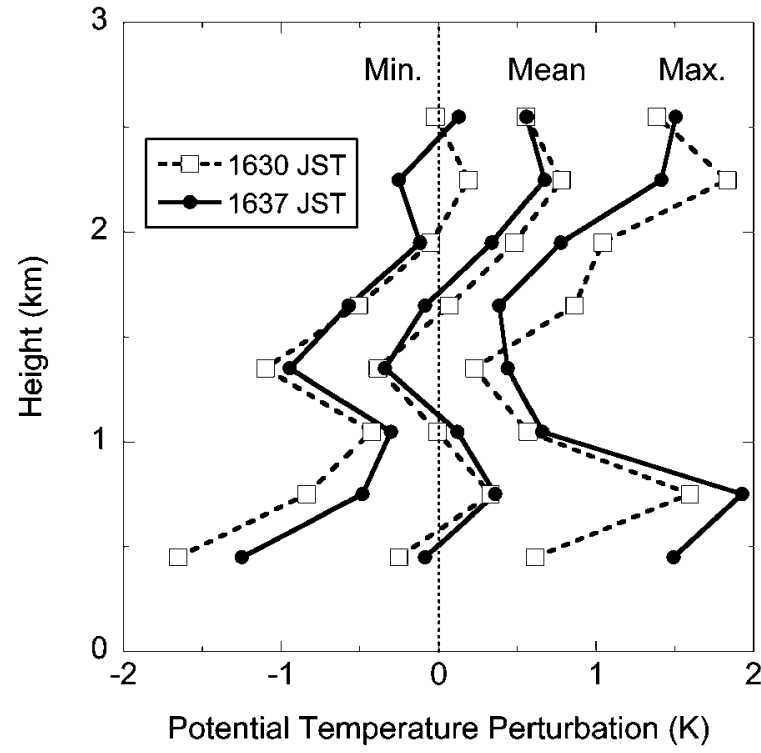

Fig. 25. As in Fig. 9, except for the snow band on February 8, 1991 at 1630 JST and 1637 JST. The profiles of potential temperature perturbations at 1630 JST and 1637 JST are indicated by dashed lines with open squares and solid lines with solid circles, respectively.

spectively) was dominant at most heights, consistently with the airflow structures that have already been described. On the other hand, the magnitude of the mean net mass transport in the band-parallel direction $\left(F_{x^{\prime}}\right)$ was very small. The non-divergent level was located at a height of around $2.1 \mathrm{~km}$. At low heights $(<0.75 \mathrm{~km})$, the large positive values of $F_{y^{\prime}}$ induced net mass divergence in the vertical direction, implying downward motion, even if $F_{x^{\prime}}$ compensated for the negative net mass transport. This resulted from a large low-level outflow occurring near the leading edge of the band. Between heights of 0.75 and about $2 \mathrm{~km}$, the signs of $F_{y^{\prime}}$ and $F_{z}$ were reversed. Negative values of $F_{y^{\prime}}$ indicated net mass convergence, while $F_{z}$ was positive, corresponding to upward mass transport. Thus, $F_{y^{\prime}}$ accounted for the upward motion in the band. A minimum of $F_{y^{\prime}}$ at the $1.35-\mathrm{km}$ height could have been in part induced by convergence between the relative ascending flow toward the leading edge and the relative descending inflow across the leading edge. Above the 2-km heights, both $F_{y^{\prime}}$ and $F_{z}$ changed signs again, implying that the divergence of the mass transport in the band-transverse direc- tion reduced the upward motion. The above results revealed the importance of the band-transverse and vertical airflow to the band circulation. Mass transport analyses at 1615, 1622, 1645, and 1652 JST exhibited characteristics similar to those in this figure.

\subsection{Time evolution of the cell}

Since the band consisted of several cells responsible for precipitation formation, the time evolution of the structure of a band portion containing an active cell was studied next. For this purpose, mean structures in a band-transverse vertical crosssection were extracted for a band portion indicated in Fig. 24. This portion was characterized by elongated large reflectivities $\geq 30 \mathrm{dBZ}$, and can be regarded as an active cell. The horizontal dimension of the analysis domain was $7 \mathrm{~km} \times 17.5 \mathrm{~km}$. The examination based on the mean structures in this vertical cross-section is pertinent because the preceding mass transport analysis has revealed the importance of the band-transverse and vertical wind components to the band circulation. To derive two-dimensional mean wind fields in the verticalcross section, we employed a variational approach to the observed winds, as in Roux (1985), which is based on a best fit two-dimensional stream function in a least squares sense.

Figure 30 shows time changes in the mean structures of wind and reflectivity fields from 1615 JST to 1659 JST. Similar time changes in the structures of the airflow and reflectivities were analyzed for other cells in the band. This figure depicts the basic character of the kinematic structures of the band explained in Fig. 26. Updrafts and downdrafts were located around the trailing and leading edges, respectively. A significant feature common to all figures except at 1659 JST was upshear-tilting updrafts for which formation the lifting of low-level inflow across the trailing edge was responsible. Downdrafts originated at either the middle or upper heights were located near the leading edge, and most of them fell down almost vertically toward the surface. Some of these entered the band across the leading edge at middle levels between 1and 2-km height. Downdrafts associated with high reflectivities were also found at low heights. Lowlevel outflow across the leading edge was distinct, resulting from a spreading of downdrafts falling to the surface. Compensation downdrafts flowing into the band across the trailing edge were, however, obscure because of the smoothing process.

The band portion examined progressed through 

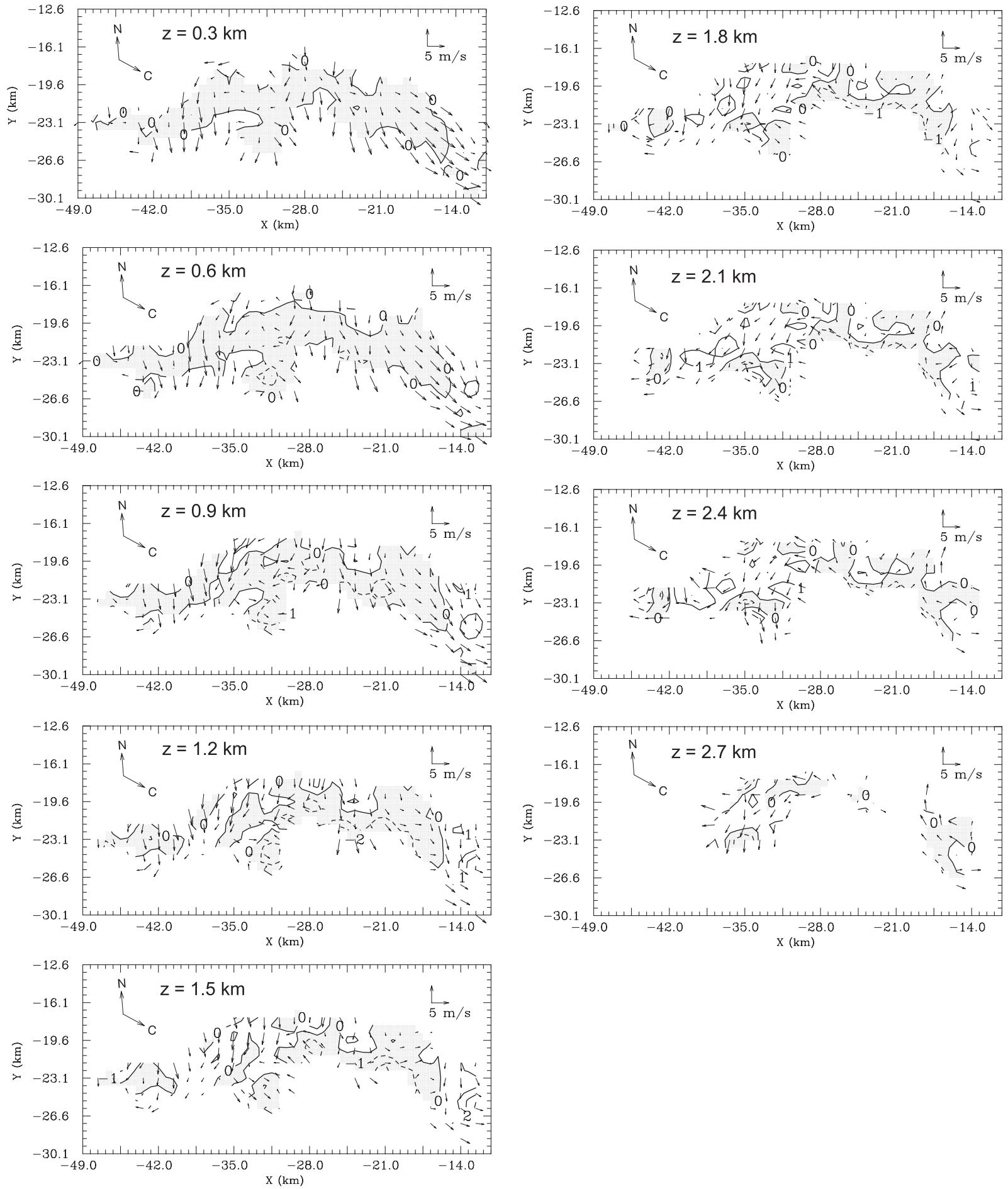

Fig. 26. As in Fig. 10, except for the data from the 0.3- to 2.7-km height at 1630 JST of the snow band on February 8, 1991. 

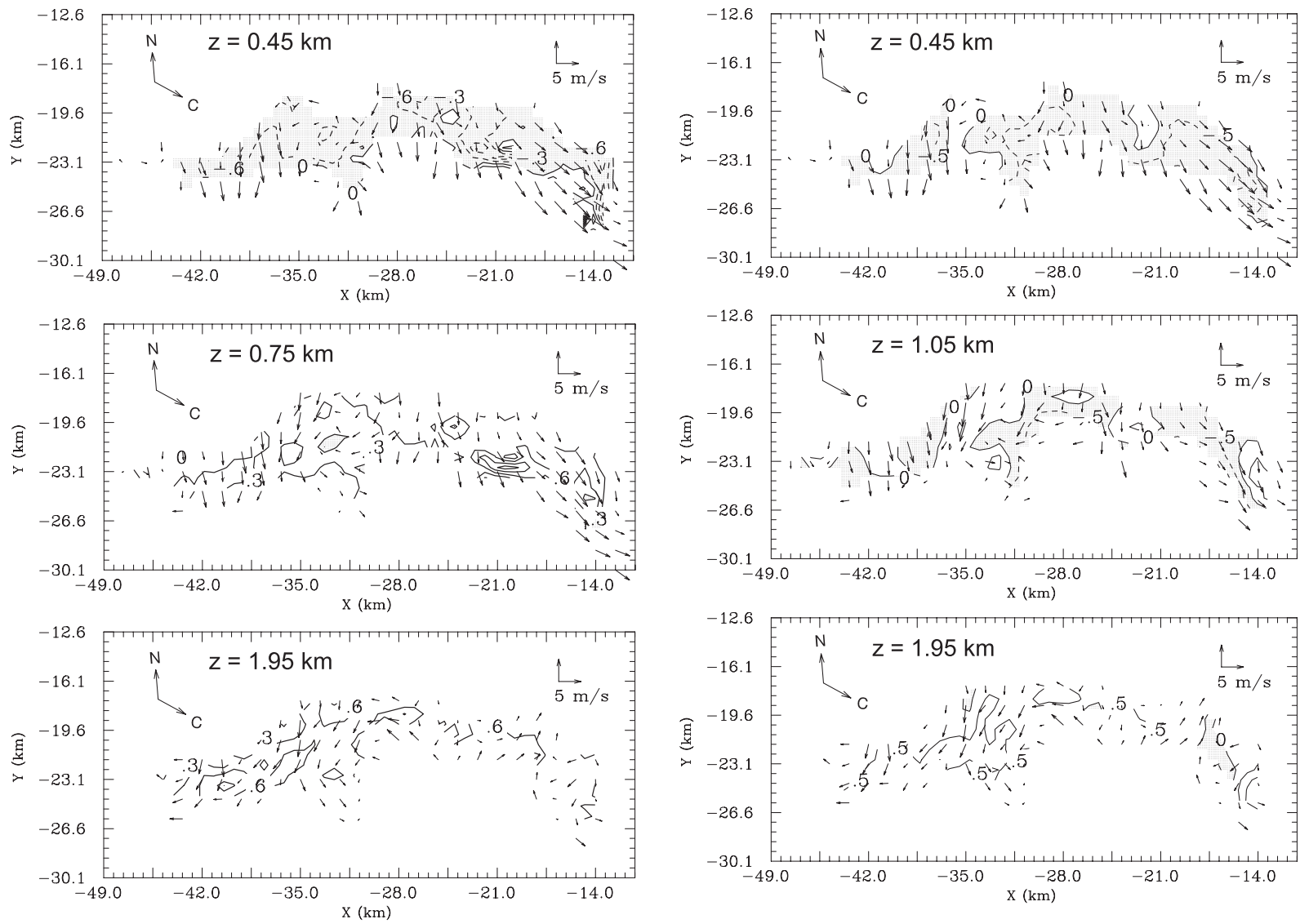

Fig. 27. As in Fig. 11, except for the horizontal cross-sections at heights of 0.45 -, $0.75-$, and $1.95-\mathrm{km}$ at 1630 JST of the snow band on February 8, 1991.

four stages; developing, mature, decaying, and reintensification. The mature stage was determined for this case on the basis of the maximum reflectivity at the lowest CAPPI level of $0.3-\mathrm{km}$ height and the vertical extent of high reflectivities $\geq 30 \mathrm{dBZ}$. We considered this band portion was in mature stage between 1622 JST and 1630 JST because a maximum reflectivity of $\sim 34 \mathrm{dBZ}$ was consistently present in the non-averaged fields at the lowest height of CAPPI in this band portion. The portion was in the developing stage at 1615 JST. Indeed, large reflectivities $>30 \mathrm{dBZ}$ were located aloft in a height interval between 0.8 and $2 \mathrm{~km}$ in the rearward portion. This implies the growth of a main body of precipitation. From 1622 to 1630 JST, the band portion was in mature stage as mentioned above. Large updrafts as much as $1.8 \mathrm{~m} \mathrm{~s}^{-1}$ were found near the trailing edge at 1622 JST, but they

gradually weakened with time. In fact, the magnitudes of updrafts around the trailing edge reduced at 1630 JST compared with those at 1622 JST even though high reflectivity exceeding $30 \mathrm{dBZ}$ still extended from the lowest height to about $2-\mathrm{km}$ height. As for the downdrafts, those flowing into the band at middle levels of around $1.5-\mathrm{km}$ height across the leading edge were discernible at 1630 JST. Furthermore, downdrafts associated with intense precipitation were recognized below the $1-\mathrm{km}$ height at around $X=7-9.1 \mathrm{~km}$ at these observation times, where $X$ is the horizontal distance. These precipitation-associated downdrafts were consistently observed from 1622 JST to 1659 JST and some of them flew out of the band across the leading edge as outflow. From 1615 JST to 1630 JST, the high reflectivity region with values exceeding $30 \mathrm{dBZ}$ inclined rearward with respect to the 

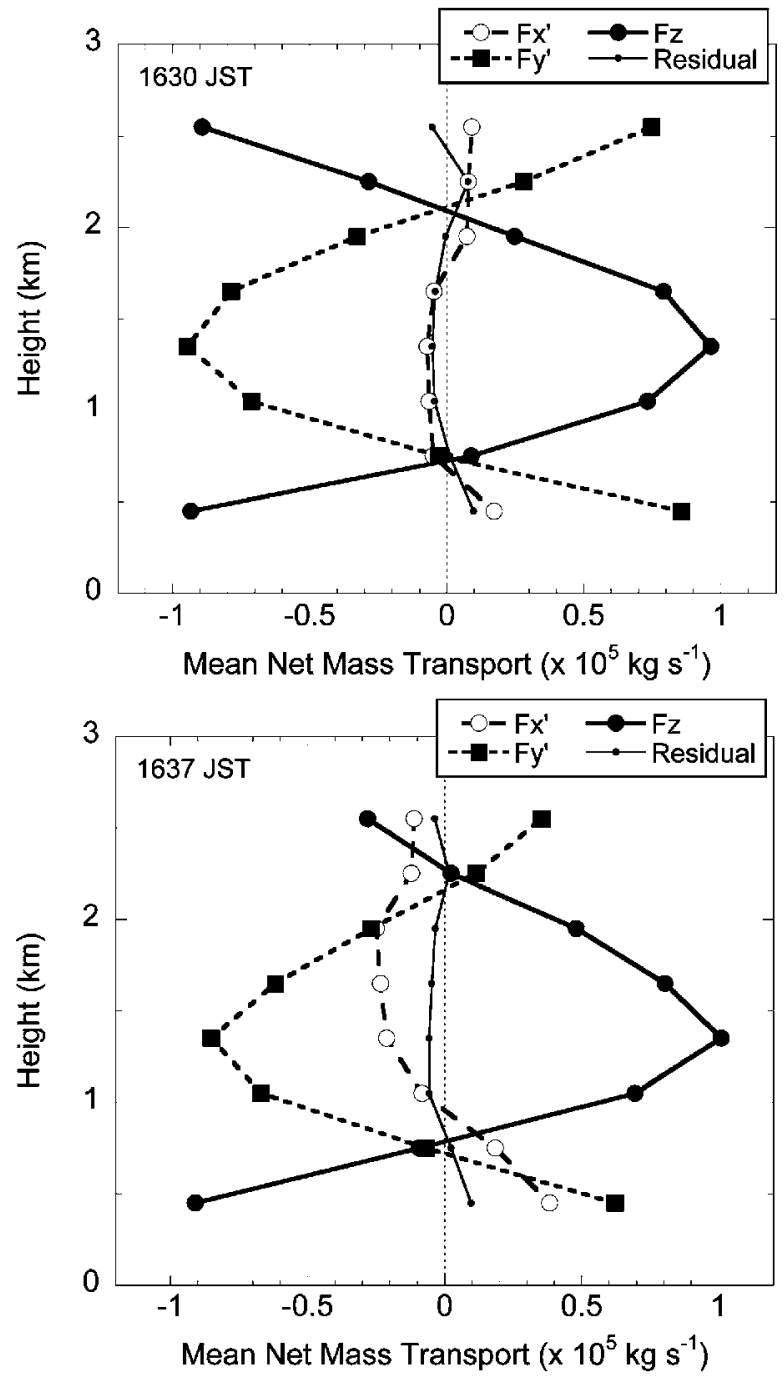

Fig. 29. As in Fig. 13, except for the results at 1630 JST and 1637 JST of the February 8, 1991 snow band.

band motion. This inclination would be for the following reason. Precipitation particles formed in updraft regions located at the rearward portion of the band were transported forward with respect to the band motion during their fall because of the large vertical shear. From 1637 to 1652 JST, the band portion was in decaying stage. Indeed, at 1637 JST and 1645 JST, the magnitude of updrafts reduced, and the vertical extent of this high reflectivity core $\geq 30 \mathrm{dBZ}$ was significantly lowered, down to around the 1-km height. Furthermore, at 1645 JST, the decay of the cell was clearly inferred from the large decrease in magnitude of updrafts around the trailing edge and the reduction of the vertical extent of the high reflectivity region exceeding $30 \mathrm{dBZ}$, which was only recognized below the $0.5-\mathrm{km}$ height. At $1652 \mathrm{JST}$, the high reflectivity region exceeding $30 \mathrm{dBZ}$ was no longer present. It should be noted here that there was a sign of reintensification of updrafts around the trailing edge between $10.5<X<14 \mathrm{~km}$. Associated with this sign, the development of a new cell could have been inferred from the upward and rearward enlargement of the $20-\mathrm{dBZ}$ reflectivity contour, as suggested in Fig. 24. The new cell development around the trailing edge was, however, not identified in the field at 1659 JST. In fact, downdrafts dominated in the cross-section, and updrafts near the trailing edge turned out to be very weak. The new cell had either not sufficiently developed, or it had decayed in a short period of time.

The time series of structures in a band-transverse vertical cross-section suggested that new cell development was often followed by the decay of the preexisting cell. The outflow originating from the preexisting cell in the band was probably important for triggering the new cell formation, as stated in subsection 4.2. The repeated generation of cells at around the trailing edge of the band would have helped to maintain the snow band.

\subsection{Vertical transport of the horizontal momentum and heat flux}

Vertical fluxes of horizontal momentum in the band-parallel and band-transverse directions, $\overline{u^{\prime} w^{\prime}}$ and $\overline{v^{\prime} w^{\prime}}$, respectively, were computed for this case in the same manner as for the snow band on January 21, 1993. Representative results at 1630 JST and 1637 JST are shown in Fig. 31a. Results at other observation times of $1615,1622,1645$, and 1652 JST showed similar characteristics to those in this figure. The respective profiles in the band-parallel and the band-transverse directions showed similar features at two analysis times. The magnitudes of the band-transverse fluxes were much larger than those in the band-parallel direction in a height interval between 1.5 and $2.1 \mathrm{~km}$. They increased sharply with height from $0.6 \mathrm{~km}$ up to $1.5-2 \mathrm{~km}$. The changes in the magnitude of the band-parallel fluxes with height were, on the other hand, relatively small. The large band-transverse fluxes could have been associated with the upsheartilting updrafts.

The vertical heat flux was also estimated in terms of virtual potential temperature perturbations, fol- 

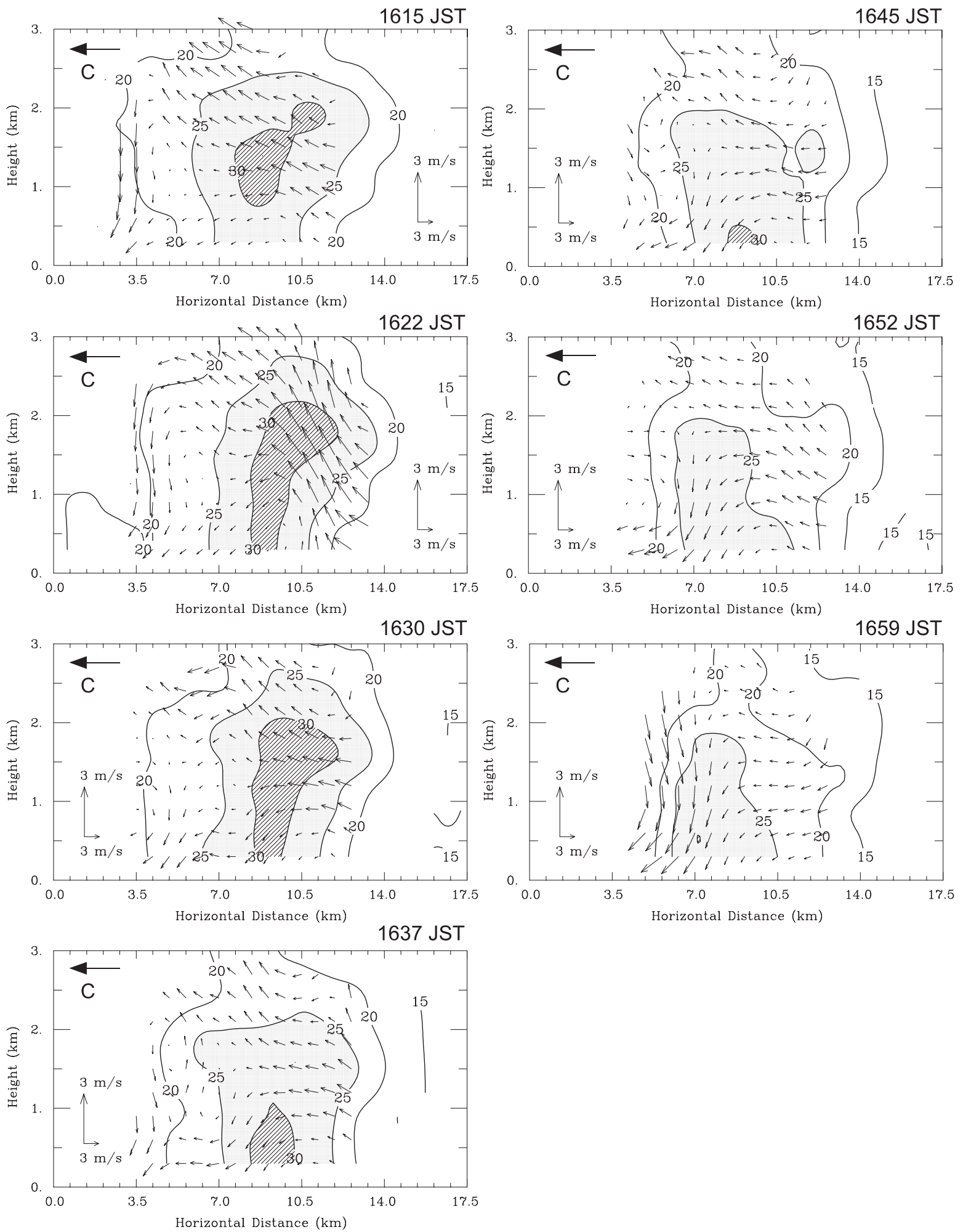

Fig. 30. Mean structure of airflow and reflectivity in a vertical cross-section for the band portion indicated in the 1630-JST field in Fig. 24. The arrows are vector representation of system-relative horizontal wind and vertical components. Reflectivity contours are at 5-dBZ intervals starting from $15 \mathrm{dBZ}$. Region with reflectivities between 25 and $30 \mathrm{dBZ}$ are stippled, while that with reflecitivties $>30 \mathrm{dBZ}$ are hatched. The arrow labeled " $\mathrm{C}$ " in each panel indicates the direction of the band motion in this cross-section. 


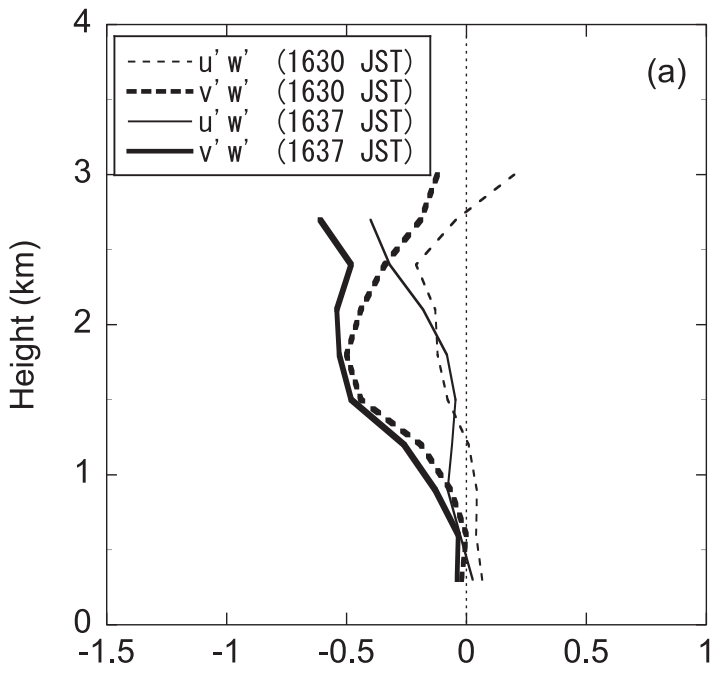

Vertical Flux of Horizontal Momentum $\left(\mathrm{m}^{2} \mathrm{~s}^{-2}\right)$

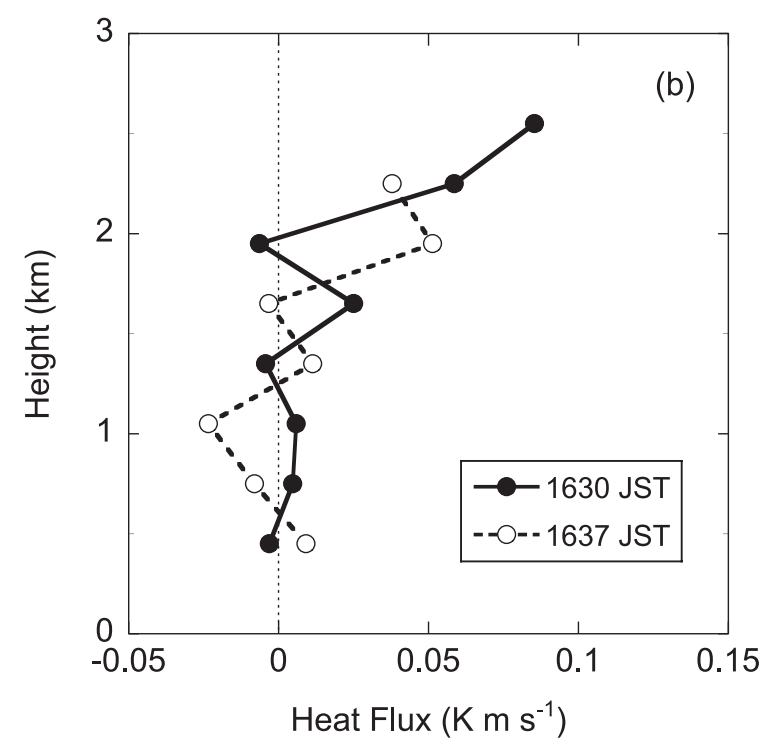

Fig. 31. As in Fig. 15, except for the profiles at 1630 JST (dashed lines) and 1637 JST (solid lines) for the February 8, 1991 snow band. The range span of abscissa in (a) and (b) is the same as that in Figs. 15a and 15b, respectively.

lowing the method employed in the previous deep case (Fig. 31b). Representative results at 1630 JST and 1637 JST are shown. The magnitude of the heat flux was small below the $1.35-\mathrm{km}$ height, whereas heat fluxes had large positive values at upper heights above $\sim 1.5 \mathrm{~km}$ and their magnitude tended to increase with height. Accordingly, the
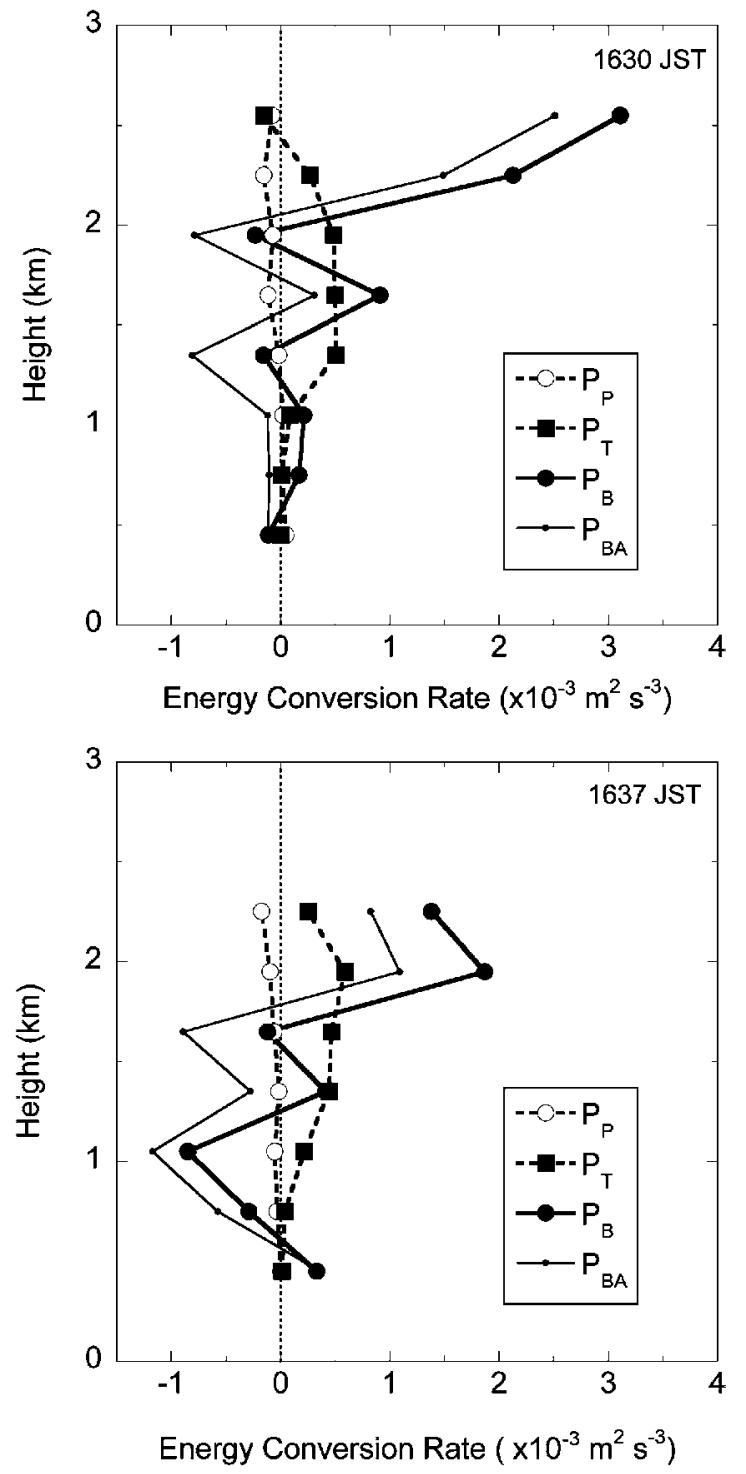

Fig. 32. As in Fig. 16, except for the results at 1630 JST and 1637 JST for the February 8, 1991 snow band.

band transported heat upward above about 1.5-km height. Profiles at 1622 JST and 1645 JST exhibited similar characters as those in this figure.

\subsection{Energy conversion rates}

Energy conversion rates involved in the band energetics were also examined for this case. The energy conversion by the band-parallel and bandtransverse vertical shear, and buoyancy (denoted as $P_{P}, P_{T}$, and $P_{B}$, respectively) were calculated by employing the same procedure as in subsection 3.8. Figure 32 shows results at 1630 JST and 1637 JST 
as typical examples. The predominance of $P_{B}$ was clear at upper heights $>\sim 2 \mathrm{~km}$. At the low and middle heights, in contrast, $P_{B}$ fluctuated, and generally had a small magnitude comparable to, or smaller than $P_{T}$. Negative values in $P_{B}$ at middle levels between 1- and 2-km in height could be attributed to the negative heat flux. As regards the shear conversion, the term $P_{T}$ was positive at most heights, whereas $P_{P}$ was mostly negative. In addition, the magnitudes of $P_{T}$ were much larger than those of $P_{P}$ in the height interval between 1.05 and $2.25 \mathrm{~km}$. Accordingly, $P_{B}$ and $P_{T}$ were important in this height interval. When the buoyancy conversion rates were computed in terms of the apparent potential temperature perturbation, they decreased substantially, except at the lowest height of $0.45 \mathrm{~km}$ (see $P_{B A}$ profile). In particular, they mostly turned to negative values at the middle and low heights, leaving positive values only at the upper heights $>\sim 2 \mathrm{~km}$. Thus, the presence of water condensates effectively suppressed the convection. In such situations, $P_{T}$ became important as in the deep snow band on January 21, 1993. Similar results were obtained in 1622-JST and 1645-JST analyses.

\subsection{Conceptual model of kinematic and thermodynamical structures}

The kinematic and thermodynamical structures of the L-mode snow band on February 8, 1991 are schematically illustrated for a band portion that contains an active cell responsible for the precipitation formation (Fig. 33). This band occurred in the early onset of a cold-air outbreak, where a large vertical shear in the band-transverse direction was present approximately in the lower half of the mixed layer. This vertical shear was directed opposite to the direction of the band motion in this direction. Since the mass transport analysis revealed the importance of the band-transverse and vertical wind components, mean airflow structures in the band-transverse vertical cross-section are displayed for three stages of developing, mature, and decaying. In addition, the sign of new cell development in the rearward portion is illustrated as reintensification stage.

The overall airflow structure of the band throughout four stages was characterized by upshear-tilting updrafts, unlike the axi-symmetric roll circulation, and the separation of the updraft and downdraft regions favored longevity. These updrafts could have originated from the low-level interaction between the subsaturated cold pool beneath the band around the surface and the unstable inflow across the trailing edge. Maximum updrafts were found in mature stage. The presence of such a cold pool was inferred from the retrieval, and it would be maintained by the evaporation of precipitation particles. The low-level temperature contrast between the cold pool and the ambient air reached about $1.3-1.7 \mathrm{~K}$. Cloud regions were retrieved in the middle and upper portions of the band, where relatively large positive perturbations of the potential temperature were deduced. The slight tilting of the high reflectivity region, or precipitation core, is also depicted by the region with reflectivities exceeding $30 \mathrm{dBZ}$. Downdrafts were located around the leading edge, originating at either the upper or middle heights, and some of these penetrated into the band at middle heights. Other downdrafts were associated with precipitation in the band below the $\sim 1-\mathrm{km}$ height. In addition, there were compensation downdrafts flowing into the band across the trailing edge in the inter-cell space originating from the upper heights. These downdrafts, regardless of their location and origin, transported drier air to the band, which induced evaporative cooling of precipitation particles to contribute to the maintenance of the cold pool. The spreading of these downdrafts around the surface resulted in the lowlevel outflow across the leading edge as well as the low-level convergence around the trailing edge with the unstable ambient air. It is likely that the spreading of downdrafts around the surface from preexisting cells in the band triggered the new cell development in the downshear side of the band, that is, around the trailing edge. This repeated generation of new cells seemed to contribute to the maintenance of the band. Such generation did not form a narrow band-like echo pattern branching off at a large angle to the orientation of the L-mode snow band.

\section{Discussion}

\subsection{Consideration of circulation in contrast with the well-documented roll-like airflow pattern}

The significant features in the airflow structures in the two L-mode snow bands analyzed in this study were the upshear-tilting updrafts in the vertical cross-sections in the band-transverse direction. Such structures have rarely been documented in most past studies of snow bands over the Sea of Japan (Fujiyoshi et al. 1998; Yoshimoto et al. 2002) 

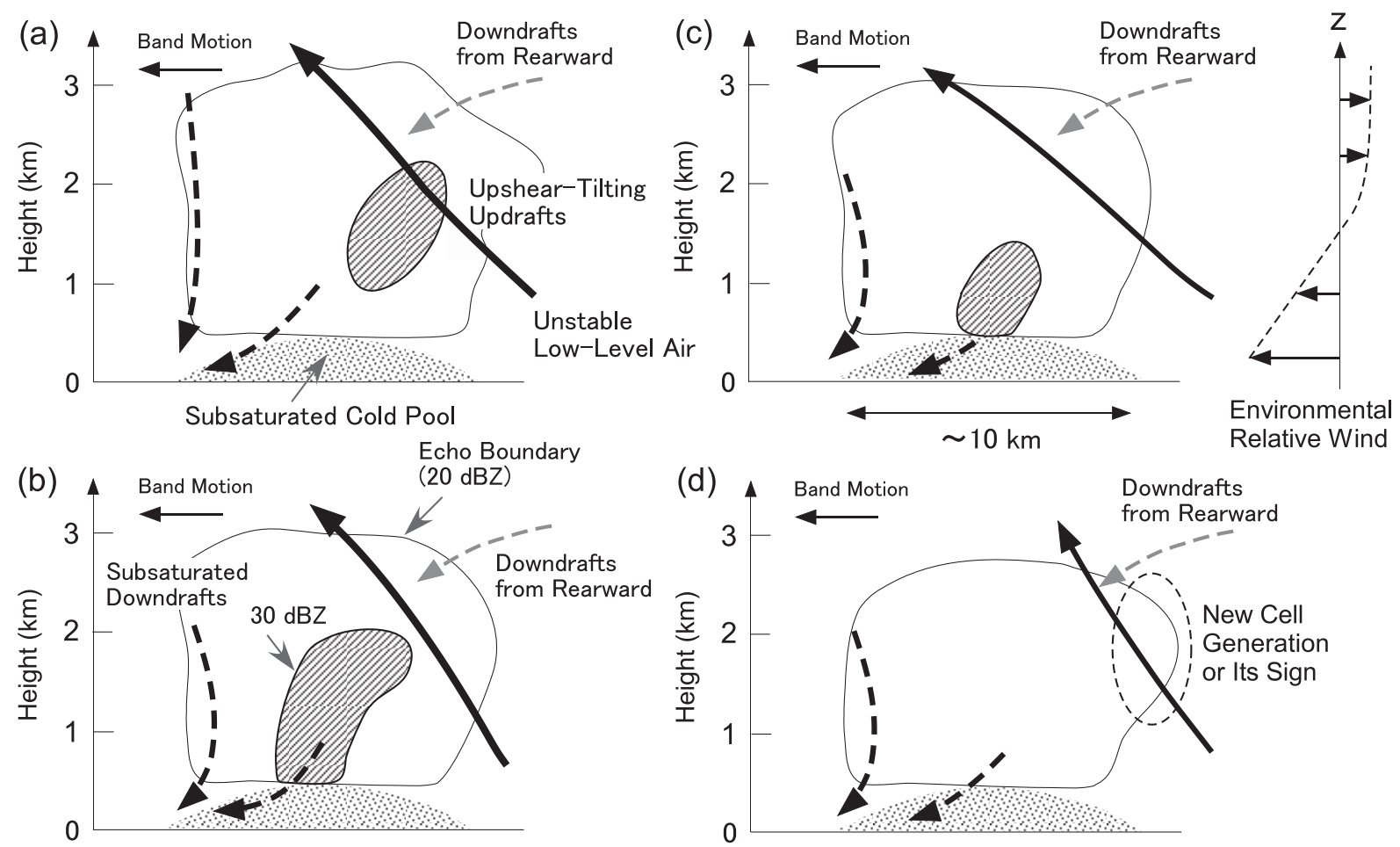

Fig. 33. Conceptual model of the kinematic and thermodynamical structures of the February 8, 1991 snow band in a vertical cross-section perpendicular to the band orientation. Major characteristics are shown. Arrows represent airflow whose horizontal components are relative to the band motion. Band portion with reflectivities $>30 \mathrm{dBZ}$ are indicated by hatching. Compensation downdrafts across the trailing edge are shown by arrows of light gray color. The profile of environmental horizontal winds relative to the band motion is also illustrated in upper-right. Subsatuated cold pool is shown by stippling. (a) Developing stage. (b) Mature stage. (c) Decaying stage. (d) Re-intensification stage where a sign of generation of new cell is marked in the downshear side of the band.

or of lake-effect snow storms over Lake Michigan (Kelly 1986; Kristovich 1993). Kelly and Kristovich reported roll-like circulation patterns from Doppler radar observations.

It is well recognized that vertical shear affects what form the circulation takes (Takeda 1971). As in deep convective systems, the circulation in the shallow convective snow bands may change according to vertical shear. For the two L-mode snow bands in this study, the magnitudes of the vertical shear were, however, small compared with those in multicellular convection. In fact, its magnitude, roughly in the lower half of the mixed layer, was $1.9 \times 10^{-3} \mathrm{~s}^{-1}$ for the January 21, 1993 case and $2.1 \times 10^{-3} \mathrm{~s}^{-1}$ for the February 8, 1991 case. In contrast, a magnitude of vertical shear of about $3.3 \times 10^{-3} \mathrm{~s}^{-1}$ between 0 - and $4-\mathrm{km}$ height produced a multicellular storm in model simulations
(Weisman and Klemp 1982), for example, for deep convective clouds.

At least two factors are considered important for the creation of upshear-tilting of updrafts and the separation of updraft-downdraft regions in these snow bands in such relatively weak vertical shear conditions compared with those in deep convective clouds: the existence of a certain depth of a vertical layer wherein the band-transverse system-relative winds were directed toward upshear and lower terminal fall velocities of precipitation particles of snow and graupels. As seen in the profiles of the band-transverse wind component (Figs. 6 and 23), the upshear-directing system-relative winds were observed in vertical layers extending from the surface up to about $1.7 \mathrm{~km}$ and $1.5 \mathrm{~km}$ for the cases in 1993 and 1991, respectively. These vertical layers may be deep enough for the formation of the 
upshear-tilting updrafts because the air parcels lifted by the low-level convergence in the downshear side could have sufficiently moved toward upshear in the horizontal and vertical directions during their ascent in these layers. If they were shallow enough and the downshear-directing wind components were dominant above these layers, the rising air parcels would have been turned to the downshear direction at lower heights, thereby causing no formation of upshear-tilting updrafts. Since snow clouds and snow bands over the Sea of Japan produce mostly snow, or graupels, or both, whose terminal fall velocities are much smaller than those of rain drops, these snow particles could remain longer in snow bands and snow clouds. With this longer residence time, a horizontal drift of snow particles during their fall in the upshear-tilting updrafts would become large even under relatively weak vertical shear so that a location of the precipitation-associated downdrafts would be separated from that of updrafts. In addition to these two factors, the shallowness of the snow bands, about 3-4 $\mathrm{km}$ deep, may be advantageous to the formation of upshear-tilting updrafts for all that the strength of the cold pool is weak. As has been observed for snow clouds and snow bands over the Sea of Japan, the temperature deficit of cold pool relative to the environment was about $1 \mathrm{~K}$ (Yamada et al. 1994; Yamada et al. 1996), which is much smaller than that exceeding several Kelvin for deep convective systems (e.g., Johnson and Hamilton 1988). This small temperature difference could limit the cold air advance into the ambient air over the warmer sea surface in the downshear direction. This relatively short distance could, however, suffice to produce a large inclination of the updrafts for shallow precipitation systems. Of course, the presence of a cold pool was found to be indispensable for the formation of upshear-tilting updrafts from high-resolution numerical experiments with a non-hydrostatic model (Yamada 2007).

\subsection{Airflow structures in the February 8, 1991 snow band}

The mean airflow structure in the bandtransverse direction in Fig. 30 was characterized by the ascending inflow from the trailing edge and the downdrafts around the leading edge. Such airflow structures have rarely been reported in past works on squall lines and rain bands, except for a snow band in wind-speed-increase zones reported by Yamada et al. (1996). They explained the forma- tion of the airflow structure in terms of the bandtransverse vertical shear directed opposite to the band-transverse propagation velocity. Accordingly, the low-level collision of the cold pool with the ambient unstable air would preferentially occur around the trailing edge, that is, on the downshear side. In the case of the snow band on February 8, 1991, the same mechanism would have operated because the direction of the band-transverse vertical shear vector was opposite to that of the band motion in this direction.

\subsection{Mesoscale organization}

Fujiyoshi et al. (1998) have already pointed out the importance of the momentum transport of downdrafts to the meso- $\gamma$ scale organization of an L-mode snow band over Ishikari Bay, Hokkaido, Japan; the low-level interaction between such downdrafts and the ambient air triggered the formation of new cells in the band. Their idea may hold true for both snow bands analyzed in this study because the new cell generation would have resulted from the low-level interaction between the downdraftgenerated cold pool and the unstable ambient air. In fact, without such a downdraft-generated cold pool, no generation of cells in the downshear side was reproduced in high-resolution numerical experiments (Yamada 2007). Other than L-mode snow bands over the Sea of Japan, the importance of such interaction to the generation of new cells, mesoscale organization, and the longevity of convective systems has been studied in numerous past works for convective systems (e.g., Simpson 1980; Peterson 1984; Liu and Moncrieff 2001; Weisman and Rotunno 2004).

Common to each of the two L-mode snow bands, the new cell generation was located at a certain horizontal distance from the band axis on the downshear side. In addition, the position of new cell formation was almost the same as or close to that of the pre-existing cells located at the upshear in the moving frame of reference. This distance was, however, not so large that the development of new cells did not change the overall echo appearance of the snow bands. The repeated occurrence of new cells did not produce an elongated bandlike echo pattern branching off at a large angle to the L-mode snow band orientation. A plausible explanation for this could be the fact that the significant decay of the pre-existing cells was followed by the sufficient development or the onset of development of new cells. In fact, for the snow band in 
1993, by the time the new cell reached maturity, the older cell had substantially decayed. Likewise, for the snow band in 1991, the new cell developed after the significant decay of the parent cell.

\subsection{Energy conversion rates}

Several terms involved in the energetics of the roll circulation were estimated in order to determine the dominant forcing mechanisms for the band maintenance. As in Weckwerth et al. (1997), the equation that describes the time change in the energy of the band circulation may consist of the buoyancy conversion and the production of energy by the band-parallel and band-transverse wind shear. Several works have been published that are relevant to the energetics of roll circulation. For example, Asai (1970) showed, according to a linear theory, that the energy production rate due to the band-parallel mean flow reached about $75 \%$ of that from buoyancy. LeMone (1973) discussed various terms involving the energetics of roll convection characterized by clear skies and scattered cumulus and found that the energy production terms from buoyancy and cross-roll vertical shear were major terms. Weckwerth et al. (1997) made a comparison between the buoyancy production term and the sum of the production rates by bandparallel and band-transverse shear for roll convection in fair weather conditions. They found that both buoyancy and shear production terms contributed to the sustenance of roll convection and that they were comparable at low heights whereas the buoyancy term dominated at the middle and upper heights. They also indicated that the buoyancy and shear production rates were, respectively, in the range of $44-109 \times 10^{-5} \mathrm{~m}^{2} \mathrm{~s}^{-3}$ and $44-$ $58 \times 10^{-5} \mathrm{~m}^{2} \mathrm{~s}^{-3}$, depending on the height.

Each term involving the energetics of the snow bands in Figs. 16 and 32 shows that the conversion rates by buoyancy $\left(P_{B}\right)$ and the band-transverse vertical shear $\left(P_{T}\right)$ were predominant. The magnitudes of the buoyancy conversion rates were about the same order as those in Weckwerth et al. (1997), suggesting that the estimation in this study is acceptable. The buoyancy conversion rates were, however, reduced significantly, or they turned to negative values at some heights, when evaluated in terms of apparent potential temperature perturbations that included the loading effect of water condensates. Such effect was not taken into account in either the linear theory (Asai 1970) or in fair weather rolls (LeMone 1973). In this situation, the band-transverse shear production became an important source of energy of the band circulation.

\section{Conclusions}

Kinematic and thermodynamical structures of two L-mode snow bands over the Sea of Japan occurring during cold-air outbreaks on January 21, 1993 and February 8, 1991 have been examined based mainly on Doppler radar data issued from a field project, which was conducted over the Sea of Japan from 1989 to 1993 in a coastal region of the Tohoku District of Japan. The echo top height was about 4 and $3 \mathrm{~km}$ for the snow bands in 1993 and 1991, respectively. Both L-mode snow bands had a multicellular structure. The snow bands in 1993 and 1991 occurred toward the end of and at the beginning of cold-air outbreaks, respectively, and they formed in environments with large band-transverse vertical shear confined to roughly the lower half of the mixed layer. The magnitudes of the band-transverse vertical shear were $1.9 \times 10^{-3} \mathrm{~s}^{-1}$ between the 0.6 - and $2.7-\mathrm{km}$ heights for the 1993 case and $2.1 \times 10^{-3} \mathrm{~s}^{-1}$ between the $0.6-$ and $1.8-\mathrm{km}$ heights for the 1991 case. The environmental band-transverse system-relative horizontal wind toward upshear was found from the lowest height of CAPPI to the $1.7-\mathrm{km}(1.5-\mathrm{km})$ height for the snow band in 1993 (1991). Thermodynamical structures of these snow bands as well as mixing ratios of water vapor and cloud were inferred through a variational-based retrieval, similar to that of Hauser et al. (1988). The major findings are summarized as follows:

(a) A pronounced feature in the kinematic structures of both snow bands was the upsheartilting updrafts in the band-transverse vertical cross-section, unlike axi-symmetric roll-like circulation patterns documented in most past studies. In addition, the band circulation for the two cases resembled a long-lasting one such that updraft and downdraft regions were separated as in the long-lasting squall line. The low-level interaction between the ambient unstable air and the subsaturated cold pool characterized by a small temperature deficit of about 1-2 K would have accounted for the formation of the upshear-tilting updrafts in the two L-mode snow bands. The presence of such a cold pool was inferred from retrieval. The magnitudes of the band-transverse vertical shear were small compared with those associ- 
ated with multicellular deep convection. At least two factors were considered important for the formation of the upshear-tilting updrafts. First, the vertical layers of the upsheardirecting band-transverse system-relative winds were considered sufficiently deep. During the ascent in such layers, the lifted air parcels would have sufficiently moved horizontally and vertically toward the upshear. Second, lower terminal fall velocities of precipitation particles (snow and graupels) allowed these particles to reside longer in the band such that large horizontal drift toward the upshear during their fall in the upshear-tilting updrafts favored the separation of updraft and downdraft regions.

(b) In the two L-mode snow bands, new cells tended to form around the downshear-side edge of the bands at a certain horizontal distance from the band axis in the band-transverse direction. The position of new cell formation was almost the same as or close to that of the corresponding pre-existing cells in the moving frame of reference. A possible generation mechanism of the new cells could have been attributed to the low-level convergence between the downdraft-generated outflow from pre-existing cells and the unstable ambient air. Since the older cells decayed substantially as the new cell developed, the snow bands would not exhibit an elongated band-like echo pattern that branched off to the downshear direction at a large angle to the orientation of the L-mode snow bands.

(c) For the energetics of the circulation, it was found that conversion by buoyancy and bandtransverse vertical shear was a dominant source of energy for both snow bands. When the buoyancy conversion was evaluated by taking into account the loading effects of cloud and precipitation, it reduced significantly, increasing the relative importance of the energy production by the band-transverse vertical shear. In contrast, energy conversion due to the bandparallel mean wind was very small in magnitude.

To date, observations of L-mode snow bands over the Sea of Japan are very limited. More observational studies of these snow bands, including those in large band-transverse vertical shear are needed for better understanding of the kinematic and thermodynamical structures. These may be bet- ter understood if temporally high resolution sampling of multiple-Doppler radar data is available.

\section{Acknowledgments}

This study is part of a $\mathrm{PhD}$ thesis at the Graduate School of Environmental Earth Science, Hokkaido University undertaken by one of the authors, Yoshinori Yamada. The authors are grateful to Professor Yasushi Fujiyoshi and Dr. Masayuki Kawashima at the University of Hokkaido for their valuable comments and discussions as well as their encouragement. Special thanks are expressed to Dr. Michel Chong at Laboratoire d'Aérologie de l'Université Paul Sabatier for his very helpful advice on retrieval processing. We wish to thank the Meteorological Satellite Center of the Japan Meteorological Agency for providing satellite images. We would also like to thank two anonymous reviewers for their valuable comments and suggestions for improving the manuscript.

\section{Appendix}

\section{Outline of retrieval of temperature perturbations and mass content of cloud and water vapor}

The retrieval of temperature and pressure perturbations and mixing ratios of non-precipitating water condensates (termed "cloud" in this paper) and water vapor in a three-dimensional volume was performed using a variational-based approach similar to that in Hauser et al. (1988). The method combines the equations of motion, the thermodynamic equation, and the water continuity equation. Furthermore, some improvements and enhancements were made as follows: three-dimensional analysis, inclusion of the acceleration and Coriolis terms in the equations of motion, and use of the eddy diffusion coefficients based on deformation tensor in the parameterization of subgrid turbulent force in the equations of motion as well as in the diffusion terms in the thermodynamic equation and the continuity equation of total water and water vapor. The acceleration terms in the equations of motion were estimated from two temporally successive dual-Doppler wind fields. The retrieval was made in a moving frame of reference in order to minimize errors in the estimation of the local time derivatives of the wind components (Gal-Chen 1982). No melting/freezing effects were considered in the thermodynamic equation. The mixing ratios of water substances and the potential temperature perturbations were staggered with respect to the 
wind components in the horizontal and vertical directions. The lowest height for the analysis was set to $0.45 \mathrm{~km}$ above the sea surface for the two Lmode snow bands. A simple treatment for the microphysical processes was, however, employed in this study such that mixing ratios and terminal fall velocities of precipitation particles were calculated from empirical formulas, respectively. The terminal fall velocities were computed from the reflectivity with a formula devised by Atlas et al. (1973). Precipitation mixing ratios were calculated from a relation between mass content of precipitation $\left(M_{p}\right)$ and radar reflectivity $(Z)$ as $M_{p}=a Z_{I}^{b}$, where $a$ and $b$ are constant, and $Z_{I}$ represents the reflectivity for ice. The constants of $a$ and $b$ obtained by Kajikawa and Kiba (1978) for graupel particles were chosen, being listed in Sassen (1987), because grauples were dominant precipitation particles for snow clouds and snow bands over the Sea of Japan (e.g., Murakami et al. 1994b; Murakami et al. 1996; Murakami et al. 2003). The value of $a$ was, however, multiplied by $1 / 3$. This change improved the magnitude of the residual relative to the functional to be minimized, and the maximum retrieved value of the mass content of cloud was close to the value from the coordinated airborne measurements (Murakami et al. 1996) when this alteration was made. Nevertheless, experiments with changing this factor between $1 / 3$ and 1 resulted in no substantial differences in the retrieved fields of potential temperature perturbations, cloud mixing ratios, and so on. The eddy diffusion coefficients were computed from the deformation tensor (Smagorinsky 1963). With these coefficients, the subgrid turbulent force was calculated as in Klemp and Wilhelmson (1978). In addition, the eddy coefficient $K$ used for the water continuity and the thermodynamic equations was assumed to be $K=3 K_{m}$ as in Hauser et al. (1988), where $K_{m}$ was that for the dynamic equation. It was found that the retrieval results were insensitive to the choice of the relation between the mass content of precipitation and the radar reflectivity. Indeed, the results obtained with the relation by Herzegh and Hobbs (1980) (listed also in Sassen 1987) were similar to those based on the relation found by Kajikawa and Kiba.

The mixing ratios of cloud $\left(q_{c}\right)$ were diagnosed, following Hauser and Amayenc (1986), as:

$$
q_{c}=\max \left(q_{T}-q_{p}-q_{v s}, 0\right),
$$

where $q_{T}$ is the total water mixing ratio, $q_{p}$ the precipitation mixing ratio, and $q_{v s}$ the saturation mixing ratio computed using the retrieved potential temperature and pressure perturbations. $q_{T}$ is defined as the sum of mixing ratios of precipitation, cloud, and water vapor. No supersaturation was considered. In order to represent the existence of super-cooled droplets in snow bands and snow clouds over the Sea of Japan (Murakami et al. 1994b; Murakami et al. 1996; Murakami et al. 2003), the freezing of cloud was assumed to occur linearly with a temperature range from $-10^{\circ}$ to $-36^{\circ} \mathrm{C}$. At temperatures higher than $-10^{\circ} \mathrm{C}$, no freezing was considered, whereas all cloud froze below $-36^{\circ} \mathrm{C}$. Thus, cloud may be composed of water, ice, or a mixture of the two depending on temperature. Accordingly, $q_{v s}$ was given as a massweighted mean of saturation water vapor mixing ratios over water and ice for the temperature range of $-10^{\circ}$ to $-36^{\circ} \mathrm{C}$. When no cloud existed, the saturation deficit $q^{\prime}$ was defined as in Hauser and Amayenc (1986):

$$
q^{\prime}=q_{v}-q_{v s},
$$

where $q_{v}$ is the water vapor mixing ratio. Negative values of $q^{\prime}$ indicate subsaturation.

Boundary conditions for the water continuity equation were as follows. At the lower boundary located at the middle level between the lowest height of CAPPI $(0.3 \mathrm{~km})$ and the surface, the relative humidity was assumed to be $85 \%$ or $45 \%$ depending on whether or not radar echoes existed, respectively, at the lowest height of CAPPI below which no vertical gradients were assumed for $q_{p}$. These relative humidities were typical values observed at a ground station located at the MRI radar site during the field project. At the top of the calculation domain $(5.25 \mathrm{~km}$ and $4.65 \mathrm{~km}$ for the January 21, 1993 and the February 8, 1991 cases, respectively), it was assumed that no cloud existed since it was set sufficiently high. As for the lateral boundary condition, the value of $q_{p}$ estimated from reflectivity was given, whereas the horizontal gradients of $q_{v}$ and $q_{c}$ were assumed to be null. Sensitivity experiments, in which the relative humidity values at the lower boundary were changed within $5 \%$ of the above mentioned values, showed that these changes did not significantly affect the results of the retrieval. These changes in relative humidity brought about variation of temperature perturbations within about $\pm 0.5 \mathrm{~K}$ and the changes in the maximum values of the cloud mixing ratios within about $\pm 10 \%$.

The processing of the retrieval necessitates the 
vertical profiles of undisturbed fields of virtual potential temperature, pressure, water vapor mixing ratios, and horizontal wind. For the snow band in 1993, each of these was given as a mean profile from two operational soundings at 0900 JST and 2100 JST at Akita. In addition, pre-processing was done on the wind field, similar to that in Roux (1993). The wind components at the grid points without dual-Doppler winds were assumed to be equal to the undisturbed value with null vertical velocity. These assumed wind data were further processed by a distance-weighted spatial averaging using a Cressman weighting function (Cressman $1959)$ with an ellipsoidal influence volume whose horizontal and vertical semi-axes were $3 \mathrm{~km}$ and $1.5 \mathrm{~km}$, respectively. This smoothing process was applied only to the grid points when Dopplerderived wind data fell into the influence volume centered at these grid points. This treatment filtered out the gaps between the assumed and observed winds. For the snow band in 1991, the grid points without Doppler-derived wind data in the domain considered were filled with the undisturbed horizontal wind field from the sounding data at 1904 JST at Tobishima Island with null vertical winds. The smoothing process for the wind fields was also made in the same manner as for the snow band in 1993. The undisturbed pressure and water vapor mixing ratios were also taken from this sounding data. The profile of potential temperature was, however, given as a weighted mean of data from two soundings at 1456 JST and 1904 JST made at Tobishima Island. The respective weighting factors were $2 / 3$ and $1 / 3$ below the $1-\mathrm{km}$ height, above which they were $1 / 3$ and $2 / 3$. This treatment was necessary to achieve good inference of temperature fields. This suggested that the undisturbed data affected the retrieval significantly in some cases for the methodology employed in this study.

The appropriateness of the estimation of heat fluxes in the snow bands was considered by comparison with those observed in other cases because there were no in situ observational data on the heat fluxes for the two snow bands. Brümmer (1999) made aircraft measurements for roll convection over the Greenland and Barents Seas during cold-air outbreaks to find that most heat fluxes were positive (upward), except near the cloud top in a few cases, and that the maximum heat flux reached about $5 \times 10^{-2} \mathrm{~K} \mathrm{~m} \mathrm{~s}^{-1}$. In the present study, maximum heat flux in terms of the virtual potential temperature perturbations was at most in the order of $1 \times 10^{-1} \mathrm{~K} \mathrm{~m} \mathrm{~s}^{-1}$ (see Figs. $15 \mathrm{~b}$ and $31 \mathrm{~b}$ ). Since this value is close to the results of Brümmer, it was considered that an appropriate estimation of heat flux had been made. This assures the adequacy of the estimation of the energy production rates by buoyancy.

Finally, a high performance of the retrieval method has been demonstrated by the comparison of the spatial distributions of retrieved cloud with those from the coordinated in situ airborne measurements for a shallow convective snow band over the Sea of Japan (Yamada 2007).

\section{References}

Asai, T., 1970: Three-dimensional features of thermal convection in a plane Couette flow. J. Meteor. Soc. Japan, 48, 18-29.

Asai, T., 1988: Meso-scale features of heavy snowfalls in Japan Sea coastal regions of Japan. Tenki, 35, 156-161. (in Japanese).

Atkinson, B. W., and J. W. Zhang, 1996: Mesoscale shallow convection in the atmosphere. Rev. Geophys., 34, 403-431.

Atlas, D., R. C. Srivastava, and R. S. Sekhon, 1973: Doppler radar characteristics of precipitation at vertical incidence. Rev. Geophys. Space Phys., 11, $1-35$.

Ballentine, R. J., A. J. Stamm, E. E. Chermack, G. P. Byrd, and D. Schleede, 1998: Mesoscale model simulation of the 4-5 January 1995 lake-effect snowstorm. Wea. and Forecasting, 13, 893-920.

Brümmer, B., 1999: Roll and cell convection in wintertime arctic cold-air outbreaks. J. Atmos. Sci., 56, 2613-2636.

Chong, M., P. Amayenc, G. Scialom, and J. Testud, 1987: A tropical squall line observed during the COPT 81 experiment in West Africa. Part I: Kinematic structure inferred from dual-Doppler radar data. Mon. Wea. Rev., 115, 670-694.

Chong, M., and J. Testud, 1983: Three-dimensional wind field analysis from dual-Doppler radar data. Part III: The boundary condition: An optimum determination based on a variational concept. J. Climate Appl. Meteor., 22, 1227-1241.

Cooper, K. A., M. R. Hjelmfelt, R. G. Derickson, D. A. R. Kristovich, and N. F. Laird, 2000: Numerical simulation of transitions in boundary layer convective structures in a lake-effect snow event. Mon. Wea. Rev., 128, 3283-3295.

Cressman, G. P., 1959: An operational objective analysis system. Mon. Wea. Rev., 87, 367-374.

Etling, D., and R. A. Brown, 1993: Roll vortices in the planetary boundary layer: A review. Bound.Layer Meteor., 65, 215-248.

Fujiyoshi, Y., N. Yoshimoto, and T. Takeda, 1998: A 
dual-Doppler radar study of longitudinal-mode snowbands. Part I: A three-dimensional kinematic structure of meso- $\gamma$-scale convective cloud systems within a longitudinal-mode snowband. Mon. Wea. Rev., 126, 72-91.

Gal-Chen, T., 1978: A method for the initialization of the anelastic equations: Implications for matching models with observations. Mon. Wea. Rev., 106, 587-606.

Gal-Chen, T., 1982: Errors in fixed and moving frame of references: Applications for conventional and Doppler radar analysis. J. Atmos. Sci., 39, 2279-2300.

Hauser, D., and P. Amayenc, 1986: Retrieval of cloud water and water vapor contents from Doppler radar data in a tropical squall line. J. Atmos. Sci., 43, 823-837.

Hauser, D., F. Roux, and P. Amayenc, 1988: Comparison of two methods for the retrieval of thermodynamic and microphysical variables from Doppler radar measurements: Application to the case of a tropical squall line. J. Atmos. Sci., 45, 1285-1303.

Herzegh, P. H., and P. V. Hobbs, 1980: The mesoscale and microscale structure and organization of clouds and precipitation in midlatitude cyclones. II: Warm-frontal clouds. J. Atmos. Sci., 37, 597611.

Hjelmfelt, M. R., 1990: Numerical study of the influence of environmental conditions on lake-effect snowstorms over Lake Michigan. Mon. Wea. Rev., 118, $138-150$.

Hsu, H.-M., 1987: Mesoscale lake-effect snowstorms in the vicinity of Lake Michigan: Linear theory and numerical simulations. J. Atmos. Sci., 44, 10191040.

Ikawa, M., H. Mizuno, T. Matsuo, M. Murakami, Y. Yamada, and K. Saito, 1991: Numerical modeling of the convective snow cloud over the Sea of Japan. Precipitation mechanism and sensitivity to ice crystal nucleation rates. J. Meteor. Soc. Japan, 69, 641-667.

Ishihara, M., H. Sakakibara, and Z. Yanagisawa, 1989: Doppler radar analysis of the structure of mesoscale snow bands developed between the winter monsoon and the land breeze. J. Meteor. Soc. Japan, 67, 503-520.

Johnson, R. H., and P. J. Hamilton, 1988: The relationship of surface pressure features to the precipitation and airflow structure of an intense midlatitude squall line. Mon. Wea. Rev., 116, 1444-1472.

Kajikawa, M., and K. Kiba, 1978: Observation of the size distribution of graupel particles. Tenki, 25, 390-398. (in Japanese).

Kawashima, M., and Y. Fujiyoshi, 2005: Shear instability wave along a snowband: Instability structure, evolution, and energetics derived from dualDoppler radar data. J. Atmos. Sci., 62, 351-370.
Kelly, R. D., 1982: A single Doppler radar study of horizontal-roll convection in a lake-effect snow storm. J. Atmos. Sci., 39, 1521-1531.

Klemp, J. B., and R. B. Wilhelmson, 1978: The simulation of three-dimensional convective storm dynamics. J. Atmos. Sci., 35, 1070-1096.

Kristovich, D. A. R., 1993: Mean circulations of boundary-layer rolls in lake-effect snow storms. Bound.-Layer Meteor., 63, 293-315.

Kristovich, D. A. R., N. F. Laird, and M. R. Hjelmfelt, 2003: Convective evolution across Lake Michigan during a widespread lake-effect snow event. Mon. Wea. Rev., 131, 643-655.

Laird, N. F., and D. A. R. Kristovich, 2004: Comparison of observations with idealized model results for a method to resolve winter lake-effect mesoscale morphology. Mon. Wea. Rev., 132, 1093-1103.

Laird, N. F., D. A. R. Kristovich, and J. E. Walsh, 2003: Idealized model simulations examining the mesoscale structure of winter lake-effect circulations. Mon. Wea. Rev., 131, 206-221.

LeMone, M. A., 1973: The structure and dynamics of horizontal roll vortices in the planetary boundary layer. J. Atmos. Sci., 30, 1077-1091.

Lin, Y.-J., T.-C. C. Wang, R. W. Pasken, H. Shen, and Z.-S. Deng, 1990: Characteristics of a subtropical squall line determined from TAMTEX dualDoppler data. Part II: Dynamic and thermodynamic structures and momentum budgets. $J$. Atmos. Sci., 47, 2382-2399.

Liou, Y.-C., T.-C. C. Wang, and K.-S. Chung, 2003: A three-dimensional variational approach for deriving the thermodynamic structure using Doppler wind observations - An application to a subtropical squall line. J. Appl. Meteor., 42, 1443-1454.

Liu, C., and M. W. Moncrieff, 2001: Cumulus ensembles in shear: Implications for parameterization. $J$. Atmos. Sci., 58, 2832-2842.

Marécal, V., D. Hauser, and F. Roux, 1993: The 12/13 January 1988 narrow cold-frontal rainband observed during MFDP/FRONTS 87. Part II: Microphysics. J. Atmos. Sci., 50, 975-998.

Miles, N. L., and J. Verlinde, 2005: Observations of transient linear organization and nonlinear scale interactions in lake-effect clouds. Part I: Transient linear organization. Mon. Wea. Rev., 133, 677-691.

Miura, Y., 1986: Aspect ratios of longitudinal rolls and convection cells observed during cold air outbreaks. J. Atmos. Sci., 43, 26-39.

Murakami, M., T. L. Clark, and W. D. Hall, 1994a: Numerical simulations of convective snow clouds over the Sea of Japan; Two-dimensional simulations of mixed layer development and convective snow cloud formation. J. Meteor. Soc. Japan, 72, 43-62.

Murakami, M., T. Matsuo, H. Mizuno, and Y. Yamada, 1994b: Mesoscale and microscale structures of 
snow clouds over the Sea of Japan. Part I: Evolution of microphysical structures in short-lived convective snow clouds. J. Meteor. Soc. Japan, 72, 671-694.

Murakami, M., Y. Yamada, T. Matsuo, and K. Iwanami, 1996: Mesoscale and microscale structures of shallow snow bands over the Sea of Japan. Preprints 12th International Conference on Clouds and Precipitation, Zurich, Switzerland, 562-565.

Murakami, M., Y. Yamada, T. Matsuo, K. Iwanami, J. D. Marwitz, and G. Gordon, 2003: The precipitation process in convective cells embedded in deep snow bands over the Sea of Japan. J. Meteor. Soc. Japan, 81, 515-531.

Okabayashi, T., 1969: Photograph of heavy snowfall on Japan Seaside on Jan. 2, 1969, taken by ESSA. Tenki, 16, 79-80. (in Japanese).

Ray, P. S., C. L. Ziegler, W. Bumgarner, and R. J. Serafin, 1980: Single- and multiple-Doppler radar observations of tornadic storms. Mon. Wea. Rev., 108, 1607-1625.

Peterson, R. E. Jr., 1984: A triple-Doppler radar analysis of a discretely propagating multicell convective storm. J. Atmos. Sci., 41, 2973-2990.

Rotunno, R., J. B. Klemp, and M. L. Weisman, 1988: A theory for strong, long-lived squall lines. J. Atmos. Sci. 45, 463-485.

Roux, F., 1985: Retrieval of thermodynamic fields from multiple-Doppler radar data using the equations of motion and the thermodynamic equation. Mon. Wea. Rev., 113, 2142-2157.

Roux, F., V. Marécal, and D. Hauser, 1993: The 12/13 January 1988 narrow cold-frontal rainband observed during MFDP/FRONTS 87. Part I: Kinematics and thermodynamics. J. Atmos. Sci., 50, 951-974.

Saito, K., M. Murakami, T. Matsuo, and H. Mizuno, 1996: Sensitivity experiments on the orographic snowfall over the mountainous region of northern Japan. J. Meteor. Soc. Japan, 74, 797-813.

Sakakibara, H., M. Ishihara, and Z. Yanagisawa, 1988a: Classification of mesoscale snowfall systems observed in western Hokuriku during a heavy snowfall period in January 1984. J. Meteor. Soc. Japan, 66, 193-199.

Sakakibara, H., M. Ishihara, and Z. Yanagisawa, 1988b: Squall line like convective snowbands over the Sea of Japan. J. Meteor. Soc. Japan, 66, 937-953.

Sassen, K., 1987: Ice cloud content from radar reflectivity. J. Climate Appl. Meteor., 26, 1050-1053.

Satoh, S., Y. Fujiyoshi, G. Wakahama, R. Shirooka, and H. Uyeda, 1992: Dual-Doppler radar observation of convergence band cloud. Proceedings, 11th International Conference on Clouds and Precipitation, Montreal, Canada, 628-631.

Simpson, J., 1980: Downdrafts as linkages in dynamic cumulus feeding effects. J. Appl. Meteor., 19, $477-$ 487.

Smagorinsky, J., 1963: General circulation experiments with the primitive equations. I: The basic experiment. Mon. Wea. Rev., 91, 99-164.

Takeda, T., 1971: Numerical simulation of a precipitating convective cloud: The formation of a "longlasting" cloud. J. Atmos. Sci., 28, 350-376.

Tsuboki, K., Y. Fujiyoshi, and G. Wakahama, 1989: Structure of a land breeze and snowfall enhancement at the leading edge. J. Meteor. Soc. Japan, 67, 757-770.

Weckwerth, T. M., J. W. Wilson, G. M. Wakimoto, and N. A. Crook, 1997: Horizontal convective rolls: Determining the environmental conditions supporting their existence and characteristics. Mon. Wea. Rev., 125, 505-526.

Weisman, M. L., and J. B. Klemp, 1982: The dependence of numerically simulated convective storms on vertical wind shear and buoyancy. Mon. Wea. Rev., 110, 504-520.

Weisman, M. L., and R. Rotunno, 2004: "A theory for strong long-lived squall lines" revisited. J. Atmos. Sci., 61, 361-382.

Yamada, H., H. Uyeda, K. Kikuchi, M. Maki, and K. Iwanami, 2004: Dual-Doppler radar observations on factors causing differences in the structure of snow clouds during winter monsoon surges. $J$. Meteor. Soc. Japan, 82, 179-206.

Yamada, Y., 1997: Numerical estimation of error variance in horizontal divergence for the adjustment of vertical winds derived from conical-scan-based dual-Doppler radar data based on the "Floating Boundary Condition" concept. Papers. in Meteor. Geoph., 48, 49-65.

Yamada, Y., 2007: Observational study on kinematic and thermodynamical structures of longitudinal snow bands over the Sea of Japan during cold-air outbreaks.-Difference in characteristics under weak and large vertical shear environment in the band-transverse direction - . Ph-D thesis of Graduate School of Environmental Earth Science, Hokkaido University. pp. 272.

Yamada, Y., T. Matsuo, M. Murakami, H. Mizuno, and K. Iwanami, 1994: Mesoscale and microscale structures of snow clouds over the Sea of Japan. Part II: Time change in airflow structures in isolated snow clouds derived from dual-Doppler radar observations. - A case study-. J. Meteor. Soc. Japan, 72, 695-708.

Yamada, Y., M. Murakami, T. Matsuo, H. Mizuno, Y. Fujiyoshi, and K. Iwanami, 1996: Mesoscale and microscale structures of snow clouds over the Sea of Japan. Part III. Two types of circulations in snow bands associated with a wind-speed-increase zone proceeding cold-air outbreaks. J. Meteor. 
Soc. Japan, 74, 593-615.

Yoshimoto, N., Y. Fujiyoshi, and T. Takeda, 2000: A dual-Doppler radar study of longitudinal-mode snowbands. Part II: Influence of the kinematics of a longitudinal-mode snowband on the development of an adjacent snowband. J. Meteor. Soc. Japan, 78, 381-403.

Yoshihara, H., M. Kawashima, K. Arai, J. Inoue, and Y.
Fujiyoshi, 2004: Doppler radar study on the successive development of snowbands at a convergence line near the coastal region of Hokuriku district. J. Meteor. Soc. Japan, 82, 1057-1079.

Ziegler, C. L., 1985: Retrieval of thermal and microphysical variables in observed convective storms. Part I: Model development and preliminary testing. $J$. Atmos. Sci., 42, 1487-1509. 